\title{
Magnetic resonance renography: optimization and clinical orientation
}

Citation for published version (APA):

de Priester, J. A. (2003). Magnetic resonance renography: optimization and clinical orientation. [Doctoral Thesis, Maastricht University]. Universiteit Maastricht. https://doi.org/10.26481/dis.20030417jp

Document status and date:

Published: 01/01/2003

DOI:

10.26481/dis.20030417jp

Document Version:

Publisher's PDF, also known as Version of record

\section{Please check the document version of this publication:}

- A submitted manuscript is the version of the article upon submission and before peer-review. There can be important differences between the submitted version and the official published version of record.

People interested in the research are advised to contact the author for the final version of the publication, or visit the DOI to the publisher's website.

- The final author version and the galley proof are versions of the publication after peer review.

- The final published version features the final layout of the paper including the volume, issue and page numbers.

Link to publication

\footnotetext{
General rights rights.

- You may freely distribute the URL identifying the publication in the public portal. please follow below link for the End User Agreement:

www.umlib.nl/taverne-license

Take down policy

If you believe that this document breaches copyright please contact us at:

repository@maastrichtuniversity.nl

providing details and we will investigate your claim.
}

Copyright and moral rights for the publications made accessible in the public portal are retained by the authors and/or other copyright owners and it is a condition of accessing publications that users recognise and abide by the legal requirements associated with these

- Users may download and print one copy of any publication from the public portal for the purpose of private study or research.

- You may not further distribute the material or use it for any profit-making activity or commercial gain

If the publication is distributed under the terms of Article $25 \mathrm{fa}$ of the Dutch Copyright Act, indicated by the "Taverne" license above, 
MAGNETIC RESONANCE RENOGRAPHY:

OPTIMIZATION AND CLINICAL ORIENTATION 
ISBN 9051707002

O.A. de Priester, Naarden 2003

Cover: Davos 1954, Jan Whegers (1893-1959). Olieverf op doek $100 \times 70 \mathrm{~cm}$.

Printed by Thela Thesis, Amsterdam 


\section{MAGNETIC RESONANCE RENOGRAPHY: OPTIMIZATION AND CLINICAL ORIENTATION}

\section{PROEFSCHRIFT}

ter verkrijging van de graad van doctor

aan de Universiteit Maastricht,

op gezag van de Rector Magnificus

Prof. Dr. A.C. Nieuwenluujzen Kruseman,

volgens het besluit van het College van Decanen,

in het openbaar te verdedigen

op donderdag 17 apri1 2003 om 16.00 uur

dloor

Jacobus Adriaan de Priester

Geboren te Oosthuizen 
Promolores

Prof. Dr. J.M.A. van Engelshoven

Prof. Dr. ir. A. Hasman

Co-promotor

Dr. ir. J.A. den Boer, Son

Beoordelingscommissie

Prof. Dr. J.P. van Hooff (voorzitter)

Prof. Dr. J.O. Barentsz (Katholieke Universiteit Nijmegen)

Prof. Dr. G.A. Heidendal

Prof. Dr. A.P. Hoeks

Prof. Dr. P.L de Leeuw 
Voor: min ouders

Iris

Costijn en Wouter 


\section{Contents}

Chapter 1

Introduction

Chapter 2

MR Renography: an algorithm for calculation and correction of cortical volume averaging in medullary renographs

Chapter 3

MR Renography by semiautomated image analysis: performance in renal transplant recipients

Chapter 4

Quantitative model description of dynamic MRI enhancement data of the transplanted kidney

\section{Chapter 5}

Automated quantitative evaluation of diseased and non-diseased renal transplants with MR-Renography

\section{Chapter 6}

Automated post-processing and enhancement parameterization in magnetic resonance renography. Patterns in hypertensive patients with and without renal artery stenosis.

\section{Chapter 7}

General discussion and conclusions

Chapter 8

Summary

Samenvatting

Acknowledgements

Curriculum Vitae 

CHAPTER 1

INTRODUCTION 


\section{The kidney}

The major function of the kidney is to maintain constant volumes and composition of the body fluids. The renal contribuiton to the homeostasis of the body fluids involves a number of specialized functions which include the excretion of metabolic end products and toxins and a number of metabolic and homonal functions $(1-3)$.

Macroscopically, the parenchyma of the kidneys is composed of two substances: the external or cortical, and the miternal or medullary substance (4). The cortex forms about three-fourth of the parenchyna. It occupies the surface of the organ and has numerous inwards prolongations which are called the renal columns of Bertin. The medulla consists of conical masses, the pyramids of Malpighi that are situated between the renal columns (figure 1).

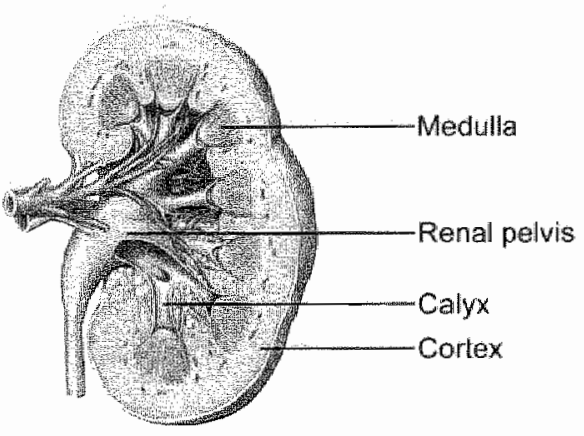

Figure 1 . Vertical section of the kidney. Cortex forms the outer part of the renal parenchyma and has numerous central projections (Columns of Bertin). Medullary pyramids are situated more centrally, between the renal columns. Urine is collected in the pelvis.

The division of the renal parenchyma into cortex and medulla reflects the anatomy of the functional units of the kidney, the nephrons. Each kidney has approximately one million of such units $(1,5)$.

Basically, the nephron is composed of a glomerulus from which fluid is filtered, and a long tubule in which the filtered fluid is converted into une on its way to the pelvis of the kidney. Blood enters the glomerulus through the afferent arteriole and leaves through the efferent arteriole. The glomerulus is a network of capillaries that are covered by epithelial cells and encased in Bowman's capsule. The pressure within the capillaries causes fluid to filter into Bowman's capsulte, from which it flows into the proximal tubule that lies in the cortex of the kidney along with the glomerulus. From here the fluid passes into the loop of Henle that is situated in the medulla. From the loop of Hente the fluid flows back to the renal cortex through the distal tubule. Finally, it flows into the collecting duct, which collects fhuid from several nephrons. The collecting duct passes from the cortex back to the medulla and empties into the pelvis of the kidney (figure 1$)(1,4,5)$. 


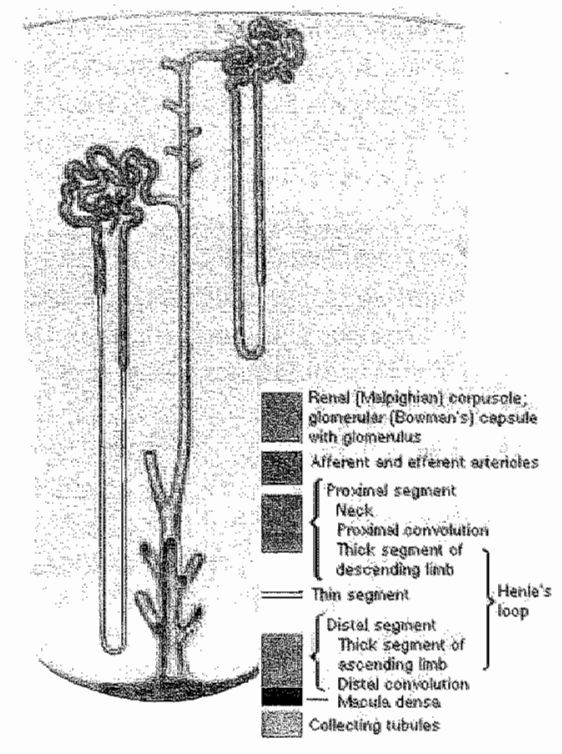

Figure 2. The nephrou. Flud is filtered in the glomerulus and is converted into urine ws if passes through the proximal fubule. Henle's loop, distal tubule and the collecting duct towats the pelvis.

\section{Diseases}

\section{a. Functional diseases of kidneys and renal transplants}

Renal function can be affected by a large variety of disorders. A detailed description of these diseases is beyond the scope of this text but a brief overview is helpful to illustrate the problems that may exist in obtaining an adequate diagnosis.

Diseases like cysts, tumours and renal calculi are macroscopically manifest and can be diagnosed confidently with radiological imaging techniques (plain films of the abdonnen, IVU, ultrasound, CT, angiography)(5).

Other diseases, however, may cause substantial functional disturbance but do not present as macroscopically visible changes in structure and morphology. Examples of such disorders are the numerous parenchymal diseases of the kidneys (insulin dependent diabetes mellitus, glomerulonephritis, interstitial nephritis, nephrosclerosis, etc.) and a variety of immunological, vascular and drug related diseases of renal transplants (rejection, ATN, cyclosporine tubulopathy, etc.)(7).

These diseases mean that diagnostic tests should not only cover morphologic allerations, but should reflect the functional status of the organ as well (8).

\section{b. Renovascular disease and hypertension}

The two most common types of renovascular disease that cause renal artery stenosis are 
atherosclerosis and fibromuscular dysplasia. Atherosclerosis accounts for 90 percent of cases with renal artery stenosis and usually involves the ostium and proximal third of the main renal artery (9). The prewalence increases with age, especially in patients with diabetes, aortollac occlusive disease or hypertension. Fibromuscular disease accounts for less than 10 percent of renal artery stenosis. It tends to affect girls and women between 15 and 50 years of age but males and subjects of older age categorics may also be affected. Classically, fibromuscular disease involves the distal two thirds of the renal arteries and its branches (9).

By decreasing renal perfusion pressure and activation of the renin-angiotensine system, these diseases thay cause renovascular hypertension (RVH). This mechanism is the underlying cause in $1-5 \%$ of patients of the general population with hypertension and may worsen preexisting primary hypertension. These patients may benefit from surgical revascularization or percutaneous intervention of the renal artery stenosis with balloon angioplasty, with or without vascular stenting.

The differentiation on imaging studies between RWH and essential hypertension is difficult because patients with essential hypertension may develop secondary atherosclerotic stenosis of the renal arteries that looks identical on imaging studies. Such differentiation is important, however, because essential hypertension does not benefit from surgical or percutaneous interventions and because of the costs, risks of complications and limited patency of these measures.

\section{Tests of renal function}

\section{a. Functional diseases of kidneys and renal transplants}

Apart from the patient history and physical examination, the clinical workup of patients with functional diseases of kidneys and renal transplants is based on three pillars:

\section{1, Laboratory tests.}

Various laboratory tests can assess the glomerular and tubular functional capacity of the kidney. The most commonly used method to assess the glomerular filtration rate (GFR) is the creatinine clearance. Renal tubular function can be evaluated by estimation of the maximal urinary concentrating ability during restricted water intake, the fractionate excretion of various solutes and the determination of the rate of protein excretion in the urine. Although these tests are useful indicators of impared renal function, the disease specificity is poor (2).

\section{Nuclear medicine.}

Nucleat scintigraphic techniques can supply additional functional information. Various tracers are available that can be categorized by the aspect of renal function they demonstrate. The most commonly used substances for functional imaging are MAG3 (technetium mercaptoacetyl-triglycime) that primarily reflects tubular secretion and ${ }^{90 \mathrm{~m}}$ TC-DTPA (diethylenetriamine-pentacetic acid) that is secreted by, and a measure of, GFR. The functional information obtained from nuclear imaging studies is robust but, due to low specificity, the
predictive value of these tests is poor $(7,10-19)$.

\section{Biopsy.}

Given the low specificity of laboratory tests and nuclear imaging, biopsy is still the standard of reference for the diagnosis of diseases that functionally affect the kidney and renal transplant $(2,6,10)$. Biopsy, however, has a risk of complications (bleeding, AV-fistula's, etc.)
that may be hazardous for the patient and the kidney $(6,20)$. 


\section{b. Renovascular disease and hypertension}

The standard of reference for the diagnosis of renal artery stenosis is intra-arterial digital subtraction angiography (ia-DSA). Commonly used, minimally invasive, alternatives are $\mathrm{CT}$ angiography (CTA) and MR-angiography (MRA).

Recent studies, performed at our department, have demonstrated that the sensitivity of CTA and MRA is inferior to that of ia-DSA (21). This holds true for both atherosclerotic renal artery disease and fibromuscular dysplasia and implies that in-DSA remains the imaging technique of choice in patients suspected of having renal artery disease.

Unfortunately, ia-DSA is an invasive technique that carries a small risk for serious complication (2). Moreover, the contrast media used in ia-DSA are nephrotoxic. This may have serious repercussions on renal function and limits its use in patients with pre-existing disturbed renal function.

Apart from investigations that assess overall renal function, the non-invasive evaluation of patients suspected of having renovascular hypertension consists of physiological studies to evaluate the renin-angiotensine system, nuclear perfuston studies to assess differential renal blood flow and imaging studies to identify remal-artery stenosis (duplex ultrasound, CTA and MRA). Methods of measuring the response of the renin-angiotensine system include reninsodium profiling, assessment of plasma renin activity before and after the administration of captopril, assessment of the effect on blood pressure and renal function of an angiotensineconverting-enzyme (ACE) inhibitor, and captopril MAG3 renography to assess differential. renal perfusion (9).

All these tests have limited sensitivity and specificity, however, and an accurate test that differentiates functional kidney diseases and that is capable to assess the functional relevance of a renal artery stenosis in terms of the existing hypertension is lacking $(9,21,22)$.

These limitations dictate the need for a more accurate functional test and form the basis for our interests in magnetic resonance renography.

\section{Magnetic Resonance Renography}

Magnetic resonance renography (MRR) is a new functional imaging technique of the kidney and renal transplant. Analogue to its nuclear counterparts, MRR is a dynamic imaging study that provides functional information in terms of changes in signal intensity of the renat parenchyma during the passage of an intravenously administered bolus of gadoliniumdiethylene triamine pentaacetic acid (Gd-DTPA)(11-13). An example of the images oblaned from a dynamic scan sequence is given in figure 3.

The main difference with nuclear scintigraphic technicues is that the superior spatial resolution of the MR image allows cortical and medullary structures to be viewed and analysed separately.

Cortical and medullary signal time curves are obtained from regions of interest (ROls) that are positioned over the peripheral cortex and the medullary pyramids (figure 4).

The main interest in MRR has been focused on this potential to functionally differentiate the renal parenchyma into cortex and medulla. This may increase disease specificity and may make it possible to differentiate disease processes that affect these different parts of the kidney and renal transplants $(7,10-19,23)$.

Additionally, the more detailed insight into renal physiology and patho-physiology may prove valuable in the diagnosis of renovascular hypertension (16). 


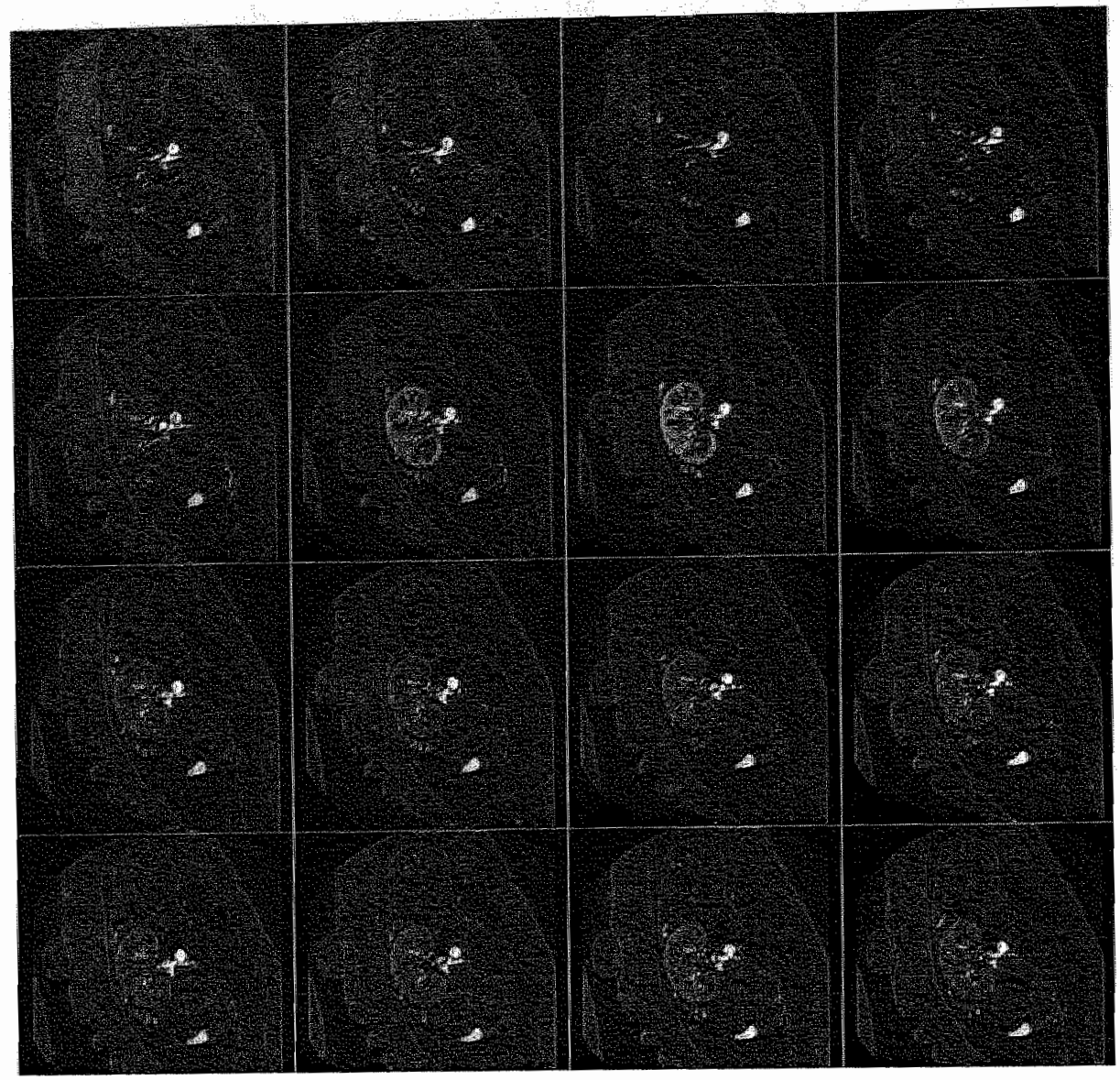

Figure 3

MRR images of a normal renai transplant during various phases of enhancement. Clear differentiation of cortical and meduilury structures, especially duting early phases of enhouncement.
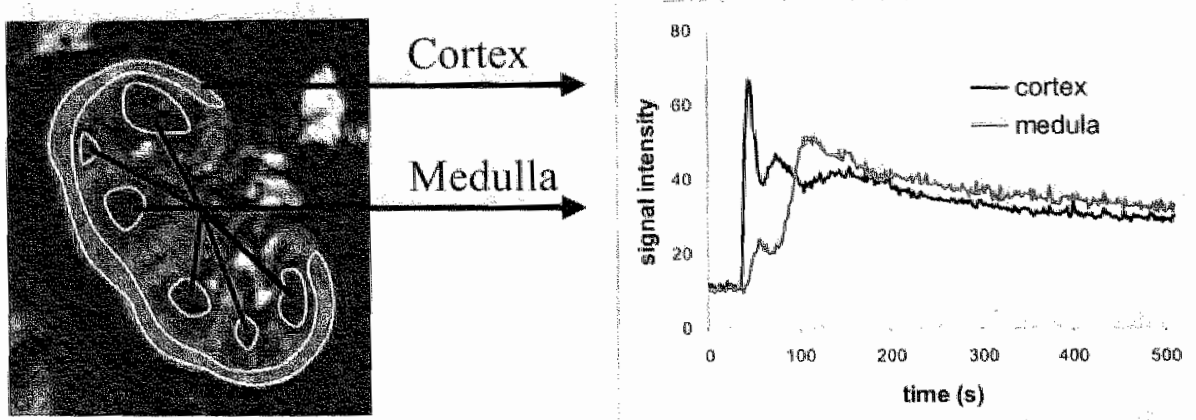

Figure 4. ROI placement and signal time curves, Cortical ROI is positioned ower the peripheral cortex. Medullary ROt consists of multiple smatler areas sitaated over the vatrious medullary pyramids. Temporal changes in signal inensity in the ROIs are expressed as cortical and medullary enhancenent curves. 


\section{Problem statement}

Although various reports thave demonstrated added value of MRR in the clagnosis of functionally diseased kidneys, renal transplants, and in RVH, MRR has not gamed widespread acceptance as a diagnostic tool $(7,10,17,19,22)$.

Various unsolved problems prevent MRR to develop from a theoretically promising technique into a mature and clinical useful tool:

\section{ROI placement, post-processing time and operator bias}

Cortical and medullary ROls are usually positioned manually. This has to be done with great preciston to obtain meaningful signal curves.

Cortical ROI placement is straightforward because the renal boundaries, under which the periferal cortex is simuted, can easily be identified due to the excellent contrast between the kidney and perinephric fat (figure 4a).

Adequate placement of medullary ROIs, however, is more difficult. To identify the medullary pyramids, the operator is dependent on the contrast between cortex and medulla. In many cases, especially in patients with diseased kidneys or renal transplants, this contrast is suboptimal (figure 5). This predisposes to inadequate ROI placement and to volume averaging with cortical tissue in the renal collumns that surround the medullary pyranids. In such cases, the medullary signal curve becomes spoiled with signal from the cortex and adequate corticomedullary differentiation, which is the hallmark of MRR, is lost. Apart from the quality of the MR image, the extent to which these problems occur depends on the experience of the operator. Obwiously, especially for the inexperienced operator, MRR postprocessing is time consuming.

\section{Enhancement quantification}

Standardized methods of quantification of cortical and medullary enhancement are lacking. Reasons for this are the noisy character of the signal curves and shallow shape of the various cortical and medullary peaks. This makes it difficult to identify and quantify these peaks in terms of time of occurrence, height and shape (figure 4).

A
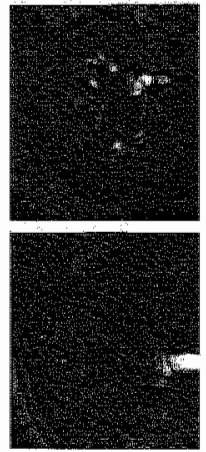

Pre-contrast
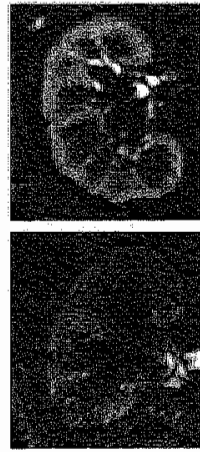

EArly Enhancement
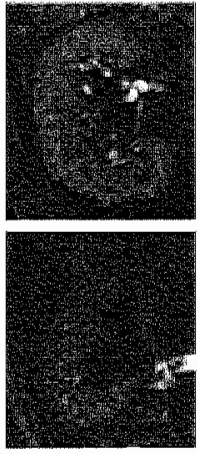

Bu seronds
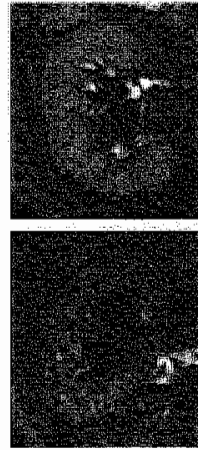

1 minute
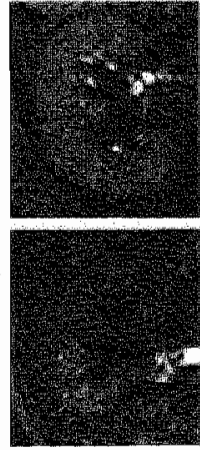

2 mintutes
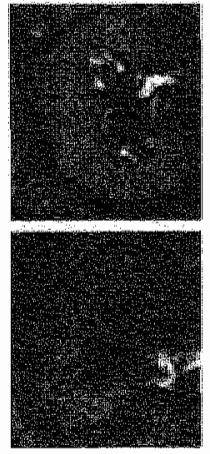

if minutues:

Figure 5 . Images from dynamic scan sequences: (A) normal tenal transplant, (B) diseased nend transplant. Compared to a nomal renal tranplant, contrast between cortes and medulla is poor in discased renal tritsplant. This makes the selection of medullary pyramids for ROI placencm difficul and predisposes to comtical volume axeraging. 


\section{Respiration induced mowement of mative kidneys}

In native kidneys, MRR data analysis is hampered by positional changes of the kidneys with respiration. One way to handle this problem is breath-hold imaging $(16,22)$.

This, however, is a suboptimal solution because variations in kidney position during the warious breath-hold periods are considerable and the technique does not account for additional sources of kidney movement like overall patient movement, bowel peristalsis and vessel pulsation $(24,25)$. Moreover, the interruption of the dymamic scan sequence during periods of respiration results in loss of fiunctional information.

\section{Outline of the thesis}

The thesis addresses these problems and presents a stepwise optimization of MRR data acquisition, data analysis and a first clinical orientation:

In chapter 2 , the current methods of curwe generation are discussed and the problem of cortical volume averaging in medullary $M R$-renographs is addressed. A mathematical algorithm that quantifies and corrects for this effect is presented.

In chapter 3, the problems inherent to manual post-processing are discussed and a computerized method of image segmentation and curve generation, in which the algorithm of chapter 2 is implemented, is presented. Its performance is tested in a group of renal transplant recipients.

In chapter 4, the problem of quantification of cortical and medullary signal curves is addressed. A physiological model of renal enhancement is proposed that facilitates quantilication of cortical and medullary enhancement in terms of a fixed set of parameters.

In chapter 5 , the methods developed in chapters 2,3 and 4 are combined to form a computerized quantitative post-processing algorithm. Its diagnostic performance is tested in a group of non-diseased and diseased renal transplant recipients.

In chapter 6 , a method for the correction of respiration induced positional change of native kidneys is implemented in the post-processing algorithms. This made it possible to extend the clinical orientation of our method to a group of hypertensive patients with and without renowascular hypertension.

Chapter 7 contains a general discussion and the conclusions of the thesis. 


\section{References}

1. Guyton A.C. Textbook of medical physiology. Philadelphia, Seunders 1991, 403-419.

2. Andreoli TE, Carpenter CCJ, Plun F, Smith LH. Cecil essentials of medicine. Phidadelphia, Saunders $1986 ; 206-251$.

3. Krestin GP. Morphologic and functional MR of the kidneys and adrengl glands. New York, Fiold and Wood 1991; 29-43.

4. Gray H. Gray's anatomy. North Dighton. JG Press 1996; 675-678.

5. Guyton A.C. Textbook of medical physiology. Philadelphia, Saunders 1991; 2341-2365.

6. Granger RG and Allison DJ. Diagnostic Radiology. Edinburgh: Churchill Livingstone; 1992; 1372-1377.

7. Sharma RK, Gupta RK, Poptani H, Pandey CM, Gujral RB, Bhandari M. The nnagnetic resonance renogram in renal transplant evaluation using dynamic contrast-enhanced MR imaging. Transplantation 1995; 59: 1405-1409.

8. Krestin GP. Morphologic and functional MR of the kidneys and adrental glands. New York, Field and Wood 1991; 69-87.

9. Safian RD, Textor SC. Renal-artery stenosis. N Engl J Med 2001; 344:431 442.

10. Szolar DH, Preidler $\mathrm{K}$, Ebner $\mathrm{F}$, et al. Functional magnetic resonance imaging of fruman renal allografts during the post-transplant period: preliminary observations. Magn Reson Imaging 1997; $15: 727-735$.

11. Kikinis R, Von Schultess GK, Jager P, et al. Notmal and hydronephrotic kidney: Evaluation of renal function with contrast-enhanced MR imaging. Radiology $1987 ; 165: 837-842$.

12. Choyke PL, Frank JA, Girton ME, et al. Dynamic Gd-DTPA-enhanced MR imaging of the kidney: Experimental results. Radiology 1989; 170:713-720.

13. Carvlin MJ, Arger PH, Kundel HL, et al. Use of Gd-DTPA and fast gradient-echo and spin-echo MR imaging to demonstrate renal function in the rabbit. Radiology 1989; $170.705-711$.

14. Semelka $\mathbb{R C}$, Hricak H, Tomei E, Floth A, Stoller M. Obstructive nephropathy: Evaluation with dynamic Gd-DTPA-enhanced MR imaging. Radiology $1990 ; 175: 797-803$.

15. Von Schultess GK, Kuoni W, Gerig G, Wuthrich R, Duewell $S$, Krestin G. Semiautomated ROI analysis in dynamic MR studies. Part II: Application to renal function examination. I Comput Assist Tomogr 1991; 15:733-741.

16. Ros PR, Gauger J, Stoupis C, et al. Diagnosis of renal artery stenosis: Feasibility of combining MR angiography, MR renography, and Gadopentetate-based measurements of glomerular filtration rate. AJR 1995; 165:1447-1451.

17. Munechika H, Sullivan DC, Hedlund LW, et al. Evaluation of acute renal failure with mangnetic resonance imaging using gradient-echo and Gd-DTPA. Invest Radiol 1991; 26:22-27.

18. Roberts TPL. Physiologic measurements by contrast enlinanced MR imaging: expectations and limitations. J Magn Reson Imaging 1997; 7:82-90.

19. Nakashima $R$, Yamashita $Y$, Tomiguchi $S$, Tsuji $A$, Takahashi $M$. Functional evaluation of transplanted kidneys by Gd-DTPA enhanced Tubo-FLASH MR imaging. Radiat Med 1996; $14: 251-256$

20. Wallace S, Schwarten DE, Smith TP, et al. Intrarenal arteriovenous fistula; transcatheter stem occlusion. J Urol 1978; 120:282-286.

21. Vasbinder GB, Nelemans PJ, Beek FJA, et al. Computed tomographic angiography and magnetic resonance angiography for the diagnosis of renal antery stenosis: a comparative study with digital subtraction angiography. Results of the renal artery diagnostic imaging study in hypertension (RADISH) trial. In preparation.

22. Lee VS, Rusinek H, Johnson G, Rofsky NM, Krinsky GA, Weinreb JC. MR renography witl low dose gadopentetate dimeglumine: Faesibility. Radiology 2001;221:371-379.

23. Semelka RC, Corrigan K, Ascher SM, Brown J, Colindres RE. Renal corticomedullary differentiation: observation in paitents with differing serum Creatinine levels. Radiology 1994; 190:149-152.

24. Vasbinder GB, Maki JH, Nijenhuis RI, et al. Motion of the distal renal artery during 3D contrast enhanced breath-hold MRA. J Magn Reson Imaging; accepted for pulblication. 
25. Katadorp DW, Vastunder GB, De Haw MW, Kemerink GJ, Van Engelshoven JM. Motion of the prowimal renal artery during the cardiac cycle. Magn Res Med 1996; 35:426-43 


\section{CHAPTER 2}

\section{MR Renography: An Algorithm for Calculation and Correction of Cortical Volume Averaging in Medullary Renographs}

J Magn Reson Imaging 2000; 12:453-459.

Jacobus A. de Priester

Jacques $\mathrm{A}$. den Boer

Eelco L.W Giele

Maarten H.L. Christiaans

Alphons Kessels

Arie Hasman

Jos M.A. van Engelshoven 


\section{Abstract}

We evaluated a mathematical algorimm for the generation of medillary signal from raw dynamic magnetic resonance (MR) data. Five healthy volunteers were studied. The MR examination consisted of a run of 100 TL-weighted coronal scans (gradient echo TR/TE $11 / 4 \mathrm{msec}$, flip angle $60^{\circ}$, slee thickness $6 \mathrm{~mm}$, temporal resolution 2 seconds).

Gadolinum-diethylene triamine pentaacetic acld (DTPA, $0.05 \mathrm{mmol} / \mathrm{kg}$ ) was injected with an injector pump ( $5 \mathrm{ml} / \mathrm{sec}$ ). Medullary MR renographs (MRRs) were calculated for regions of interest whth strong and moderate cortical volume averaging (CVA). A reference medullary MRR, devold of CVA, was obtaned Percentual signal differences between calculated and reference medulary MRRs were estimated for each consecutive scan. Run averaged values of these differences were calculated. Mean values, after subtraction of the resting state signal, were $+0.2 \%(\mathrm{SD} 97 \%$ ) and $+0.7 \%$ (SD 9.0\%) for areas with strong and moderate CVA, respectively. We conclude that with this algorithm reliable extraction of medullary MRRs is leasible, providing a unique tool for clinical evaluation of medullary disease. 


\section{Introduction}

The MR-renograph (MRR) is obtained from a dynamic Tl-weighted MR examination of the kidneys and provides functional information on the kidney in terms of changes in signal intensity of the renal parenchyma after gadolinim-diethylene triamine pentaacetic acid (DTPA) injection (1-3). The MRR is an altemative to the functional radionuclide renograph with potential advantages. The superior spatial resolution of the MR image allows cortical and medullary structures to be functionally separated, a feature that is not possible with scintigraphic techniques (1-6). Separate and combined analysis of cortical and medullary signal curves may be of future importance in the differentiation of kidney disease $(1,4,7-12)$. Thus far, most of the literature has focused on cortical MRR. The (patho)physiologic information contained in medullary MRRs, however, could be valuable in providing information about diseases primarily affecting the medulla (i.e. toxic nephropathy) or affecting the medulla in the early stage (i.e. urinary tract obstruction, tubulointerstitial diseases) (13-15).

In various reports on dynamic MR of the kidney, functional information is obtained by selectively placing regions of interest (ROIs) over cortical and medullary tissue and estimating time-dependent changes in signal over these areas $(1-9,11,12,16)$. The cortical ROI is placed over the peripheral cortex beneath the renal surface. Since the renal boundaries can be identified with ease due to the excellent contrast between the kidney and the perinephric fat, cortical ROI placement is a simple and straightforward procedure. Moreover, if the cortical ROI is kept sufficiently narrow, volume averaging with the medullary pyramids, which are located more centrally in the kidney, can be avoided safely even if corticomedullary contrast is suboptimal.

ROI placement over the medullary areas is much more difficult. For adequate selection of medullary tissue, the operator is dependent on the contrast between cortical tissue and the medullary pyramids, which is present only during early renal enhancement, in which cortical tissue enhances and medullary tissue retains its lower signal intensity.

A frequently encountered problem in patients with decreased renal perfusion or parenchymal disease is suboptimal contrast between cortex and medulla $(5,16)$. In these cases, the conditions necessary for adequate medullary ROI placement are lacking. This predisposes to incorrect ROI placement and to volume averaging with cortical tissue located in the renal columns surrounding the medullary pyramids. As a result, ROls intended to provide medullary functional information are in fact a reflection of cortical as well as medullary function. From such signals, inspection of the medullary function is difficult and unreliable. In fact, by losing adequate corticomedullary functional differentiation, one of the major objectives of MRR is lost.

We have developed an algorithm with which cortical volume averaging in medullary structures can be quantified and corrected for, and adequate medullary MRRs can be obtained.

\section{Theory}

When a large corticomedullary $\mathrm{ROI}$ is defined in the MR image of the kidney, its timedependent signal $\left(C M_{t}\right)$ will be a combination of true medullary signal $\left(M_{t}\right)$ and signal from cortical tissue $(C)$ present in the renal columns surrounding the medullary pyramids (Figure 1). 


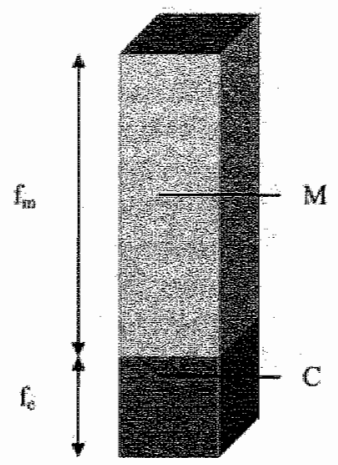

Figure 1. Schematic representation of cortical volume averaging in corticomedullary areas. Corticomedullary signal (CM) is a reflection of cortical and medullary signal ( $C$ and $M$ ) with fractional volumes $f_{c}$ and $f_{w}$. respectively. Mathematically: $C M=f_{e} x C+f_{m} x M$.

If the selected tissue volume is composed of a cortical fraction $f_{c}$ and a medullary fraction $f_{m}$ the measured signal can mathematically be written as:

$C M_{t}=f_{c} \times C_{t}+f_{m} \times M_{t}=f_{c} x C_{t}+\left(l-f_{c}\right) \times M_{t}$

so that:

$M_{t}=\left(C M_{t}-f_{c} \times C_{d}\right) /\left(I-f_{c}\right)$

Equation [2] states that the true medullary signal $\left(M_{t}\right)$ can be obtained by correcting corticomedullary signal $\left(C M_{t}\right)$ with cortical signal $\left(C_{t}\right)$ weighted by the fraction of its volume present in the corticomedullary ROI. Cortical signal can be obtained from ROIs situated over the peripheral cortex. The first assumption is that the cortical tissue of the renal columns has identical dynamic properties as the peripheral cortex. When this is so, the signal obtained from the latter can be used in Eq. [2] as an estimate of $C_{f}$. This means that if we are able to estimate the cortical volume fraction $f_{i,}, M_{s}$ can be calculated.

The algorithm used to estimate $f_{c}$ is based on differences in dynamic properties of gadolinium in cortical and medullary tissue in the early phases of renal enhancement. The larger intrarenal arteries (interlobar, arcuate, and interlobular) are mainly located in the cortical structures. This implies that a contrast agent can only reach the medullary pyramids (by either vascular supply, interstitial space diffusion, and/or tubular excretion) after it has arrived in the cortical areas. This delay in medullary enhancement is visibly substantiated in dynamic MR sequences on which the cortical structures are seen to enhance first, followed by the medullary pyramids. In mixed corticomedullary ROls however, arterial enhancement starts at the same time as in the cortical ROIs (see Figure 3a).

The second assumption is that this early arterial enhancement is caused by the cortical tissue component in the corticomedullary ROI.

Referring to Eq. [1], if to is defined as the last point in time of the unenhanced phase of the cortical ROI, enhancement of the corticomedullary ROI at time $t$ is given by:

$$
C M_{t}-C M_{t^{0}}=f c \times\left(C_{t}-C_{t(0)}\right)+\left[\left(l-f_{c}\right) \times\left(M_{t}-M_{t 0}\right)\right]
$$

During early enhancement, medullary tissue is stationary $\left(M_{t}=M_{t}\right)$ : 
$(1-f) x\left(M_{1}-M_{0}\right)=0$

Combining Eqs. [3] and [4]:

$C M_{i}-C M_{i o}=f_{c}\left(C_{t}-C_{i 0}\right)$

This means that:

$f c=\left(C M t-C M t_{0}\right) /\left(C t-C t_{0}\right)$

The right-hand side in this equation is the ratio of the early enhancement of the mixed corticomedullary ROI and that of the cortical ROI, and can be obtained from the data. The calculated cortical volume fraction $f_{c}$ can be introduced in Eq. [2] to extract a medullary MRR.

In the study presented here we tested both assumptions by computing $M_{t}$ for ROIs with different cortical volume fractions and by comparing these signals mutually and with a reference $\mathrm{ROI}$.

\section{Materials and methods}

\section{Volunteers and MR Imaging}

After informed consent was obtained, five healthy volunteers (all male, aged 22-39, average 27,5 years) were examined in this study. MR images were obtained on a $1.5 \mathrm{~T}$ imager, gradient strength $10 \mathrm{mT} / \mathrm{m}$, slew rate $15 \mathrm{~T} / \mathrm{m} / \mathrm{sec}$ (Philips ACS-NT, Best, The Netherlands). MR studies started with a series of static scans; coronal and sagittal plan scans (spin echo; TR/TE $182 / 10 \mathrm{msec}$ ), followed by an oblique multislice coronal T1-weighted scan, angled throught the long axis of both kidneys (spin echo; TR/TE $550 / 14 \mathrm{msec}$ ). The plane of section of the static TI-weighted spin-echo sequence in which a maximal amount of renal tissue was wisible was chosen as the scan plane of the dynamic sequence. The dynamic scan sequence consisted of a run of $100 \mathrm{TL}$ weighted single-slice gradient echo scans (TR/TE 1.1/3.4 msec, flip angle $60^{\circ}$ ) with a slice thickness of $6 \mathrm{~mm}$, field of view (FOV) $400 \mathrm{~mm}$, rectangular field of view $90 \%$ scan matrix $256 \times 256$, and scan percentage $80 \%$ (resulting voxel size $6.0 \times 2.0$ $\mathrm{x} 1.6 \mathrm{~mm}$ ). This scan has little sensitivity to $\mathrm{T} 2^{\text {* }}$ effects since the short TE and is strongly T $\mathrm{T}-$ weighted because of the large flip angle. Scans were performed every 2 seconds without breathholding. After the tenth dynamic scan, gadolinim-DTPA (Magnevist, Schering, Germany) was injected in a dose of $0.05 \mathrm{mmol} / \mathrm{kg}$ as a rapid bollus with a flow rate of $5 \mathrm{~m} / \mathrm{sec}$ by using an MR injector pump (Medrad Spectris, Medrad, Maastricht, The Netherlands). Bolus time was less than 2 seconds in all wollunteers. The gadolinium-DTPA injection was immediately followed by a saline $0.9 \%$ flush (dose $20 \mathrm{ml}$, flow rate $5 \mathrm{ml} / \mathrm{sec}$ ). The combination of a strongly T 1 -weighted scan and the low dose of gadolinium-DTPA aims at an MR response that increases monotonically with the gadolinium-DTPA concentration (17).

\section{Image Analysis}

For each data set (two kidneys per volunteer), image analysis was perfomed on a work station (Easy vision, Philips). On postcontrast scans with maximal corticomedullary contrast, four ROls were defined, one overlying the peripheral cortex (RI) and three (R2R4) overlying the medullary pyramids, thereby including variable amounts of cortical 
tissue (Figure 2). R2 (large cortical volume fraction) was placed over both medullary pyramidg and renal columns, and R3 (moderate cortical volume fraction) was positioned within $\mathrm{R} 2$, outlining all visible medullary pyramids, excluding the renal columns. R4 was composed of medullary areas that were considered by inspection to be devoid of cortical tissue. Contrast between cortex and medulla in each of the medullary pyramids was excellent, so that $\mathrm{R} 4$ could be selected with confidence. The relative positions of the warious ROIs were kept fixed for the entire examination. To correct for motion caused by breathing, the ROIs were replaced as a group for each consecutive scan. Signal-time curves were generated for the various ROIs.
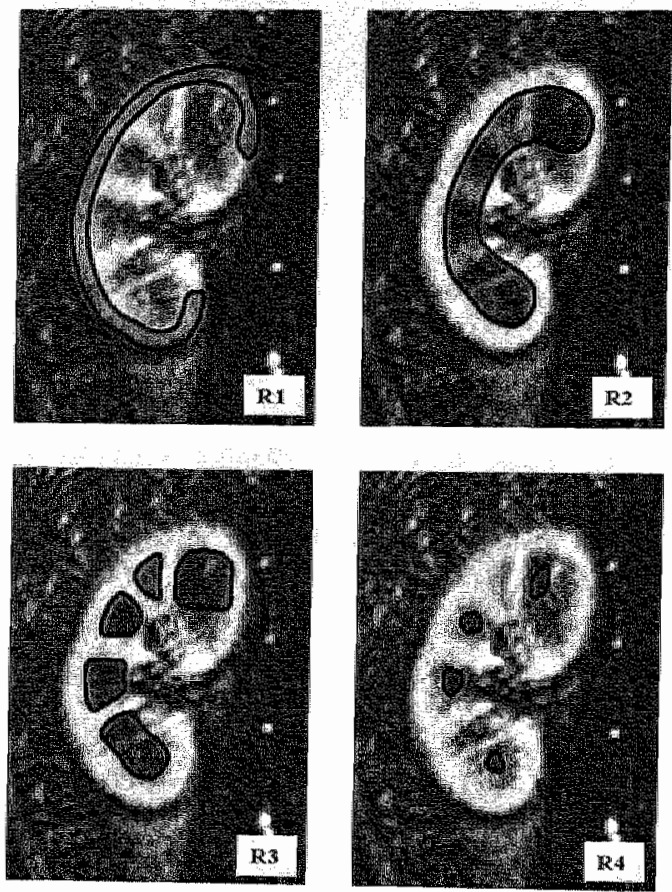

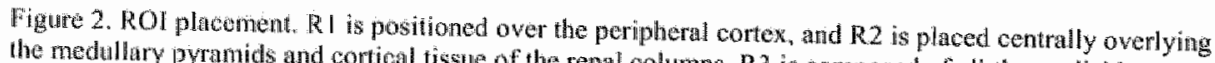
the medullary pyranids and cortical tisste of the remal colums. R3 is composed of all the avallable modullary pyramids, wheress in R4 only those medullary areas withou cortical volume averaging (maximal delined by $R 2$.

\section{Signal Analysis}

Data were transported to a personal computer and fitted into a spreadsheet program (Excel, Microsoft, Redmond, WA) with which the algorithm was executed automatically. For all signal-time curves, the mean signal of the resting state was calculated from the ten dytnmic scans that were made before Gd-DTPA was injected. The first scan showing of the resting ancement, defined as an increase in signal of at least 1.4 times the mean signal last scan of the resting determined and served to define a time interval consisting of the time interval straight lines were fitted through scans of cortical enhancement. Within this (R2 and R3) signal curves. Contical volume fractical (R1) and mixed corticomedullary dividing the slopes of fitted lines of the comtictions of R2 and R3 were calculated by 
the fitted line of the cortical signal curve. This is demonstrated graphically in igure $3 a$. After estimation of the cortical volume fractions medullary MRRs were calculated using Eq. $[2]$.

\section{Data Analysis}

Calculated medullary MRRs were compared with MRRs obtained from R4, which were considered as the reference for medullary enhancement. This was done by estinating differences in signal between each consecutive scan of the calculated medullary MRRs and the corresponding scan of the reference MRR. These differences were standardized by division through the mean signal of the resting state of the reference MRR and expressed as percentages. Their average over the entire run was obtained for each kidney and called run averaged percentual differences.

In a second analysis, calculated and reference MRRs were reduced by subtraction of their mean resting state signal. Again, differences were standardized, and run averaged percentual differences were calculated.

\section{Results}

The mean cortical volume fraction was 0.53 for $\mathrm{R} 2$ (range $0.41-0.64$ ) and 0.40 for $\mathrm{R} 3$ (range $0.19-0.52$ ) (Table 1 ).

A typical case is demonstrated in Figure 3 (data from volunteer 1 , left kidney). Figure $3 a$ shows the cortical MRR (from RI) in conjunction with corticomedullary signal-time curves (from R2 and R3) and the reference MRR (from R4). The cortical signal contribution in corticomedullary areas is manifested by the early enhancement that starts at the same time as in the cortical area and by the early peak, which is a reflection of the cortical peak. Also demonstrated in Figure 3 a are the lines that were fitted through the cortical as well as the corticomedullary signals during early enhancement. As pointed out previously, the cortical volume fractions of the corticomedullary ROIs were calculated from the relative slopes of these lines.

\section{Table I}

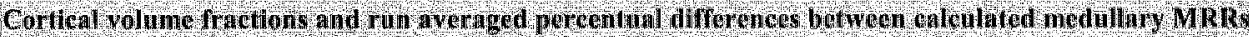
and gold standard medillary MRR

$\mathrm{R} 2$

fe

Wollunteer kidney

$1+$ Righ

Left 047

2

$$
\text { Right }
$$

Leff

Right

Left

4 Right

Lef

5 . R Righ Left

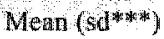

0,52

047

061

061

0.52

0.64

0.58

046

04

0.45

0.53 run averaged difference $(\%)$ uncomected $(8 \mathrm{~d})$ oorrectud $(\mathrm{sd})^{\text {mk }}$ $287(136)+254(26)$ $4201(12.5)+50(139)$ 13.8(2) $+255(146)$

$96,(51)$ $38.3(28,2)$

$7,7(7,2)$

$+9,(1,0)$

$66(4,5)$

$0,901)$

$+49(12)$
$18(37)$

$99(12,1)$

$101(76)$

of $137(144)$

$-27,(7,3)$

$40,8(6.6)$

$87(59)$

$22(6.8)$

+ 2077$)$

in:

036

038

0.49

0.50

0.46

0,52

0,43

0119

0.29

0,35

0.40
) 1

mon werdged diforonce $(\%)$ uncontected (sd) corrected(ad) $416.5(72) \quad{ }_{1} 6 \quad(8.8)$

$414(129) \quad 002(131)$

$10.5(8.9) \quad 400 \quad 104)$

$\$ 203(124) \quad+87(127)$

$480(25) \quad 104(8.3)$

$+23,1(212) \quad+4,9(10,4)$

$13.4(0.4) \quad+14(57)$

$448(22) \quad+02(49)$

$142(1.8) \quad-22,(40)$

$07(2,1) \quad$ a 1,57$)$

$+94(98) \quad 40790)$

* Differences are normalized to resting state signal reference medullary MRR

* Conrected $=$ after subtraction resting state signal

* Calculated from the mean wariance 
In Figure $3 b$ calculated medullary MRRs are demonstrated; together with the cortical and the reference MRR. The medulary behaviour of the calculated MRRs is clearly demonstrated. Its enhancement is delayed, and the reflection of the cortical enhancement peak has disappeared. As can be seen from this figure, the algorithm resulted in an overestimation of medullary signal intensity both in the resting state and during enhancement. Moreover; this overestimation was higher for the calculated medullary MRR obtained from $\mathrm{R} 2$ (large $\mathrm{f}_{\mathrm{c}}$ ) than the one obtained from $\mathrm{R} 3$ (small $\mathrm{f}_{\mathrm{c}}$ ).

Overestimation of calculated medullary signal was found in all volunteers but was highly variable between individuals and their kicneys. This is reflected in the run averaged percentual differences with the reference MRR (Table 1), ranging between $-0.9 \%$ and $438.3 \%$ for $\mathrm{R} 2$ (mean $+149 \%$ ) and between $-0.7 \%$ and $+23.1 \%$ (mean $+9.4 \%)$ for $\mathrm{R} 3$. In Figure $3 c$, calculated and reference MRRs are shown after subtraction of their mean signal of the resting state. In these graphs curves are given in terms of enhancement, instead of absolute signal values. Caleulated and reference MRRs are positioned much closer together than in Figure 3b, and the differences in signal between the two calculated medullary MRRs observed in Figure 3 a have decreased and are now barely above the noise. This effect was observed in all the kidneys included in our study: mean values of run averaged percentual differences decreased to $+0.2 \%$ for $\mathrm{R} 2(\mathrm{SD} 9.7 \%)$ and to $+0.7 \%$ for R3 (SD 9.0\%) (Table 1).

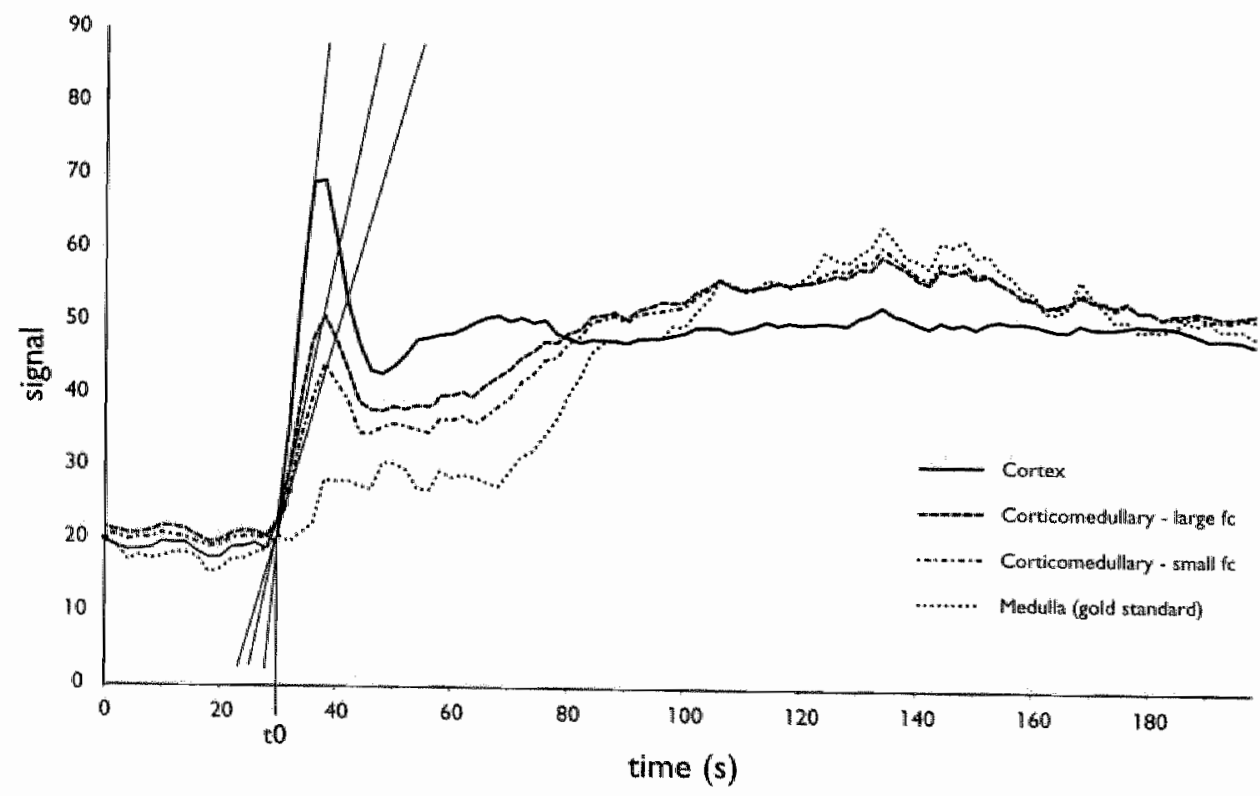

fig $3 a$ 

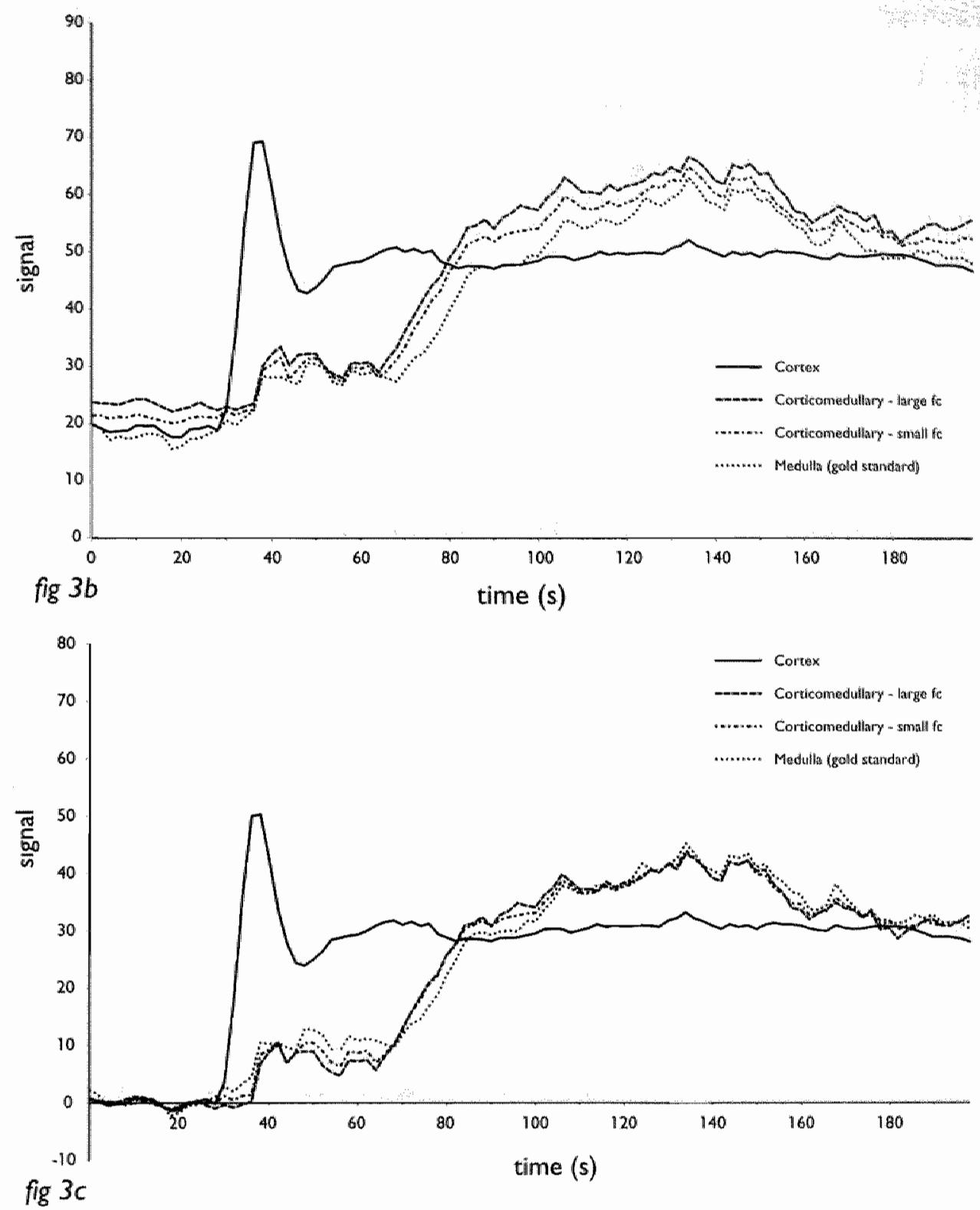

Figure 3. A: Cortical MRR from RI and corticomedullary MRRs from R2 and R3 (large and moderate fc, respectively) are demonstrated in conjunction with reference medullary $M R R$ from $R 4$. Enhancement of corticomedullary MRRs starts at same time as that of cortical MRR and is due to cortical tissue in the corticomedullary volume. Its fraction $(f c)$ is given by the quolient of the slopes of lines fitted throught the last scan of the resting state (ro) and the first two scans of enlancement of the cortical and conticomedullary MRRs. B: Medulary MRRs calculated with the algorithm in conjunction with cortical and reference medullary MRR. Note overestimation of medullary signal, which is systematically stronger for callculated medullary MRRs obtained from R2 (large $f c$ ) than for R3 (moderate $f c$ ). C: After subtraction of mean signal of the resting state, overestimation decreases, and differences between callculated MRRs from areas with large and moderatefc are barely larger than noise. 


\section{Discussion}

The use of a small medullary ROI (R4) over the medullary pyramids to generate a reference MRR was possible in our study because it was performed on healthy volunteers. In the volunteers, contrast between contex and medulla (in the early vascullar phase of bolus passage) was sufficient to allow positioning of these ROIs. Intially, we intended to test our algorithm on the data from a group of renal transplant recpients who were examined previously. In this group however, contrast between cortex and medulla was insufficient to select the medullary reference area with confidence.

Our study proves that the delayed medullary enhancenent is a reliable basis for calculation of cortical volume veraging in corticomedullary $\mathrm{ROIs}$. In addition, this study also provides a validation of our hypothesis regarding the delayed enhancement of the medulla. This in turn allows two calculated medullary MRRs to be obtaned from these ROIs. The calculated medullary MRR has important adwantages; it does not carry uncertainty of inadvertent cortical contamination, and it can be based on a large $\mathbb{R O I}$, giving access to a high signal-to-noise ratio.

In applying the algorithm, however, care should be taken to correct medullary signal curves for their resting state signals. In terms of absolute signal values, the procedure results in overestimation of medullary signal. This overestimation is observed in 9 of the 10 kidneys included in our study and is highly variable both between individuals and between kidneys in one individual.

An important characteristic of this error is that it occurs in both the nonenhanced and enhanced phases of the scan sequence and that the amount of overestimation is invariably larger for MRRs obtained from ROIs with large cortical volume fractions than for those derived from areas in which smaller amounts of cortical tissue are included. This characteristic suggests the cause of the error.

We propose that the assumption underlying the algorithm that the kidney is a twocompartment system is in fact an oversimplification of renal physiology. Both of these compartments (cortex and medulla) are assumed to be enhancing in nature. Additional nonenhancing tissues within the renal parenchyma like connective tissue in the interstitial space and nonactive nephrons are ignored by the algorithm but could well be of influence on renal dymamics. Another source of nonenhancing tissue is extrarenal tissue that may be left in the cortical $R O P$ even when careful adjustment is performed. Different distribution and architecture of these structures in contex and medulla offer an explanation for the observed overestimation of medullary signal in calcullated MRRs.

The explanation is substantiated by the observation that the amount of overestimation can be decreased if renographic curves are expressed in relative, rather than absolute signals. Since these tissues are nonenhaneing in nature, their influence will be equal in both the resting state and the enthanced phases of the generated MRRs. Therefore, if the resting state signal is subtracted from the calculated medullary MRRs, the influence of nonenhancing tissues can be cancelled out. This is visible in our data (Figure $3 \mathrm{c}$ and Table 1) as a dramatic decrease in the previously existing differences between calculated and reference medullary enhancement only MRRs. Moreover, the pre-existing differences between absolute value MRRs obtained from ROls with large and moderate cortical volume fractions have become negligible. In various publications on MRR, the inner and outer layers of the medullary pyramids are reported to have different enhancement characteristics $(2,3,6,8)$. This inhomogeneity in medullary enhancement is unaccounted for by our algorithm in which cortical and medullary stmetures are supposed to enhance homogeneously. Grven the high similarity of signal curves 
obtained from ROIs with different distribution and location of medullary tissue, we believe that the error introduced by this simplification of renal physiology is acceptable In conclusion, with the algorithim presented in this paper, medullary MRRs can be generated by using two time-intensity curves from the kidney one from the onter renal cortex and a second from the remaining part of the renal parenchyma. The medullary enhanoenent obtained is shown to be an accurate representation of medullary behaviou. Care should be taken that calculated medullary MRRs are conrected for their resting state signals In the proposed technique the medullary MRR can be generated automatically which makes the procedure easy to perform and reduces openator dependency. Moreover, maximal amounts of medullary tissue may be included, even if not visually assessable, which makes generated medullary MRRs less noisy and more representative of global medullary function. This is of special importance in patients with diseased kidneys or renal transplants in whom corticomedullary differentiation is obscured.

The medullary renogram obtained by $\mathrm{MR}$ is a novel piece of information in the diagnosis of kidney function. Its availability is expected to be of importance in future developments of functional evaluation of the kidney. We are presently collecting patient data 10 assess its clinical significance. As yet the data collection is laborious because respinatory movement has to be compensated for by manual replacement of the various ROIs, which is a labour-intensive task. We are currently working on an algorithm providing automated realignment as well as ROI selection. The fully automated version of the analysis will make MR renography an easy, virtually noninvasive tool. 


\section{References}

1. Kikinis R, Von Schultess GK, Jager $\mathrm{P}$, et al. Normal and bydronephrotic kidney: evaluation of renal function with contrast-enhanced MR imaging. Radiology 1987; $165: 837-842$.

2. Choyke PL, Frank JA, Grron ME, et al. Dynamie Gd-DTPA-enhanced MR imaging of the kidney: experimental results Radiology 1989,170:713 720 .

3. Carvin MJ Arget PH, Kundel HI, et al Use of Gd-DTPA and fast gradient-echo and spinecho MR imaging to demonstrate renal function in the rabbit. Radiology 1989; 170:705-711.

4. Semelka RC Hricak H. Tomei $\mathrm{E}$, Floth $\mathrm{A}$, Stoller M. Obstructive nephropathy: evaluation with dynamic Cd-DTPA menhanced MR imaging. Radiology 1990; 175:797-803.

5. Von Schultess GK, Kuoni W. Gerig G. et al. Semiauromated ROI analysis in dynamic MR studies. Patt II: Application to renal function examination. J Comput Assist Tomogr 1991; $15: 733-741$.

6. Ros PR, Gavger $J$, Stoupis $C$, et al. Diagnosis of renal antery stenosis: feasibility of combining MR angiography, MR renography, and gadopentetate-based measurements of glomerular filtration rate, ANR 1995; 165:1447-11451.

7. Munechika $H$, Sullivan DC, Hedlund LW, et all. Evaluation of acute renal failure with magnetic ressonance imaging using gradient-echo and Gd-DTPA. Invest Radiol 1991;26:2227.

8. Shama RK, Gupta RK, Poptani H, et al. The magnetic resonance renogram in renal transplant evaluation using dynamic contrasterihanced MR imaging. Transplantation 1995; 59: $1405-1409$.

9. Roberts TPL. Physiologic measurements by contrast enhanced MR imaging: expectations and limitations, J Magn Reson Imaging 1997; 7:82-90.

10. Kettritz U. Semelka RC, Brown ED, et al. MR tindings in diffuse renal parenchymal disease. J Magn Reson Imaging 1996; 1:136-142.

11. Szolar $D H, H_{x}$ Preidler $K$, Ebner $\mathbb{F}$, et al. Functional magnetic resonance imaging of human renal allografts during the post-lransplant period: preliminary observations. Magn Reson Imaging $1997 ; 15: 727-735$.

12. Nakashima $R$, Yamashita $Y$, Tomiguchi $S$, Tsuji A, Takahashi $M$. Functional evaluation of transplanted kidneys by Gd-DTPA enhanced Turbo-FLASH MR imaging. Radiat Med 1996; 14:251-256.

13. Cronin RE, Henrich WC. Toxic nephropathy. In: Brenner BM, editor. Brenner and Recter's the kidney. New York: WB Saunders; 1996:1680-1711.

14. Curhan GC, Zeidel M.L. Urinary tract obstruction. In: Brenner BM, editor. Brenner and Recter's the kidney. New York: WB Saunders; 1996:1936-1958.

15. Rubin RH, Cotran RS, Tolkoff-Rubin NE. Urinary tract infection, pyelonephritis and refix nephropathy. In: Brenter BM, editor. Brenner and Recter's the kidney. New York: WB Saunders; $1996: 1597-1654$.

16. Semelka RC, Corrigan $\mathrm{K}$, Ascher SM, Brown VI, Colindres RE. Renal conticomedullary differentiation: observation in patients with differing serum creatinine levels. Radiology $1994 ; 190: 149-152$.

17. Takeda M, Katayama, Tsutsui T, Komyana T, Mizusawa T. Does gadolinium-diethylene triamine pentascetic Acid enhanced MRI of the kidney represent tissue concentration of contrast media in the kidney? In vivo and in vitro study. Magn Reson Imaging 1994; 12:42127. 


\section{CHAPTER 3}

\section{MR Renography by Semiautomated Image Analysís: Performance in Renal Transplant Recipients}

J Magn Reson Imaging 2001, 14:134-140

Jacobus A. de Priester

Alphons G.H. Kessels

Eelco L.W Giele

Jacques A. den Boer

Maarten H.L. Christiaans

Arie Hasman

Jas M.A. van Engelshoven 


\section{Abstract}

We evaluated a method of semiautomated analysis of dynamic MR image series in renal transplants. Nine patients were studied twice, with an average time interval of 7 days. MR examination consisted of a rin of 256 T 1 -weighted coronal scans (GE; TR/TE/flip: = $11 / 3.4 / 60^{\circ}$, slice thickness $-6 \mathrm{~mm}$, temporal resolution $=2$ seconds). Gadolinium-DTPA $(0.05 \mathrm{mmol} / \mathrm{kg})$ was injected with an injlector pump $(5 \mathrm{ml} / \mathrm{second})$. MR renographs of the cortex and medulla were obtained by segmentation of the renal transplant and placement of wo regions of interest (ROIs) overlying the peripheral and central renal parenchyma. In the first 100 frames of the renographs, analysis of variance (ANOVA) demonstrated significant intraclass correlation coefficients with mean values for the cortex and medulla of 0.47 and 0.59 , respectively. We conclude that the procedure is a robust technique that generates meaningful signal curwes: 


\section{Introduction}

MR-renography (MRR) is a dynamic MR examination that provides functional information of the kidney and renal transplant in terms of changes in signal intensity of the renal parenchyma after gadolinium-DTPA injection ( 1 -3). The high spatial resolution of the MR image allows cortical and medullary structures to be separated, a feature that is not possible with scintigraphic techniques and that may be of importance in separating disease processes affecting different parts of the kidney or renal transplant (1-12). Although biopsy is still the standard of reference for diagnosis of diseases affecting the kidney and renal transplant, early reports indicate the possible usefulness of MRR in discriminating disease processes such as acute rejection and acute tubular necrosis $(8,10,11)$.

The MR renograph is the time-dependent signal intensity of suitably placed regions of interest (ROIs) over cortical and medullary tissue (1-12). ROIs are usually hand-placed by the operator, who selects cortical and medullary tissue by visual inspection of the early-entanced images on which contrast between cortical, medullary, and perinephric tissue is optimal. In cases in which contrast between cortex and medulla is suboptimal, however, ROI positioning may be more difficult and time consuming, thereby requiring skill and experience from the operator.

In this work we present and evaluate a new method to derive cortical and medullary MR renographs of renal transplants by means of semiautomated $\mathrm{ROl}$ placement. The obtained renographs were tested nonparametrically on reproducibility.

\section{Materials and methods}

\section{Patients}

Nine renal transplant recipients (three men and six women, 46-66 years old, mean age 53.6 years) were included in this study. These patients were selected from a population of renal transplant recipients who took part in a larger clinical MRI study. Consecutive patients entering this study were asked if they were willing to participate in the reproducibility study and have a second MR session. All patients were in good clinical condition and had a stable renal function for a period of at least 3 months prior to the investigations (creatinine clearances ranging between $22.3 \mathrm{ml} / \mathrm{min}$ and $94.2 \mathrm{ml} / \mathrm{min}$, median $62.5 \mathrm{ml} / \mathrm{min}$ ). Patients with diseased renall transplants, who usually do not have stable renal function, were not included. None of the patients were on diuretics. Immunosuppressive drug regimes consisted of Azathioprine and Prednisone in one patient, Cyclosporine in three patients, and Tacrolimus in five patients. After written informed consent was obtained, the volunteers were examined twice with a mean time interval between examinations of 7 days (range 6-9 days). This project was approved by the medical ethics committee of our hospital.

\section{MRI Procedure}

To standardize hydration and induce diuretic behavior of the kidney, patients were hyperbydrated by administering $500 \mathrm{ml}$ sodium chloride $0.9 \%$ intravenously 1 hour prior to the MR session.

MR images were obtained on a $1.5 \mathrm{~T}$ imager, gradient strength $10 \mathrm{mT} / \mathrm{m}$, slew rate $15 \mathrm{~T} / \mathrm{m} /$ second (Phillips ACS-NT, Philips, Best, The Netherlands). MR studies started with coronal and sagittal planscans $(S E ; T R / T E=182 / 10)$, followed by an oblique multislice coronal $\mathrm{T}$ l-weighted scan through the long ax is of the renal transplant $(\mathrm{SE} ; \mathrm{TR} / \mathrm{TE}=550 / 14)$. 
The long-axis images were used to select the optimal scanplane for the dynamic sequence. In designing the dynamic scan sequence, our objective was to combine optimal T1-weighting with sufficiently high temporal resolution.

Optimal Tl-weighting was obtained by using a spolled gradient echo sequence with the shortest possible TR and TE. When we started our studies in 1995 these were $11 \mathrm{msec}$ and 3.4 mose, respectively. These parameters were combined with variable flip angles and tested on a series of botlles with increasing gadolinium-DTPA concentrations. Signal enhancement proved optimal with a flip angle of $60^{\circ}$.

Gadolinim has the same dynamic properties as TC-DTPA. Therefore, enhancement characteristics known from renal scintigraphy could serve as an indicator for the temporal resolution requited in our dynamic scan sequence. The quickest phenomena known from nuclear studies oecur during early enhancement when peaks may reach their maximum values within 10 seconds. To describe such phenomena accurately we aimed at a temporal resolution of 2 seconds. This could be achieved by choosing a rectangular field of view (FOV) of $90 \%$ and a scan percentage of $80 \%$ (scan matrix of $256 \times 256$ ).

The dymamic sequence consisted of a run of 256 frames, together defining a time interval of approximately 8.5 minutes. Slice thickness was $6 \mathrm{~mm}$ and FOV was $400 \mathrm{~mm}$, resulting in a woxel: size of $6.0 \times 2.0 \times 1.6 \mathrm{~mm}$.

Because water is reabsorbed from the renal tubules, gadolinium concentration in the neplarons can increase dramatically, which may lead to loss of signal because of T2 effects. The use of prehydration limits the concentration increase to about 10 times (13). The use of a small dose of eontrast agent (half the normal dose: $0.05 \mathrm{mmol} / \mathrm{kg}$ ), as suggested in Ref. 14, further reduces the risk of unwanted signal loss.

The contrast agent (Magnevist, Schering, Germany) was injected after the 10th frame of the dynamic scan sequence as a rapid bolus with a flow rate of $5 \mathrm{ml} / \mathrm{sec}$ by using an MR-injector pump (Medrad Spectris, Medrad, Masstricht, The Netherlands). The gadolinium-DTPA injection was immediately followed by a saline flush $(0.9 \%$, dose $20 \mathrm{ml}$, flow rate $5 \mathrm{ml} / \mathrm{sec})$. 


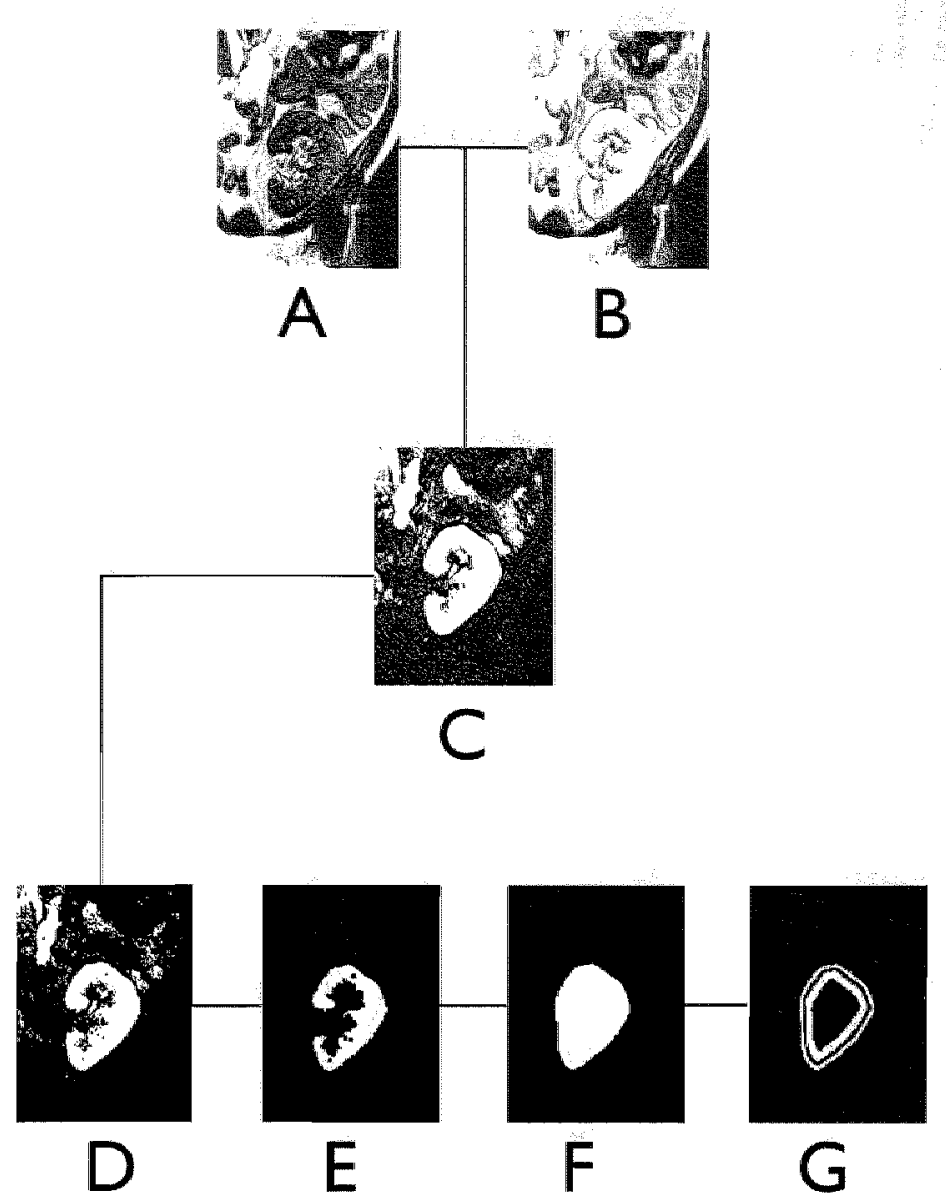

Figrure 1. Transplant segmentation and ROl definition. Added signals of (A) precontrast and (B) early-enthaned images are (C) subtracted and threshotded to yield a binary image, D. Pixels with signals above threshold walue are rendered white. E: Objects smaller than 700 pixals are removed, resulting in pixel arefoverlyng transtant parenchyma. F: Area is closed oxer the renal hilum; all pixels within this area ato made white and whe oulot tim of pixels is removed. G: A two-pixel-thick layer is removed from a massive object; the reatlting image is subtracted from the original inage nesulting in a band owerlying the petipherd cortex and hilumi A second band is created front two additional images oblained after removal of a five- and a nine-pixel-thick layer from the original object. G: After subtraction a lour-pixelethick band is created, located paral lel to the outer band with an interspace of two pixels.

\section{ROI definition}

Image analysis was performed on a Sun Sparc Ultra 30 computer (Sun Microsystems Netherlands, Amersfoort, The Netherlands) with EasyScil software (Philips, Best, The Netherlands).

The algorithm used to define the ROIs consisted of three steps. First a renal object was defined. In this step two groups of frames were used. The first group consisted of the first 10 frames of the dymamic scan sequence, all made before gadolinium-DTPA was injected. The second group consisted of the next 30 frames, obtained during the time interval in which 
gadolinim-DTPA strongly enhances the peripheral renal parenchyma. The frames within each group were added, so that two new images were obtained (Figure $I A$ and IB). The unenhanced image was subtracted from the enhanced image (Figure IC). The subtraction inage was segmented by thresholding (threshold value half of the maximum pixel value), creating binary (black and white) inage in which pixels with a signal above the theshold walue were white and the remaining pixels black (Figure ID). All objects smaller than 700 pixels were removed from the binary image, resulting in an image that contaned only one object that corresponded to the renal cross section (Figure IE). The outer rim of this object, defining the peripheral renal boundary, was closed over the renal hilum and all pixels lying within this area were included in the object. With an erosion filter the outer layer of pixels, prone to volume averaging with surrounding perirenal structures, was removed from the object. The renal object obtained in this way included the locus of renal parenchyma and hilar stuctures (Figure 1F).

From this object (second step), the two outer layers of pixels were used to define a peripheral band overlying the renal cortex and hilum (Figure 1G). A second, more inwardly located band was defined which consisted of a four-pixel-thick layer located parallel to the peripheral band with an interspace of two pixels (Figure $1 G$ ). This central band was composed of medullary tissue in the renal pyramids, cortical tissue in the renal columns, and hilar structures. In Figure 2 A these layers are shown superimposed over the original image.

Finally (third step), the non-hilar area was delineated by a hand-drawn line (Figure 2B). The parts of the bands located inside this area were used to define a peripheral and a central $\mathrm{ROI}$ (Figure 2C).

\section{Curve Generation}

The two ROIs that were generated were copied to all the scans of the dymamic series. As can be seen in Figure 2, the outer ROl overlayd the peripheral cortex. This ROI served to obtain cortical signal-time curves. The central ROI was positioned over both contical tissue of the renal columns and medullary tissue of the medullary pyramids. Medullary signal curves were obtained from this mixed corticomedullary area with the mathematical algorithm presented in our previous work (15).

For the 240 frames starting with the first frame of enhancement the mean nonenhanced signal was subtracted. To correct for differences in amplification settings of the MR system between the two examinations of each patient, the signals to be compared were rescaled by normalizing the area under euch curve to 100.

\section{Statistics}

Data analysis was based on analysis of variance (ANOVA) (16). To inspect the potential diagnostic value of the obtained cortical and medullary MR renographs the variation in curve shape that occurred for the same patient between the two examinations was compared with
that observed for the different patients of the population.

Differences between curves can be caused by three factors: 1) differences between patients leading to interpatient variance $\left(\sigma^{2}\right.$ inter $), 2$ ) differences within patients, and 3 ) measurement errors. The latter two factors constitute the intrapatient variance $\left(\sigma_{\text {intra }}^{2}\right)$. For each frame $\sigma^{2}$ inm and $\sigma^{2}$ inter were determined with a one-way ANOVA table. To reduce noise, the moving averages of $\sigma^{2}$ intra and $\sigma^{2}$ inter of 20 adjacent frames (M20) were calculated, creating average values of $\sigma^{2}$ intra and $\sigma^{2}$ inter at $220(240-20)$ timepoints. Note that this type of variance averaging still was an inspection of the data at full temporal resolution; averaging the variances merely specifies groups of 20 frames as the basis for the test.
The hypothesis that $\sigma_{\text {inter }}^{2}=0$ was tested with a Fisher statistic ( $\mathrm{F}=\left(\sigma_{\text {intra }}^{2}+2 \times \sigma_{\text {inter }}^{2}\right)$ 
( $\sigma^{2}$ ints). If this hypothesis were true it would mean that patients could not be differentiated by curwe shape. The critical value of $F$ above which the hypothesis could be rejected was $F_{0}$ os $0,8,9=3.23$.

An ahernative way to express this criterion mphasizes the reproducibility of signal ouves within the patient by using the intraclass comelation coefficients $\left(1: \mathrm{c} .=\sigma^{2}\right.$ inter $/\left(\sigma^{2}\right.$ intra $\left.\sigma_{\text {inter }}\right)$. Clearly, i.c. $=(\mathrm{F}-1)(\mathrm{F}+1)$, so that its significance lewel is 0.53 . Assessnent of i.c. was performed for both cortical and medullary signal curves.
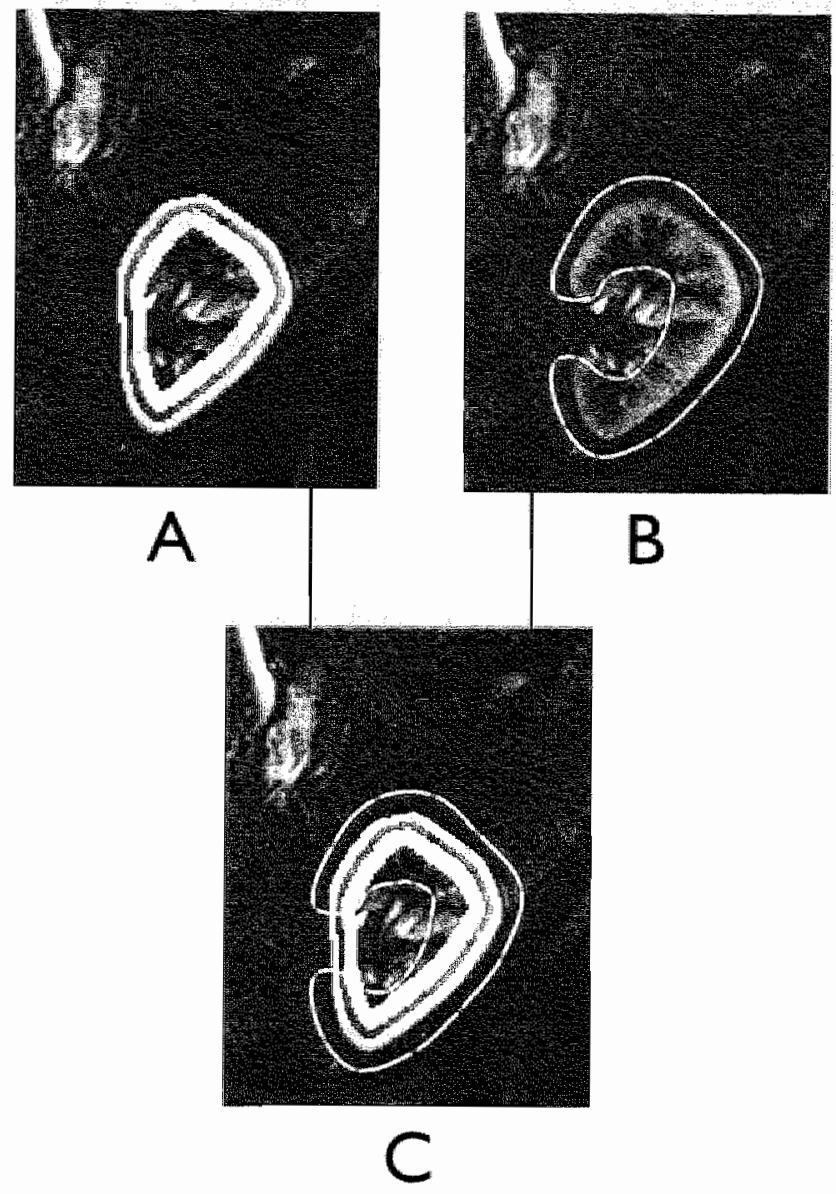

B

Figure 2. A: Autonatically generated bands are superpositioned over the original early-enluaced image. B: The hilar area is circumscribed by a hand-drath line. C Parts of the bands located within this area were used for measurement.

\section{Results}

The cortical and medullary signal curves of two typical cases are demonstrated in Figure 3. Comparing cortical and medullary curves from the first and second examination, a clear similarity in shape but a discrepancy in amplitude can be noted. It is for this reason that the 
curves were rescaled by nomalization of the area under the curve in order to make a comparison in terms of curve shape possible.

Intra- and interpatient statadard deviations $\left(\mathrm{SD}={ }^{2}\right.$ ) and intraclass correlation coefficients are shown in Figures 4 and 5 , respectively. For both the cortex and medulla, differences between intra- and interndividual SDs were most pronounced during the early phases of enhancement (Fig 4) and then were often significant (Fig. 5 ).

Intraclass correlation coefficients ranged between 0.22 and 0.79 for the cortex (mean 0.47 ), and between 0.26 and 0.86 for the medulla (mean 0.59 ).
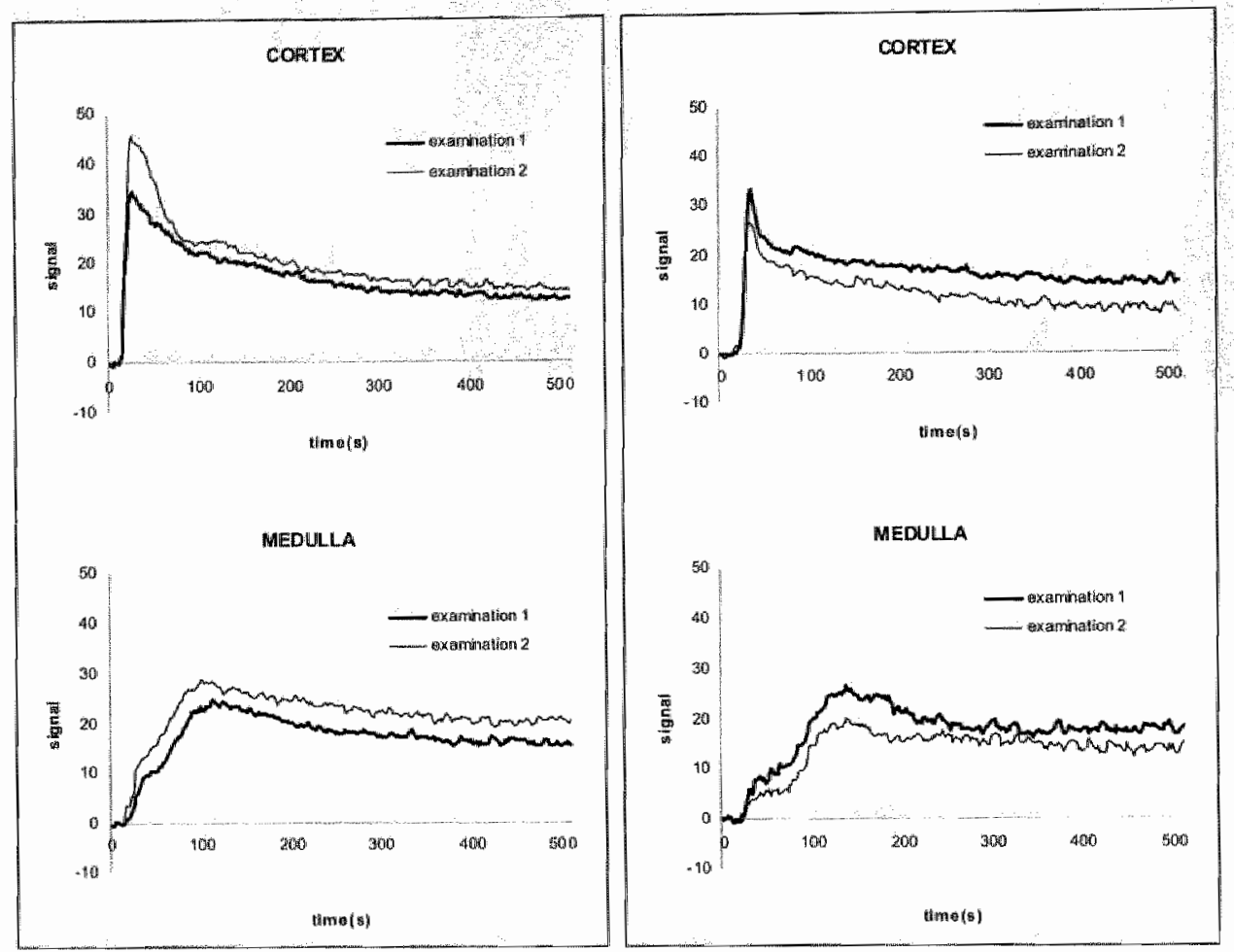

Figure 3. Contical and medulary sigral curves for two patients: first and second examinations. Curves show similarity of shape but difference in curve amplifude.

\section{Discussion}

In testing oul method of image analysis our objective has been to get an impression of the reproducibility of the data during the entire time interval of enhancement. One can expect differences in enhancement amplitude at any given timepoint as well as differences in the temporal shape of the enhancement curves. Only differences in enhancement amplitude at comparable timepoints were evaluated in our analysis. ANOVA of the temporal shape of the curves was not carried out. Another artificial limitation of our analysis is that we restricted ourselves to inspection of the mean over the sum of 20 adjacent data points. Clearly, other independent smoothing procedures are conceivable, and could have demonstrated further 
significances. The present analysis, however, already shows significant distinetion between inter-and intrapatient variance. This is sufficient for the purpose of this article, becase it demonstrates the validity of our method of data collecting and processing.

As shown in Figure 5, significant intraclass correlation coefficients occur during the first 100 frames after start of enhancement. Thus it is in this early period that we have observed significant differences in the enlancement curves between patients. Interestingly, during this time interval these differences are more significant for the medulla than they are for the cortex. In addition, the figure shows that the tail of the medullary signal curve is informative whereas the corresponding part of the cortical signal curve cannot be used to differentiate individual patients from the population. This shows that the separate observation of the medullary enhancement is an important part of the data analysis. We believe this is the first time that this contribution of the medullary enhancenent curve has been demonstated. In summary, our analysis shows that the MR renographs carry information about the differences between patients. Most of the information is offered in the medullary signal curves and in the early parts of the cortical signal curves.

We emphasize that we have not shown whether, or to what extent, the curves allow discrimination between healthy and diseased renal transplants. However, our data do provide a sufficient basis for further research in this direction, which is currently taking place at our department. Data of clinically diseased patients, as well as a more complete analysis of the signal curves (including the estimation of appropriate enhancement parameters (amplitude, time, and shape)) of the cortical as well as the medullary enhancenent curves, establishment of ranges of normality for such parameters, and establishment of the influence of different pathologies on paraneter values will be needed.

Our method of automatic image analysis is a new approach for postprocessing in MRR. Cortical and medullary signal curves are obtained from two band-shaped ROls that are generated after automatic segmentation of the renal transplant. The only operator input required is exclusion of the hilar area. The two ROl signals are used to derive the cortical and medullary signals, as discussed in Ref. 15. This derivation makes use of the high temporal resolution of the data.

Because manual selection of ROIs is circumvented our method offers potential logistic advantages. Postprocessing is shortened (taking less than 5 minutes), operator bias is kept to a minimum, and, as shown in Figure 2, the band-shaped ROIs are defined with a thickness and position that optimize the amount of tissue included while avoiding volume averaging with surrounding structures. These bands compete favorably with other approaches because the ROls include a larger amount of cortical (peripheral ROI) and medullary tissue (central ROI), leading to signal curves that are an optimal representation of cortical and medullary function. A point of interest is the possibility of translating our method to native kidneys. Currently our method is only applicable to renal transplants because we are unable to correct for respirationinduced motion. The unchanging position of renal transplants during the investigation makes segmentation relatively simple, and $\mathbb{R O I s}$, once defined, can be copied without hazard of misplacement to all the frames of the scan sequence. Obviously, this is a different issue in native kidneys, which change considerably in position during respiration. One way to solve this problem would be breathold imaging. This, however, would result in large temporal deficits in enhancement curves, and inevitably to loss of functional information. We are currently working on a method to quantify renal movement during respiration. If this proves possible, our method of computerized image analysis as presented in this articte would. become applicable to native kidneys. 


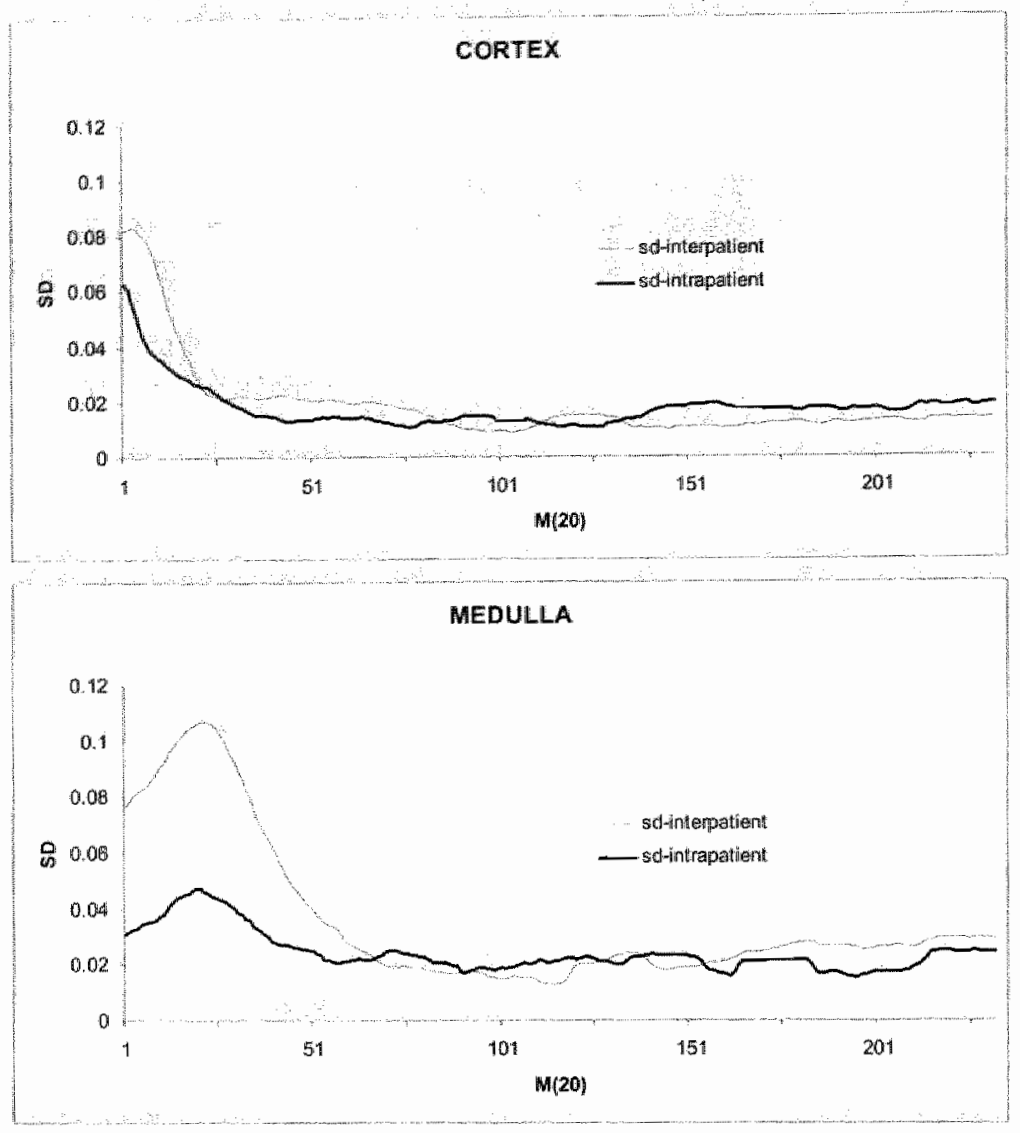

Figure 4. Intra- and interpatient SDs of running averages of 20 consecutive frames (M20). Differences between initra- and interpatient SDs are most pronounced during early frames of enhancement and are stronger for the nedullta.

We conclude that the automated image analysis presented here is a robust technique that simplifies postprocessing and generates meaningful cortical and medullary signal curves. The results from our study indicate that further studies in renal transplant recipients and attempts to translate the method to native kidneys are justified.

\section{Acknowledgements}

We thank Marc Geerlings, information technologist, for creating an easy-to-handle interface and for his help in creating the pictures. 


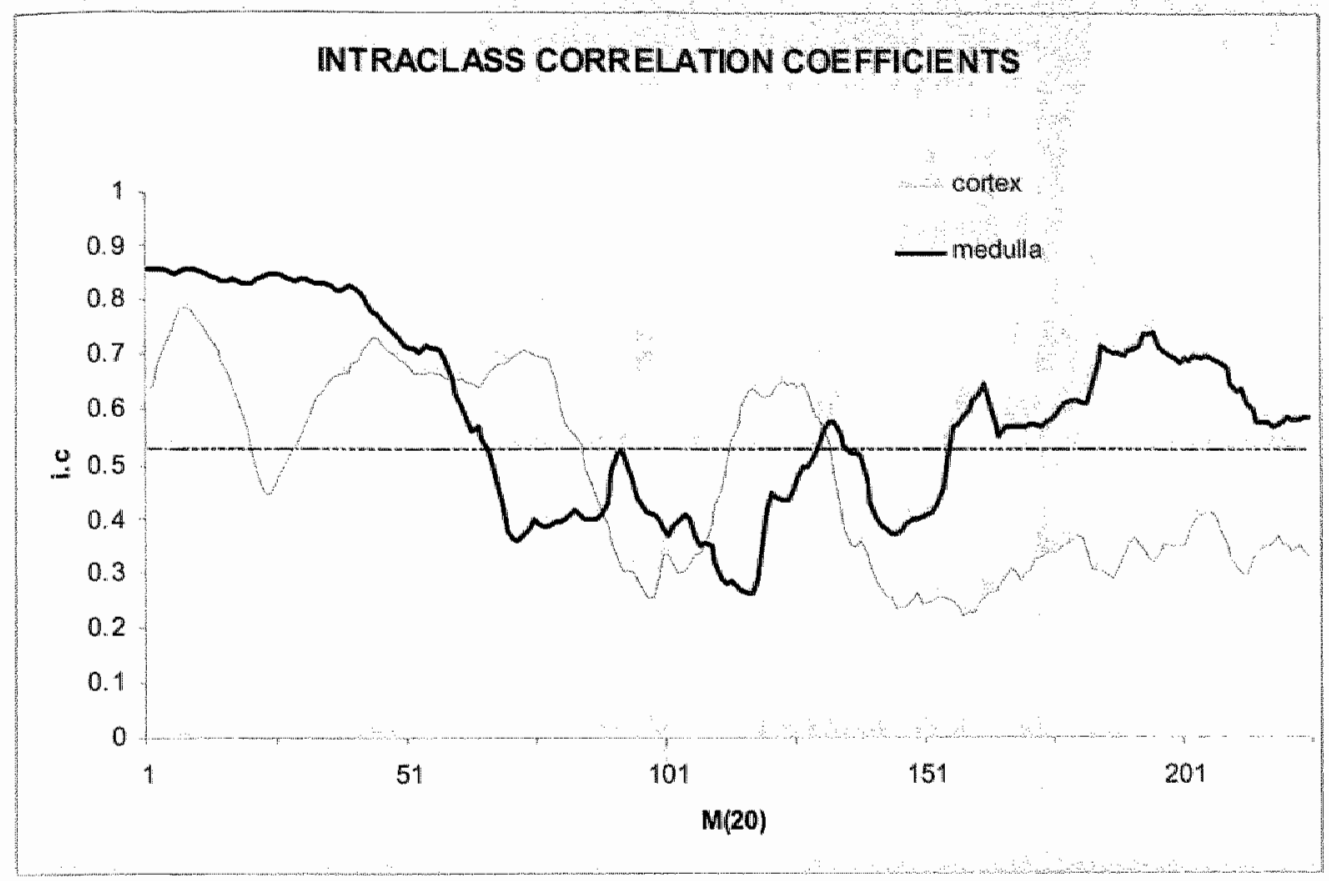

Figure 5. Intraclass correlation coefficients of ruming averages of 20 consecutive frames (M 20). Horizontal line denotes level of significance $(r=0.53)$; higher values indicate reproducibility. Note that valuable information is obtained during the early halves of cortical and medullary enhancement, and at the tail of the medullary signal curve. 


\section{References}

1. Kikinis $R$, von Schultess GK, Jager $P$, el al. Normal and hydronephrotic kidney: evaluation of renal function with contrust-enhanced MR imaging. Radiology $1987 ; 165: 837-842$.

2. Choyke PL, Frath JA, Griton ME, et al. Dymamic Gd-DTPA-enhanced MR maging of the kidney: experimental results. Radiology $1989 ; 170: 713-720$.

3. Carvin MJ, Arger PH, Kundel HL, et al. Use of Gd-DTPA and fast gradient-echo and spin-echo MR imaging to demonstrate remal function in the rabbit. Radiology 1989; 170:705-711.

4. Semelka RC, Hricak H, Tomei E, Floth A, Slolter M. Obstructive nephropathy: evaluation with dynamic Gd-DTPA-enhanced MR imaging. Radiology 1990; 175:797-803.

5. von Schultess GK, Kuoni W, Gerig G, Wutlurich R, Duewell S, Krestin G. Semiautomated ROl analysis in dynamic MR studies. Part II: application to renal function examination. J Comput Assist Tomogr 1991; 15:733-741.

6. Ros PR, GatgerJ, Stoupis $C_{*}$ et al. Diagnosis of renal artery stenosis: feasibility of combining MR angiography, MR renography, and gadopentetate-based measurements of glomerular filtration rate. Am J Roentgenol 1995; 165:1447-1451.

7. Munechika $\mathrm{H}$, Sullivan DC, Hedl und LW, et al. Evaluation of acute renal failure with magnetic resonance imaging using gradient-echo and Gd-DTPA. Invest Radiol 1991; 26:22-27.

8. Sharma RK. Gupta RK. Poptani H, Pandey CM, Gujrall RB, Bhandart M. The magnetic tesonance renogram in renal transplant evaluation using dynamic contrast-enhanced MR imaging. Transplantation 1995; $59: 1405-1409$.

9. Roberts TPL. Physiologic measurements by contrast enhanced MR imaging expectations and limitations. I Magn Reson Imaging 1997;7:82-90.

10. Szolw $\mathrm{DH}$, Preidler $\mathrm{K}$, Ebner $\mathrm{F}$, et al. Functional magnetic resonance imaging of human renal allografts during the post-transplant period: preliminary obserwations. Magn Reson Imaging 1997; 15:727-735.

11. Nakashima $R$, Yamashita $Y$, Tomiguchi S, Tsuji A. Takahashi M. Functional evaluation of transplanted kidneys by Gd-DTPA enhanced Turbo-FLASH MR imaging. Radiat Med 1996; 14:251-256.

12. Semelka RC, Corrigan K, Ascher SM, Brown JJ Colindres RE. Renal corticomedul 1 ary differentiation: observation in patients with differing serum creatinine levels. Radiology 1994; 190:149-152.

13. Guyton AC. Textbook of medical physlology. Philadelphia: Saunders, 1991:403-445.

14. Takeda M, Katayama Y, Tsutsui T, Komeyama T, Mizusawa T. Does gadolinium-diethylene triamine pentaacetic acid enhanced MRI of the kidney represent tissue concentration of contrast media In the kidney? In wivo and In vitro study. Magn Res Imaging 1994;12:421-427.

15. DePriester JA, Giele ELW, DenBoer JA, et aI. MR-renography: an algorithm for calculation and correction of cortical volume averaging in medullary renographs. $J$ Magn Reson Imaging 2000; $12: 453 \times 459$.

16. Shrout PE, Fleiss JL. Intraclass correlations: uses in assessing rater reliability. Psychol Bull 1979; $86: 420 \times 428$ 


\section{CHAPTER 4}

\section{Quantitative model description of dynamic MRI enhancement data of the transplanted kidney}

Submitted

Parts of this chapter were published in:

J Magn Reson Imaging 2001; 14:134-140

Jacob A. den Boer

Jacobus A. de Priester

Marc J.H.M. Geerlings

Walter $\mathrm{H}$. Backes

Eelco L.W. Giele

Alphons G.H. Kessels

Maarten H.L. Christiaans

Arie Hasman

Jos M.A. van Engelshoven 


\section{Abstract}

\section{Purpese}

To evaluate a method for extracting quantitative functional information from MR enhancement data in transplanted kidneys.

\section{Methods}

Enhancenent data of cortex and medulla from dynamic MR kidney studies were obtained twice from ten clinically patent renal transplant recipients. Based on a physiological model, enhancement curves were preseribed to show one arterio-venous and two nephronal peaks and a tail with nine free parameters. These curves were fitted to the data.

\section{Results}

The residue after fitting was 1.35 (cortex) and 1.46 (medulla) times the noise. The $95 \%$ confidence interval of the obtaned parmeter values varied between $\pm 2 \%$ and $\pm 46 \%$. Of most parameters the intra-class correlation was significant, indicating a much smaller difference in parameter value within patients than between patients. The glomerular filtration rate as obtained from enhancement parameters correlated to the creatinine clearance with $\rho=$ 0.66 .

\section{Conclusion}

Our results indicate the potential diagnostic value of the combination of dynamic enhancement and curve fitting. 


\section{Introduction}

With dynamic MRI of the kidney (also called MR renography) the uptake and passage of a contrast agent bolus through the kidney is observed over time. This is a complex phenonenon because the agent is contained not only in the arterio-venous compartment but also in the nephrons and the renal interstitial space. The contrast agent that is taken up in the nephrons will travel through the cortex as well as the medulla, with a delay and a concentration that depends on the arterio-venous concentration as well as the filtering action of the kidney. A number of researchers has studied kidney enhancement with MRI in animal models (1-7), native human kidneys (8-14), as well as renal transplants (15-18). In these articles progress is shown in the understanding of the effects of renal (transplant) disease on the shape of cortical and medullary enhancement curves $(2,4,5,8,10-17,19-21)$.

In earlier reports we presented an experimental technique that provides cortical and medulan kidney response with high temporal resolution, high signal to noise ratio and removal of partial volume effects from the medullary data $(22,23)$. In a recent atticle we showed in at group of patients. with renal transplants that the enhancement data obtained with our technique are reproducible and potentially meaningful (24).

Thus far, a complete quantitative description of the MR observable response has not been given. We hypothesize that such quantification potentially increases the diagnostic value of MR renography. The present article describes an attempt to reach such a description by using a parametric representation of enhancement curves of which the main features follow from a physiological model.

\section{Subjects and data acquisition}

\section{Subjects}

Ten renal transplant recipients without clinical symptoms and satisfactory renal function were examined twice within a time interval of less than two weeks between examinations. One hour before the start of the examination, the patients were given 0.5 liter of saline $0.9 \%$ applied intravenously. The creatinine clearance of each patient was assessed prior to each of the MR examinations. Informed consent was obtained from all patients. The ethical committee of the hospital admitted the protocol.

\section{MRI}

The MR studies started with a multislice axial T2-weighted scan (FSE; TR/TE/TF=300/150/20) through the kidneys, followed by an oblique multislice coronal Tl-weighted scan, angled through the long axis of both kidneys (spin echo; TR/TE $550 / 14$ msec). Of this scan, the slice in which a maximal amount of renal tissue was visible was chosen as the scan plane of the dynamic sequence. The dynamic scan consisted of 256 strongly TI weighted spoiled gradient echo images (TR/TE/flip $=11 \mathrm{~ms} / 3.4 \mathrm{~ms} / 60^{\circ}$ ) with field of view of $400 \mathrm{~mm}$, slice thickness of $6 \mathrm{~mm}$, a resolution of $205 \times 256$ and rectangular field of view $90 \%$ (resulting in a voxel size of $6.0 \times 2.0 \times 1.6 \mathrm{~mm}$ ). The images were obtained with a temporal resolution of $2 \mathrm{~s}$, starting $20 \mathrm{~s}$ before motor driven bolus injection of 0.05 mmol/kg Gd-DTPA dimeglwmine (Magnevist, Schering $A G$, Germany) at a rate of $5 \mathrm{~mL} / \mathrm{sec}$. The MR equipment was a $1.5 \mathrm{~T}$ Gyroscan NT system (Philips Medical Systems, The Netherlands). The body coil was used as receive coil. Contical and cortico-medullary data were obtained from large concentric, kidney shaped 
ROIs, generated as described previously (22). Figure 1 shows an example of these $\mathbb{R O I s}$, superimposed over the kidncy image. The outer ROI starts one pixel inside the kidney contou and is 2 pixels thick; the inner starts 3 pixels further inside and is 4 pixels thick. The callyx region is excluded. The signal from the inner ROI has a medullary as well as a cortical contribution, the latter arising mostly from cortical tissue in the columns of Bertin. The cortical contribution is removed algorthmically $(22,23)$.

The kidney volume was detemined from the mult shice T2-weighted inages.

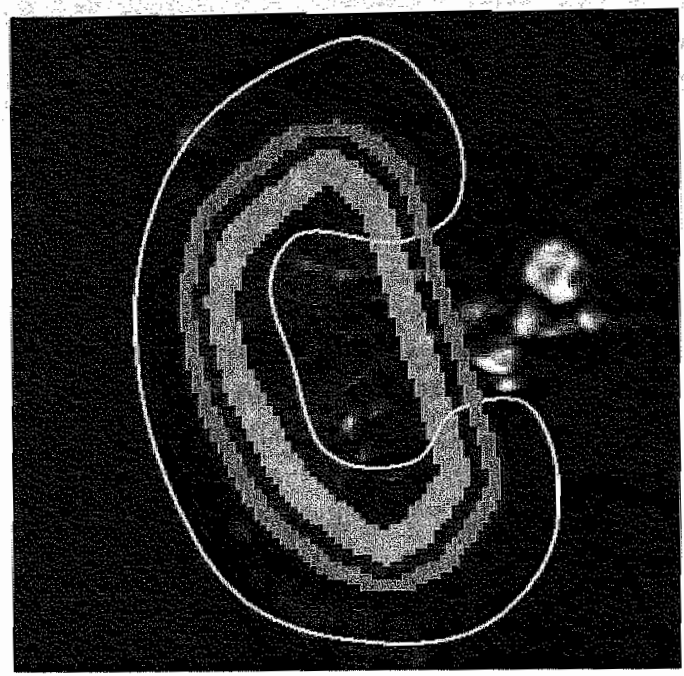

Figure 1. MR image of the kidney shorty after arrival of the bolus. Two at tonatically generated concentric ROI's are show as gray objects. The onter ROl is contical the imer ROI crosses medullary pyramids as well as cortical columns. The lute that excludes the kidney ealyx is drawn manuglly.

\section{Description of the playsiological model}

The physiological model that was used to describe cortical and the medullary enhancenent data is based on the ideas of Choyke (2) and Wolf (3). It interprets the enhancement as the result of the arterio-venous as well as the nephronal history of the contrast agent passage. During bolus passige, an arterio-venous peak is expected both in the cortex and the medulla, the medullary arterio-venous peak being of smaller amplitude. The medullary peak is relatively late and slow. This is because in the medula the blood pressure drops in the long peritubular capillary systen which, in combination wh permeability of the capillary walls, results in a slow passage of the bolus ( 25 ).

Part of the agent is filtered in the glomeruli and is transported through the nephrons. We will call this part the "the filtered bollus". As opposed to water, the contrast agent is not reabsorbed so that its concentration increases along the path of the nephron. From its cortical origin onwards, the nephron has three branches, folded as a hairpin. It traverses the medulla in the proximal convoluted tube and loop of Henle, teenters the cortex in the distal convoluted tubes and continues in a collecting tube that traverses the medulla again, ending in the renal calyx. Symchronicity of these events in the nephrons will cause the filtered bolus to reside in the kidney as a thin concentric shell. 
The shell moves through the kidney, leading to the occurrence of temporal concentration maximat in each of the concentric ROIs $(1,2,14,17)$. Given the folded path of the nephron, the contrast agent resides alternatingly in the cortex and the medulla. The cortical and nedullary renograms show this as enhancement maxima. So, the model predicts three peaks in the cortical as well as in the medullary renogram, as observed already by Wolf ( 3 ), and illustrated schematically in figure 2 . The first peak reflects the passage of the bolus of contrast agent through the arterio-venous compartment and will be called the arterio-venous peak. The second and third peak reflect the excretory path through the nephrons of the filtered bolus:

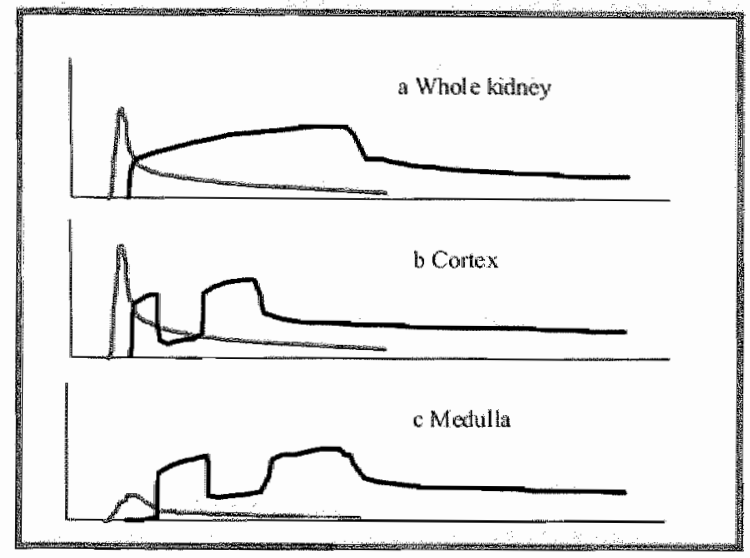

Figure 2. Schematic drawing of the arterio-wenous (gray curves) and nephronal enhancement (black curves) of the kidney after bolus injection, in an idealized case.

a) Signal of the entire kidney. The arterio-venous sigmal has a sharp peak during bolus passage and then drops to a low and decayng level. Part of the bolus enters the nephrons. Extraction of water from the nephrons causes the concentration of the contrast aggent to rise. This resuits in a sharp increase in the nephron signal that continues growing unil the filtered bolus leaves the nephron. After that the, the nephron signal decays al a rate that follows that of the arterio-venous signal.

b) Signal from a cortical ROI. The large arterio-venous signal corresponds to the large cortical blood volume The nephron signal resembles that in a) as long as the contrast agent resides cortically, accumulating in the proximal convoluted tubules. This creates the first nephronal cortical peak. The cortical signal drops when the bolus passes into the nephronal toops of the modula. When the agent fows bak into cotical area in the distal convoluted tubes it generates the second nephronal cotical peak.

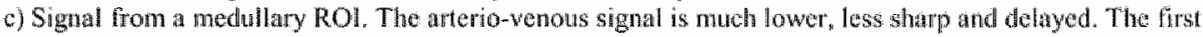
nedulary mephronal signal peak appears when the contrest agent flows from the cortex into the long loops of Henle. Signall decreases when it leaves the medulla to the cortex and rises agan when reonicring the medulla in the collecting wibes to yield the second medulary peak which lasts until the contrast agent lowws the meplurons. After the bolus passage, the continuing filtering of the contrast agent from the artertal system aneates a background signal that increases uritl the botus levves the kidney and decays thereafter.

these peaks will be called nephronal peaks. After the filtered bolus has left the kidney, most of the contrast agent still remains in the soft tissues and circulation of the patient. Its renal excretion will continue and the tail of the renal enhancement curve will follow the slow decay of the contrast agent in the body.

The linearity of the MR signal at the time of the various peaks is discussed in Appendix A. In the modeled physiological behavior of the kidney it is possible to determine the glomerular" filtration rate from the signal enhancement. This is described in Appendix B. 


\section{Enhancement curve fitting}

The observed enhancement data (cortical as well as medullary) were compared to a parametrically defined curve $E(t)$ that expresses the expected three peaks and the tail of the enhancement data. Its mathematical expression is given in $\mathrm{Appendix} C$. Although the total number of parameters defining $E(t)$ is 13 , the number of free parameters is less. Firstly, the arrival time $t_{a}$ is determined independently by inspection of the pre-arrival data. Secondly, some constraints on the parameters are introduced. Table 1 gives an overview. Some of the constraints represent domain knowledge of the problem because they define aspects of the enhancement curve that are expected from the physiological model (e.g. non-negative values and defined temporal order of signal peaks). Other constraints are arbitrary; their motivation is argued in the discussion.

The fit between clata and parametric curve was obtained with a Marquardt Levenberg algorithm (26). A default set of patient independent start values for the free parameters was used. The software was developed in our laboratory. The data analysis was carried out on an Ultra Spurc Sun computer using EasyScil, an image processing software environment provided by Philips Medical Systems.

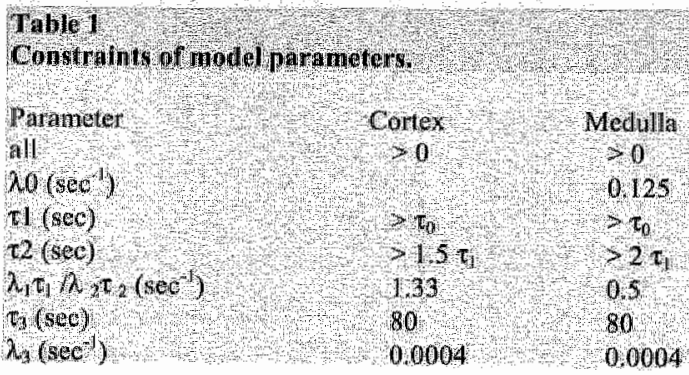

\section{Data analysis}

Given enough parameters, curve fitting will always succeed but when the number of parameters to be fitted is too large, parameters that have little influence on the resulting curve shape will in a numerical fitting procedure be overly sensitive to noise. This means that the fit procedure has to be analyzed on quality of the fit between the obtained curve and the data points as well as on parameter sensitivity to noise. In addition, the obtained parameter values have to be inspected on their power to discriminate between patients as well as on consistency with the underlying physiological model. In all, this leads to four steps in the data analysis. (1) Quality of fit. To obtain an estimate for the quality of fit of the enhancement curve, the mean squared residue $P_{e}$ between the complete fitted enhancement curve and all data points, 256 in total, was determined. The measurement noise in the data was estimated from the last 100 data points (data from the tail of the curve); Apart from noisy spikes and decay, this part of the enhancement curves showed no visually apparent structures. These data points were fitted by a decay function with a bi-exponential shape, expected from pharmacokinetic modeling (27). We assumed that the residues between fit and data during decay were caused by noise only and we defined the noise power $P_{n}$ as the mean square of these residues. The ratio $P_{0} / P_{n}$ was calculated and used as a measure of the quality of fit

(2) Sensitwity to noise. The confidence limits per parameter due to the noise were estimated indirectly. The MR scan cannot be repeated to generate more than one representation of the noise. So, instead, per parameter we observed the increase of the squared sum of the residues when that parameter was changed away from its optimum value and curve fitting was 
repeated with the remaining free coefficients. Doubling of the squared residue corresponds to an increase of the error from noise by one standard deviation. This procedure is allowed when the noise distribution is normal (26).

(3) Reproducibility: For each of the obtained parameters we compared the differences within patients (between sessions) and those between patients with an analysis of variance

(ANOVA). Per parameter the intra-class correlation coefficient (ICC) was deternined. At $\alpha=$ 0.05 , its significance level is 0.52 .

(4) Consistency with the physiological model. Expected values of the enhancement of the cortical arterio-wenous peak and the first medullary nephronal peak as derived in Appendix A were compared to the observed peak amplitude parameters. Equation B5 was used to calculate the glomerular filtration rate (GFR) and this quantity was compared with the creatinine clearance $(C C)$ in terms of equality of mean and correlation.

\section{Results}

Parametric enhancement curves were obtained by fitting equation $\mathrm{C} 4$ to each cortical and medullary data set. All fitting procedures succeeded without intervention from the operator. In none of the cases it was necessary to adapt the starting values of the parameters. The number of iterations was typically less than 300 and always less than 1000. Figure 3 shows some typical examples of cortical and medullary enhancement data, together with the fitted model curves and its composing functions.

(1) Quality of fit. The mean squared residue $P_{e}$ of the data with the fitted enhancement curve and the noise power of the data $P_{n}$ were determined per case. The means of these quantities and their ratio over all cortical and medullary curves are shown in Table 2 . The medullary data were noisier than the cortical data, as expected from the indirect generation of these data by weighted subtraction (22). The table shows that the mean ratio $P_{e} / P_{n}$ was slightly larger than one, whereas for perfect fits it should have had a value 1 .

(2) Noise sensitivity of the free parameters. The assessment of paraneter sensitivity was done for three randomly chosen cases (The workload of the test is considerable and the results of the test for each of the three cases were similar). Per free parameter the average of the variance over the three cases was used to estimate the $95 \%$ confidence intervals. These are given in Table 3 per parameter as percentage of its mean value.

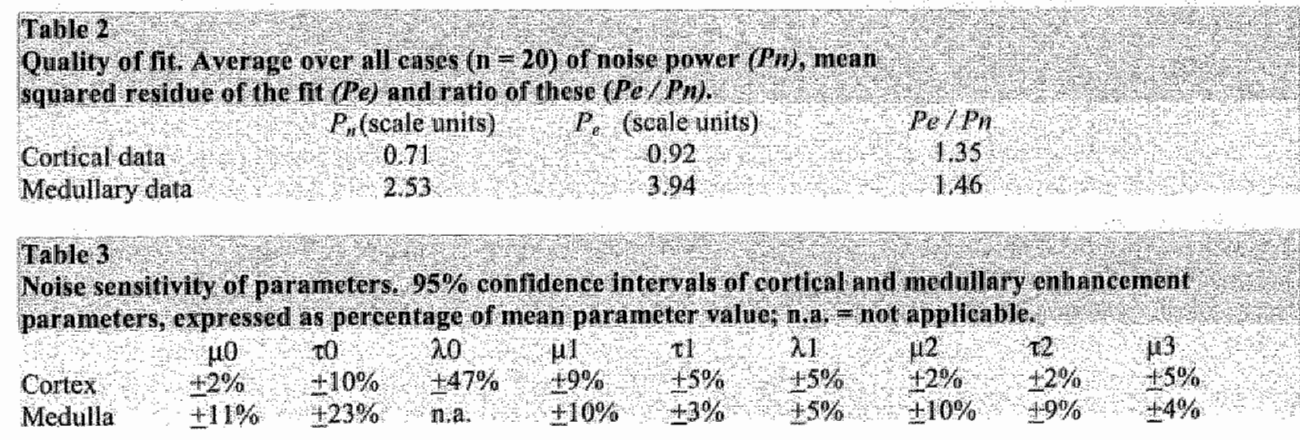



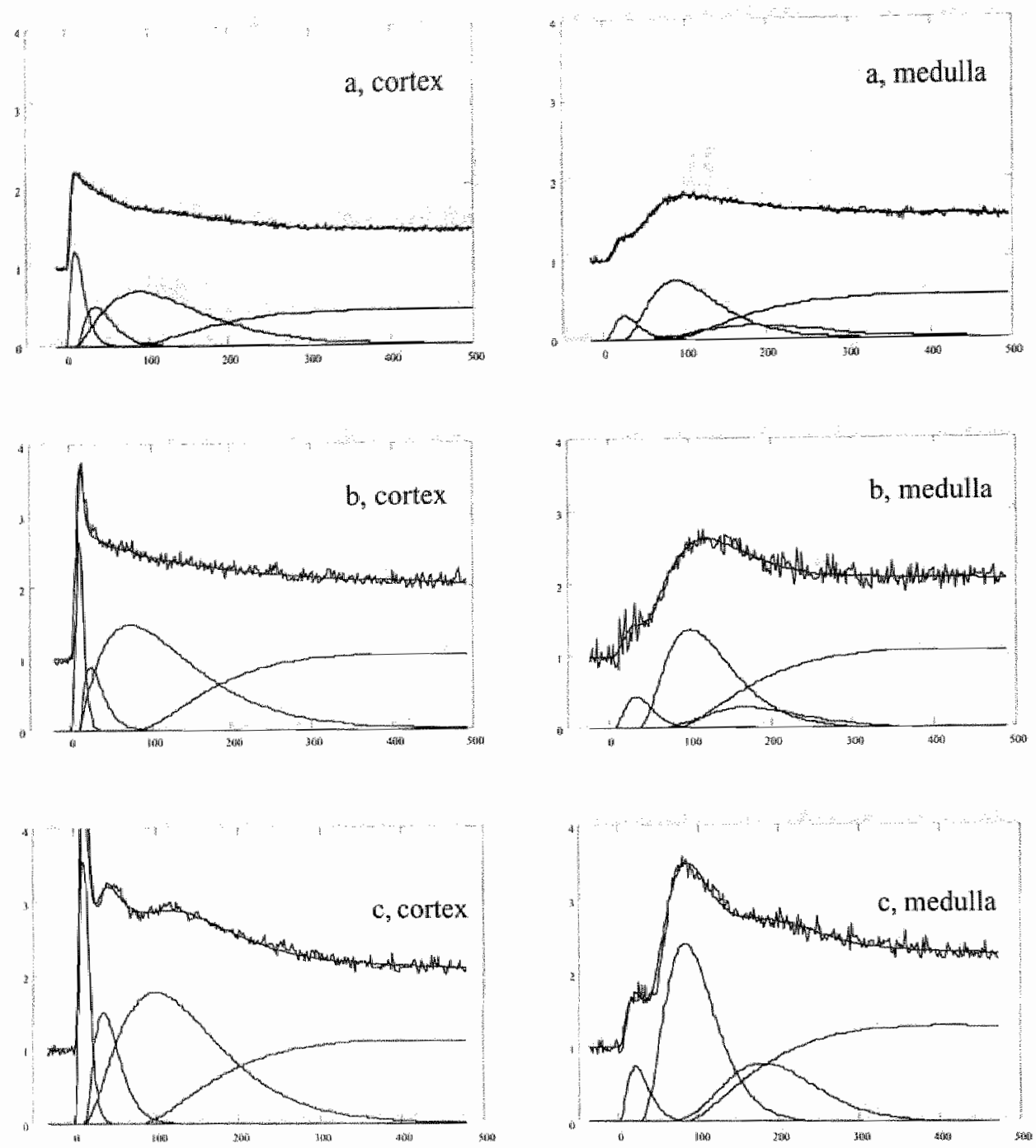

Figure 3. Cottical and medullary enkancement data (noisy curve), fitted enhancement curnes (upper smooth line, equation C4) and composing funchions (lower smooth lines, equations $C l$ and $C 3$ ) for three cases. The enhancement data and lifted curves ane offset by one scale unit to visually separate them from the composing functions. The horizontal scale is the time after injection, in seconds. Case al shows no separate peaks in cortical and modullary curves and relatively low entharucement. lin case b) enhancenent is larger and the cortical arteriovenous peak stands out visibly, Case c) shows clearly separated sharp arterio-venous and nephronal peaks in contex as well in medulla.

(3) Reproducibility. Table 4 summarizes the results of this analysis. The Table lists for which parameters the ICC was significant. Earlier, we used identical statistical methods to report a model-free analysis of the same enhancement data (24). In that study 230 contelation coefficients of the enhancement value at each time point were obtained. The median and $10-$ 90 percentile range of these correlation coefficients are shown in the table for comparison. 


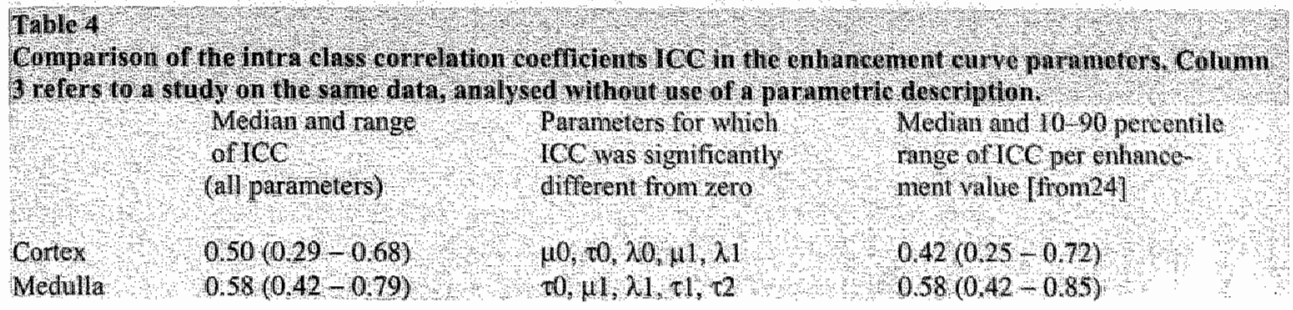

(4) Consistency with the physiological model. Table 5 shows the means and the ranges of the parameter walues. The ranges of the characteristic peak widths (equation $\mathrm{C} 2$ ) are added in the table. The predicted enhancement for the arterio-venous cortical peak and the first medullary nephronal peak were obtained with help of the intra-arterial and intra-nephronal concentrations as estimated in Appendix $\mathrm{A}$; the corresponding enhancement is found with figure $\mathrm{A} / \mathrm{b}$ for a fast and slow spin exchange regime. These predictions are added in the Table next to the corresponding peak amplitude parameters.

Table 6 shows statistics of the glomerular filtration rate (GFR) calculated by use of equation B5. Shown are: the mean value of GFR over all exams, the mean ratio of GFR and creatinine clearance (CC) and the correlation coefficient $p$ between GFR and CC. Figure 4 shows the correlation diagram.

1ables

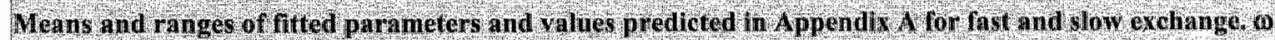

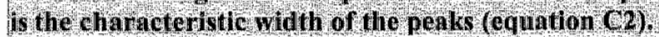

\begin{tabular}{|c|c|c|c|c|c|}
\hline & Panameter & & tex & & dullo \\
\hline & & Mean & Range & Mean & Ratige \\
\hline Arterib venous peaks & $\mu_{0}+$ & 2,1 & $12+48$ & 055 & 02417 \\
\hline & Appendix $A$ & mast & $1810 w 29$ & & \\
\hline & $\mathrm{co}_{0}(\mathrm{kec})$ & 101 & $5-14$ & 24 & 12.41 \\
\hline & $1 / 2,(\mathrm{sec})$ & 32 & $10-63$ & 8 & $(1 \times \mathrm{ed})$ \\
\hline & $\operatorname{ar}(\mathrm{sec})$ & 13 & $8=19$ & 32 & $20-49$ \\
\hline Early neplironal peaks & $\mathrm{H}_{\mathrm{l}}$ & 086 & $04-19$ & .37 & $96-36$ \\
\hline & Appendix A & & & 441,59 & $66 \times 27$ \\
\hline & $\mathrm{Alsec})$ & 19 & 1227 & 38 & $40=75$ \\
\hline & $1 \lambda_{2}(\mathrm{sec})$ & 49 & $38-59$ & 27 & $8-43$ \\
\hline & $00,(\mathrm{sec})$ & 125 & $16-137$ & 181 & 134,24 \\
\hline Tails & $113 \times$ & 073 & $0.4-15$ & 091 & $0,5-21$ \\
\hline & $\tau_{3}(\mathrm{sec})$ & 80 & $(f x e d)$ & 80 & $($ fxed $)$ \\
\hline & $W_{2}(\mathrm{sec})$ & 2500 & (frod) & 2500 & $(6 x \mathrm{de})$ \\
\hline & $1 / \mathrm{A}_{\mathrm{A}}(\mathrm{sec})$ & 89 & $52-11,4$ & 21 & $16-32$ \\
\hline & $0,1 \mathrm{sec})$ & 28 & $18-41$ & 80 & $59-102$ \\
\hline Lale nephromal peaks & $\mu_{3}$ & 1, & 0723 & 044 & $0.13-1.5$ \\
\hline & $t_{2}(\mathrm{sec})$ & 75 & $62-92$ & 157 & 109.204 \\
\hline
\end{tabular}

Table 6

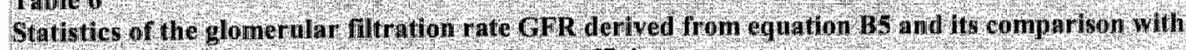

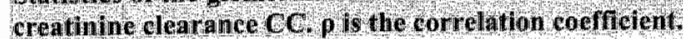

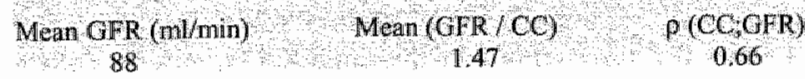




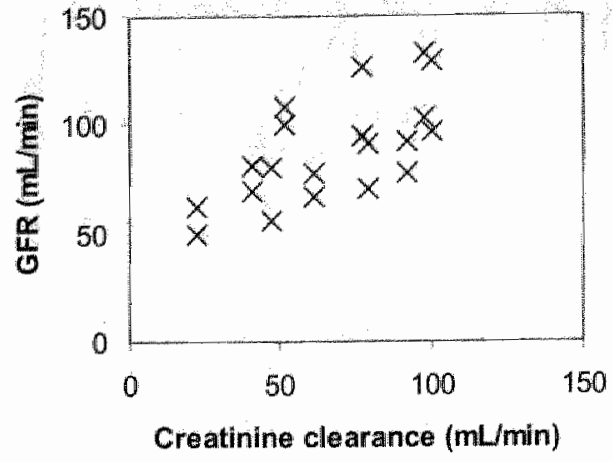

Figure 4. Correlation diagram of $G F R$ (equation B5) and $C C$.

\section{Discussion}

We have inspected the feasibility of fitting enhancement curves to enhancement data. The inspection consisted of four steps. The results of the first step (Table 2) show that the data can be fitted with a mean square residue that is only slightly larger than what would be caused by noise only. It means that the number of free parameters used has been sufficiently large to obtain acceptable fits, but it leaves the questions of sensitivity and reproducibility unanswered. If the number of parameters is too large the algorithm will be capable to generate low residues in the fits with various combinations of parameter values. This would mean that the noise sensitivity of parameter vahes would be large. Therefore, we introduced parameter constraints with help of domain knowledge and we changed the status of some of the parameters into fixed, with a value equal to the average over all cases observed before. This was done for $\lambda_{0, \mathrm{~m}}$ (medulla), for $\lambda_{3}$ and $\tau_{3}$ (cortex and medulla) and for the ratio $\lambda_{1} \tau_{1} / \lambda_{2} \tau_{2}$ (cortex and medulla) as summarized in Table 1 . The last constraint was used to remove $\lambda_{2}$ as a free parameter. Admittedly with these choices the other parameter values are influenced, but we considered this to be allowed because the physiological interpretation of our parameters is a formal one only. Use of the constraints resulted in only marginally increased residues and in noise sensitivities of the parameters (Table 3), neaning that the number of free parameters was reduced adequately.

The third aspect of the data inspection concerned the reproducibility of the fitting procedure in tams of its patient discriminating power. ANOVA of the obtained parameters between sessions and patients (Table 4) showed that for most free parameters, the differences between patients were significantly larger than within patients (between sessions). The reproducibility tested in this way included the influence of differences in true kidney behavior between sessions, that of the dynamic MR acquisition procedure as well as that of the parametric analysis. The first wo aspects were already reported in an earlier study on the same enhancement data (24). Table 4 shows that the significance of the obtained parameter values 
(the present study) is not less than that observed in at previous study in which a non parametric analysis was performed. This means that the reduction to 9 cortical and 8 medullary free enhancement parameters did not result in loss of information. Moreover, the parametric presentation of the information aids the clinical interpretation of the enhancement curve by focusing the attention on the main features of the data, in terns of amplitudes, time and shape of the enhancement peaks.

The consistency of the data with the physiological model could not be formally proven. The obtained tests are indicative only. A critical property of the enhancement in this respect is the degree of non linearity of the signal. In earlier work $(1,2,14,17)$ strong signall loss was reported during nephronal passage. Our results do not substantiate this.

Table 5 gives the enhancement predicted with Appendix $A$ in the cases of arterial passage in the cortex and nephronal passage in the medulla under two extreme assumptions on the rate of spin exchange between the Gd-DTPA rich lumina (arterio-venous or nephronal) and the remainder tissue. For the first case the rate of spin exchange is indifferent and both predictions fall within the experimental range of $10_{0,}$. For the second case, only the prediction for slow exchange regime falls in the experimental range of $\mu_{t, m}$. Slow spin exchange in the kidney during contrast agent passage is also inferred from experimental data in (32). Figure Al shows that during nephronal passage the linearity of the slow exchange signal is compromised and the signal does not only increase with the amount of Gadolinium but also with the volume of the nephronal lumen. Newertheless, at the expected peak concentration ( 2 $m M)$, the signal loss as observed in $(1,2,14$ and 17$)$ does not yet occur.

The explanation for this difference in kidney behaviour is probably that in the earlier studies scan methods were used that, in comparison to our method, were more likely to suffer from signal extinction by $\mathrm{T} 2$ 年 decay due to longer TE's and higher amounts of gadolinium-DTPA. The relation between signal strength and concentration was tested further by calculating the GFR. The mean value of $G F R / C C$ should be about 0.9 because the $C C$ tends to slightly overestimate the GFR (28). The observed values in our study were somewhat larger, possibly caused by saturation of the nephronal signal. However, the obtained mean value of $G F R$, mean value of $G F R / C C$ as well as the correlation between $G F R$ and $C C$ (Table 6) are encouraging and confirm that the signal linearity is sufficient to allow interpretation of the enhancement in physiologicall terms.

The provisional conclusion from the inspection of our results is that in renal transplants, the curve fitting procedure is accurate and reproducible and at least one of the measures of renal function $(G F R)$ is observed.

In view of the reported complexity of the kidney response (1-24), it remains difficult to claim generalization of these conclusions outside the narrow borders of the volunteers in our sample. Some supportive comments can however be given.

Fitstly, one can remark that changes in prehydration $(2,3)$ show only subtle changes in enhancement next to much stronger changes after strong dehydration. This suggests that our preloading technique could possibly be omitted without much loss of reproducibility. Secondly, one can judge from comparison of Figure $A$ la and $A \mid \mathrm{I}$ that at high concentration the mephronal signal suffers from T2 decay. MR systems of recent design are technically capable of considerable reduction of $T E$, which will avoid that problem. In the third place, we have developed an algorithm for correction of movement of the native kidney $(30)$. We are hopeful that, when applied to dynamic MR data of native kidneys, this will allow the use of our data processing technique in that context. The native kidney can be expected to have a larger perfusion rate and a larger $G F R$, but not necessarilly a larger max imum contrast agent concentration so that the linearity of our scan method does not need to be compromised. Clinical diagnostic use of our method requires extensive validation. A first walidation study of the diagnostic use of kidney enhancement data in dynamic MR, expressed by our parametric 
description, was completed in a group of diseased and non-diseased renal transplant recipients and showed a high sensitivity and specificity (31).

In conclusion, we have obtained parametric enhancement curves of cortical as well as medullary enhancement data from dynamic MRI of renal transplants, with high quality of fit and an acceptable accuracy of the obtained enthancement parameters. These parameters describe the enhancement curves in a manner that is consistent with a physiologic model of the kidney. The observed parameter values reproduce satisfactorily and the obtained values of GFR correlate well to creatinine clearance. The results of this study hold promise for the diagnostic use of quantitative dynamic MRI in symptomatic kidney transplant patients or even in native kidneys. 


\section{Appendix A: Linearity of the signal}

The passage of Gd through the kidney is characterised by a strongly inhomogeneous distribution and unusually high concentrations. What does this mean for the MR signal during the cortical and medullary nephronal enhancement peaks?

The background information needed for a signal analysis is incomplete and estimates of the physiologic properties of the kidney and the physical properties of the spin system have to be introduced. These estimates and a signal analysis are given below.

\section{The peak value of the contrast agent concentration during cortical arterial passage}

The molar mass $M_{a}$ of the arterial bolus equals the injected mass $(0.05 \mathrm{mmol} / \mathrm{kg} \times 75 \mathrm{~kg}), M_{a}$ $=3.75 \mathrm{mmol}$. At a blood flow of $6.5 \mathrm{~L} / \mathrm{min}(35)$ and a mean duration of the bolus passage in the renal artery of $13 \mathrm{~s}$ (mean width of the arterial bolus passage, Table 5), the distribution. volume of the bolus will be $1.4 \mathrm{~L}$ and the expected peak arterial lumen concentration $c_{\mathrm{a}}$ will be about $2.7 \mathrm{mM}$ (comparable to the experimental estimate in (34)). In the cortex the fractional arterio-venous wolume $w_{a, c}$ is about $40 \%(28)$, so that the voxel averaged peak concentration $c w_{a, c}$ equals:

$$
c v_{a, c}=c_{a} \times v l_{a, c}=2.7 \times 0.4=1.1 \mathrm{mM}
$$

\section{The peak values of the contrast agent concentration concentration during medullary nephronal passage}

No published values of the peak concentration of the contrast agent in the nephrons are known. Animal experiments were described in (32-34) but in these a steady state of the intrarenal Gd-DTPA concentration was reached by exposing the kidney to a constant arterial concentration, unlike the situation after bolus injection. In $(21)$ the concentration was measured in surgical biopsies taken from patients five minutes after bolus injection, but after that delay the filtered fraction of the bolus could already have left the kichey. For the experimental conditions used in this report an estimate of this concentration is obtained as follows:

In a normally perfused kidney, the fraction of the cardiac output that reaches each kidney is $10 \%$ and in the case of a normal glomerular filtration rate, about $20 \%$ of the plasma is filtered when this blood passes through the glomeruli (35). Hence the amount of contrast agent $M_{f}$ contained in the filltered bolus is $M_{r}=M_{\alpha} \times 0.1 \times 0.2=0.075$ mmol. We assume that the filtered plasma shifts through the nephron as a compact short filtered bolus, short enough to be completely contained in the ROI at the time of a medullary peak. In this report, that $\mathbb{R O I}$ represents a shell with a volume of about $12 \%$ of the kidney volume or $12 \%$ of $0.3 \mathrm{~L}$. The ROI averaged concentration $c v_{n}$ in the medulla at the nephronal peak time follows as

$$
c v_{t a n}=M_{f} /(0.12 \times 0.3)=2.0 \mathrm{mM}
$$

At that time, the filtered bolus resides in one of the three branches of the folded nephron. When the nephron luminal volume is about $50 \%$ of the kidney volume (28), per branch its value is $15 \%$, so that the fractional volume of the nephron luminal compartment in which the filtered bolus resides is $v_{m, m}=0.15$. As a result the estimated concentration $c l_{n_{0}, w_{q}}$ of that compartment is: 


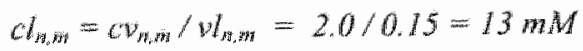

\section{Credicnt echo signal in compartmentalized tissue}

For the spoiled Gradient Echo signal as used in this report, the relation between signal $S$ and concentration $c$ in homogeneous tissue is given by:

$$
S(c)=\frac{\sin (\varphi)\left(1-\exp \left(-T R\left(1 / T_{18}+r_{1} c\right)\right)\right)}{1-\cos (\varphi) \exp \left(-T R\left(1 / T_{10}+r_{1} c\right)\right)} \exp \left(-T E\left(1 / T_{20}^{*}+r_{2}^{*} c\right)\right)
$$

This is the usual equation (see e.g. (36)) in which TR and TE are the repetition time and the echo time, $\varphi$ the flip angle, $T_{I 0}$ and $T_{20}^{*}$ * the relaxation times of the native tissue, $r_{3}$ and $r_{2} *$ the $T_{f^{*}}$ and $T_{2}^{*}$-relaxivities of the contrast agent in that tissue and the star symbol is added to remind of the role of field deformation by susceptibility in gradient acho imaging. In compartmentalized tissue with contrast agent concentrations that differ per compartment, the MR signal follows from the scan method used, the relaxation times per compartment and the rate of exchange of the spins (water molecules) between the compartments (29). For extremely slow and extremely fast exchange, the calculation is straightforward. In a fast exchange regime, eq. A 1 can be applied immediately when for all compartments the value of the voxel averaged concentration $c v$ is used.

In a slow exchange regime, however, eq. $A$ I has to be applied to each compartment separately. For $S_{n, m}$ the nephronal signal in kidney medulla in particular, the total signal is the sum of the signal $S /$ from the nephron lumen compartment and the extranephronal signal $S e$, each weighted by their fractional compartment volume:

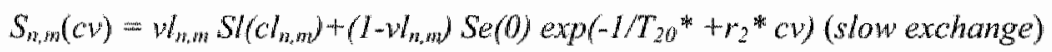

$S /\left(c / s_{n, m}\right)$ and $S e(0)$ follow from eq. A1. The exponential factor included in the contribution of Se describes the susceptibility effect $\left(\mathrm{r}^{*}\right)$ from the intranephronal presence of the contrast agent (29). The signal from the extranephronal compartment is seen to have no $T_{/}$decay, because this space does not contain contrast agent.

\section{Estimates of relaxation rate and relaxivities in the kidney medulla}

To use eq. Al and/or eq. A2 as predictors of the enhancement, the correct spin exchange rate and relaxivities have to be entered. In figure Alawe used $r_{4}=3.75 \mathrm{mM}^{-1} \mathrm{~s}^{-1}$, the value for plasma at $1.5 \mathrm{~T}(27)$. $T_{2}$, relaxation was neglected. The calculated enhancement $E(c v)=$ $S(c v) / S(0)-1$ as function of $c v$ is given for the fast and slow exchange regimes, for four values of $\%$. At given $c v$, the enhancement is lower in the case of slow exchange because of signall saturation. Experimentally, for the effective relaxivity $r$ for Gd DTPA in rat (32) and pig (33) kidney cortex at $1.5 \mathrm{~T}$, values of 1.1 and $1.2 \mathrm{mM}^{-1} \mathrm{~s}^{-1}$ were observed. These low values suggest signal saturation. which points to slow spin exchange between intra- and extranephronal kidney tissue (32).

Figure Alb deals with the sume cases as figure $1 \mathrm{a}$, but now the $T_{2}^{*}$ relaxation is included in the calculation. Experimentally observed values of $r$ in plasma at $1.5 \mathrm{~T}$ are $4.8(33)$ and $4.9 \mathrm{mM}^{-1} \mathrm{~s}^{-1}$ (21) whereas in the rat and pig kidney cortex values of $7.9 \mathrm{mM}^{-1} \mathrm{~s}^{-1}$ (32) and $2.0 \mathrm{mM}^{-1} \mathrm{~s}^{* 1}$ (33) were found respectively. To illustrate the possible occurrence of high $\mathrm{r}_{2}$ in the thuman medulla, in figure $1 \mathrm{~b}$ the value of $7.9 \mathrm{mM}^{-1} \mathrm{~s}^{-1}$ was used. The figure shows that for the echo time used, the saturation is stronger, but at voxel concentrations $c v<2 \mathrm{mM}$, the enhancement increases with concentration. 
Trable All

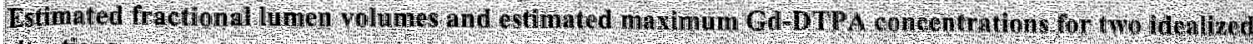
11010 10 its:

Volume filled with high

Gd-DTPA concentration:

Fraction of voxel wolume

Voxel averaged concentration

\section{Cortical}

arterio-venous lumen

\section{Medullary nephron himen}

$w_{m, m}=0.15$

$\mathrm{w}_{\mathrm{n}} \mathrm{c}=0,40$

$\mathrm{cr}_{\mathrm{n}, \mathrm{e}}=11 \mathrm{mM}$ $\mathrm{x}_{\mathrm{m}}=20 \mathrm{~mm}$
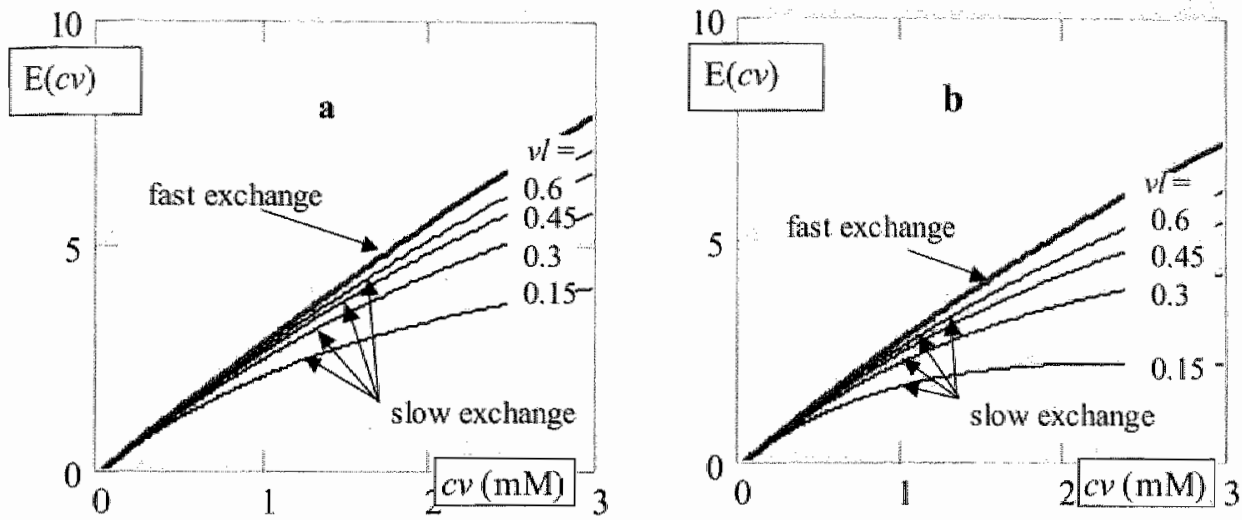

Figure A1. Theoretical values of enhancement $E(c v)$ versus concentration $(v v$ of the confrast angent witlu spoiled gradient echo signal used experimentally (eq A1 and A2, with TR/TE/flip $=11 \mathrm{~ms} / 3.4 \mathrm{~ms} / 60^{\circ}$ ). Signals are calculated for tissue that is composed of two compartments: lumen (arteriowenous and nephronal) and parenchyma. The contrast agent is present only in the lumen, with fractional volume per yoxel $w /$. Per diagram the signals for fast exchange (thick solid line) and slow exchange (thin solid lines) are compared. Native relaxation times of all tissue are assumed as $T_{10} \approx 1$ s and $T_{20}=0.1 \mathrm{~s}$ and relaxivities of the contrast agent are als discussed in the text.

The diagrams apply to values of the fractional nephron volume $y=0.15100 .6$.

a: without $T_{2}^{\text {* }}$ relaxation. $\mathrm{b}$ : with $T_{2}$; relaxation.

In both diagrams, the slow exchange signal shows saturation, especially for siriall values of w. At large concentrations, $\mathrm{T}_{2}$ relaxation becomes important. 


\section{Discussion}

Pigure Alb can be used to interpret our experimental values of nephronal enhancement peaks. At concentrations not too much different from $c \nu_{k}=2 \mathrm{mM}$, and nephronal compartment volumes not too much different from $h_{h}=0,15$, the signal is seen to increase with $w h$ This increase is strong when $t_{\text {, }}$ is small. Our hypothesis is that during peak nephronal signal enhancement this situation prevails for strongly $T 1$ weighted gradient echo scans in the Kidney medulla The hypothesis is consistent with experimental observation of low $T_{I}$ relaxivity in the kidney in (32) and (33).

As discussed in Appendix B, MR renography studies allow the observation of kidney perfusion and GFR. That observation is valid only when the relative nephron volume is not too small and does not vary too much between patients. For the case of prehydrated patients these are reasonable assumptions. 


\section{Appendix B: GFR approximated by enhancement parameters}

The amount $M_{f}$ of contrast agent filtered from the bolus follows from the glomerular filtration rate $G F R$ and the arterial concentration $c l_{o}$, corrected for hematocrit Hot as:

$$
M_{f}=G F R(1-H t c) \int_{\text {bolus }} c l_{a} d t
$$

According to the model, the enhancement $\Delta S$ of the signal is proportional to the voxel concentration of the agent.

During bolus passage, the agent resides in the blood vessels, which means that at that time the arterial concentration $c l_{a}$ can be observed by the arterial cortical signal enhancement $E_{a, a}$

$$
E_{a, c}=g_{a, c} c v_{a, c}=g_{a, c, c} c l_{a} v l_{a, c}
$$

, where $g_{a, c}$ is the enhancement factor per unit concentration and is related to the scam method, $\mathrm{Cl}_{a, c}$ is the voxel concentration in the cortex during arterial bolus passage and $v l_{a, c}$ the fractional luminal volume of the blood vessels in the cortex.

The amplitude of the peak medullary peak enhancement during nephronal bolus passage $\hat{E}_{n, m}$ reflects the presence of the entire mass $M_{f}$ of the filtered bolus inside the medullary tissue in the shell shaped region, as described in Appendix A:

$$
\hat{E}_{n, m}=g_{n, m} c v_{n, m}=g_{n, m} \frac{M_{f}}{V_{s h e l l}}
$$

$g_{n, m}$ has an analogous meaning as $g_{a, c}$ in equation $\mathrm{B} 2$ and $\mathrm{V}_{\text {shell }}$ is the volume of the medullary tissue in the shell.

Combination of equations $\mathrm{B} 1, \mathrm{~B} 2$ and $\mathrm{B} 3$ gives an expression for GFR:

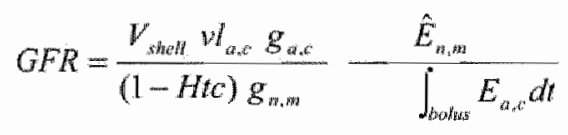

To derive GFR, the first medullary enhancement peak will be used because of its high intraclass correlation coefficient (Table 4). The right hand side of equation B4 is shown as the product of two groups of factors. Estimated patient independent values will be used for the factors in the First group: $V_{\text {shenl }}$ is about $0.12 V_{k t h e y}$ (Appendix A); Hic is about $0.4(28)$ and $v l_{a, c}$ is about $0.4(28)$. The ratio $g_{n, m} / g_{a, c}$ depends on the concentration of the contrast agent and the tissue properties of cortex and medulla. It can be estimated from Appendix $A$ and at unit concentration its value is 1.6 . With these estimates, the value of the first group of factors on the right hand side of equation B4 is $\alpha V_{k i d n e y,}$ with $\alpha=0.13$.

For the second group of factors, the observed kidney volume and parameters of the $M R$ renogram as defined in Appendix $C$ can provide the value. $\hat{E}_{n_{0}, t}$ is the peak amplitude $\mu_{l_{\text {, ra }}}$ of the first medullary nephronal peak, $E_{a, c}$ is the cortical arterial peak amplitude $\mu_{0, c}$ and the 
integration can approximated by the product of amplitude and width of that peak (see equation C2) So, equation B4 can be replaced by one that represents GFR in terms of the fit parameters as:

$$
G F R=\alpha V_{\text {kiturey }} \frac{\mu_{1, m}}{\left(\tau_{\sigma, \epsilon}+1 / \lambda_{0, c}\right) \mu_{0, c}}
$$




\section{Appendix C: Mathematic description of the enhancement curve}

The observed enhancement data are compared to parametric enhaneement curves that are fitted to the data by shape adaptation through the choice of parameters. Both for cortex and medulla, these enhancement curves are clefined from four composing functions, ench of which shows a single maximum and a uniform decrease everywhere outside this maximum.

Together they allow the generation of an enhancement curve with three peaks and a tail as prescribed by the physiological model. All functions have zero values outside their definition regions and each function is described with two parameters.

Each of the three peaks $(i=0,1,2)$ is zero for $\mathrm{t}<0$ and described with a gamma variate function [37]:

$$
g v_{i}(t)=\left(\frac{t}{\tau_{i}}\right)^{\lambda_{i} \tau_{i}} \exp \left(\lambda_{i}\left(\tau_{i}-t\right)\right) \quad(t>0)
$$

In this equation, $\tau_{i}$ is the time at which the maximum of $g v(t)$ occurs and $\lambda_{i}$ is the decay rate. The characteristic width $w_{i}$ of the gamma variate functions is given as

$$
w_{i}=\tau_{i}+\frac{1}{\lambda_{i}}
$$

Figure C1a is a graphical representation of the gamma variate function.

The tail of the signal curve is described by a merging exponential decay function we ( $t$ ). This function is zero until for $t>0$ it increases first and subsequently merges gradually to a slow exponential decay with time constant $1 / \lambda_{3}$.

$$
m e(t)=A\left(1-\exp \left(-\frac{t}{\tau_{3}}\right)\right)^{2} \exp \left(-\lambda_{3} t\right) \quad(t>0)
$$

The factor $A$ normalizes me (t) to a value I at the last observed time point. Figure CIb shows the shape of $m e\left(t-\tau_{3}\right)$.

The enhancement curve starts at the arrival time ta of the contrast agent. It is the sum of the composing functions, shifted over time and weighted with the amplitudes $\mu_{i}$.

$$
E(t)=\mu_{0} g v_{0}(t-t a)+\mu_{1} g w_{1}\left(t-t a-\tau_{0}\right)+\mu_{2} g v_{2}\left(t-t a-\tau_{0}\right)+\mu_{3} m e\left(t-t a-\tau_{3}\right)
$$



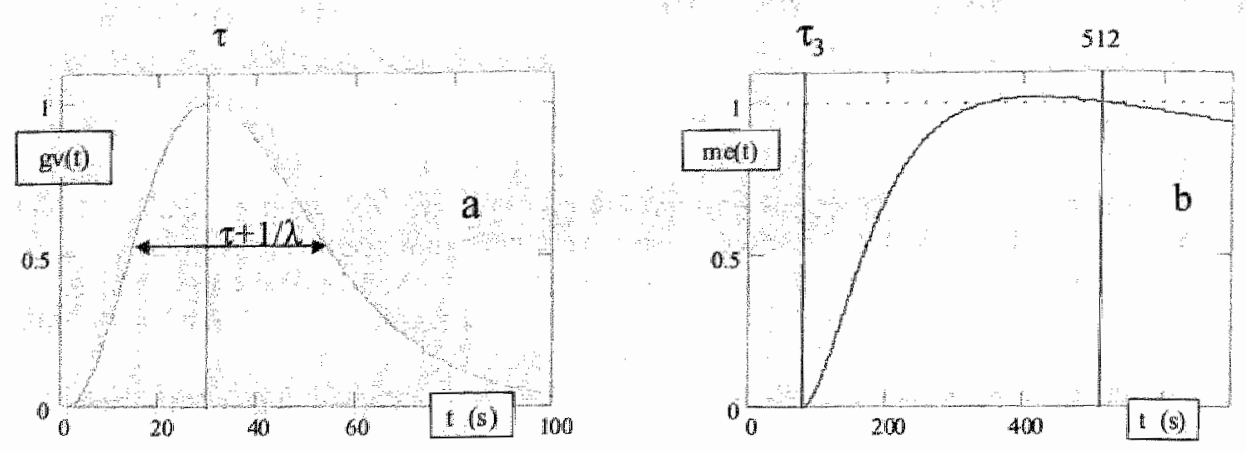

Figure $\mathrm{Cl}$. Functions tised to compose the enhancenent curve

a) Example of a gamma variate function according to equation $C 1$ with patrameters $\tau=30 \mathrm{~s}$ and $\lambda=0.1 \mathrm{~s}^{-1}$; the characteristic width $t+1 / \lambda$, as defined in equation $\mathrm{C} 2$ is indicated.

b) Matched exponential decay function according to equation $\mathrm{C} 3$ with parameters $\tau 3=80 \mathrm{~s}$ and $\lambda .3=0.0004 \mathrm{~s}^{-1}$. 


\section{References}

1. Carvlin M.J., Arger P.H., Kundel H.L. Axel, L, Dougherty L, Kassab E.A. Moore B. Use of GdDTPA and Fast Gradient Echo and SE MRI to demonstrate renal tunction in the rabbit. Radiology 1989; 170:705-711.

2. Choyke P.L., Frank, J.A., Girton M.E., Inscoe W. W., Carwin M.I., Black J.L., Austin, H.A, Dwyer A.J., Dynamic Gd-DTPA-enhanced MRI of the kidney: experimental results. Radiology 1989; 170:713-720.

3. Wolf GL, Hoop B, Cannillo JA, Rogowska JA, Halpern EF. Measurement of renal transit of Gadopentetate dimeghumine with echo planar MR imaging. JMRI 1994;4:365-372.

4. Trillaud H, Roques F, Degreze P, Combe C, Grenier N. Gd-DOTA tubular transit asymmetry induced by angiotensin-converting enzyme inhibitor in experimental renovascular hypertension. JMRI 1996; 1:149-155.

5. Munechika H, Sullivan C, Hedlund LW, Beam CA, Sostman HD, Herfkens RJ, Pelc N. Evaluation of acute renal failure with MRI using gradient echo and Gd-DTPA. Investigative Radiology 1991; 26:22-27.

6. Fransen R, Muller HJ, Boer WH, Nicolay K, Koomans HA. Contrast enhanced dyramic MRI of the rat kidney. J.Am.Soc Nephrology 1996; 7:424-430.

7. Baumann D, Rudin M. Quantitative assessment of rat kidney function by measuring the clearance of the contrast agent Gd(DOTA) using dynamic MRI. Mag.Res.Im.2000; 18:587-595.

8. Semelka RC, Hricak H, Tomei E, Floth A, Stoller M. Obstructive Nephropathy: Evaluation with dynamic Gd-DTPA-enhanced MRI. Radiology 1990; 175:797-803.

9. Von Schultess GK, Kuoni W, Gerig G, Wuthrich R, Duewell, Krestin G. Semiautomated ROI analysis in dynamic MR studies. Part II: Application to renal function examination. JCAT 1991; $15: 733-741$.

10. Laissy JP, Faraggi M, Lebtahi R, Soyer P, Brillet G, Mery JP, Ment Y, Le Gudulec D. Functional evaluation of normal and ischaemic kidney by means of Gd-DTPA enlanced turboFLASH MRI: a preliminary comparison with 99Tc-Mag3 dynamic scintigraphy. Mag. Res. Im. 1994, 12:413-419.

11. Ros PR, Gauger J, Stoupis C, et all. Diagnosis of renal artery stenosis: Feasibility of combining MR angiography, MR renography, and Gadopentetate-based measurements of glomerular filtration rate. AJR 1995; 165:1447-1451.

12. Furukawa A. Murata K, Morita R. Evaluation of renal function using Gd-DTPA dynamic MRI. Nippon Acta Radiologica 1996; 56:264-274.

13. Taylor J, Summers PE, Keevil SF, Saks AM, Diskin J, Hilton PJ, Ayers AB. MR renography: optimization of pulse sequence paranneters and Gd-DTPA dose, and comparison with radionuclide renography. MRI, 1997; 15:637-649.

14. Grenier N, Trillaud H, Combe C, Degreze P, Jeandol R, Gosse P, Douws C, Palussiere I. Diagnosis of renovascular hypertension: feasibility of captopril-sensitized dynamic MRI and comparison with captopril scintigraphy. AJR 1996; 166:835-843.

15. Sharma RK, Gupta RK, Poptani H, Pandey CM, Gujral RB, Bhandari M. The MR renogram in renall transplant evaluation using dynamic contrast-enhanced MRI. Transplantation 1995; 59: 1405- 11409.

16. Szolar DF-1, Preidler $K$, Ebner $F$, al. Functional MRI of human renal allografts during the posttransplant period: preliminary observations. Mag. Res. Im. 1997; 15:727-735.

17. Dupas B, Bach-Gansmo T, Blancho G. Franconi IM, Havet 'T, Leaute F. Gadolinium-enhanced MR imaging of nomal renal transplants. An evaluation of a $]^{\mathrm{I}} \mathrm{I}$-weighted dynamic cho-planar sequence. Acta Radiol. 1999; 40:250-4.

18. Nakashima R, Yamashita $Y$, Tomiguchi S, Tsuji A, Takahashi M. Functional evaluation of transplanted kidneys by Gd-DTPA enhanced Turbo FLASH MRI. Radiation Medicine 1996; $14: 251-256$.

19. Krestin GP, Schuhmann-Giampieri G, Haustein J, Friedmann G, Neufang KFR, Clauss W, Stockl B. Functional dynamic MRI, pharmacokinetics and safety of Gd-DTPA in paticnts with impaired renal function. Eur Radiol 1992; 2:16-32.

20. Kikinis R, von Schulthess GK, Jager P, Durr R, Bino M, Kuoni W, Kubler O. Normal and 
hydronephrotic kidney: evaluation of renal function with contrast enhanced MRI. Radiology 1987; 165:837-842.

21. Takeda M, Katayama Y, Tsutui $T$, Komeyama T, Mizusawa T. Does Gd-DTPA enhanoed MRI of the kidney represent tissue concentration of contrast media in the kidney: In vivo and in vitro study. Mag. Res. Im. 1994; 12:421-427.

22. De Priester JA. Giele ELW, den Boer JA, Christians MHL, Hasman A, Kessels AGH, van Engelshowen MA MR Renography: an algorithm for calculation and correction of cortical volume averaging in medullary renographs. MMRI 2000, 12.453460 .

23. Giele ELW, de Priester JA, Blom JA, den Boer JA, van Engelshoven JMA, Hasman A Reduction of noise in medullary renograms from dynamic MR images, JMRI 2000, 11:149-156.

24. De Priester IA, den Boer IA, Kessels AGH, Giele ELW, Christiaans MHL, Hasman A, van Engelshoven JMA. MR - renography by semiautomated image analysis: performance in renal transplant reepients. JMRI 2001; 14:134-141.

25. Moran GR, Prato FS. Modeling tissue contrast agent concentration: a solution to the tissue homogeneity model using a simulated arterial input function. Mag Res Med 2001; 45:42-45.

26. Press W.H. Numerical Reeipes in C, $2^{\text {nd }}$ ed., Cambridge UP, 1996, chapter 15.

27. Weinmann HI, Laniado M, Mutzel W. Pharmacokinetics of Gd-DTPA/ Dimeglumine after intravenous injection into healthy volunteers. Phys, Chem. Phys. Med. NMR 1984; 16:167-172.

28. Guyton A.C. Textbook of medical physiology. Saunders, Philadelphia, 1991.

29. Donahue KM, Weisskopf RM, Burstein D. Water diffusion and exchange as they influence contrast enhancement. JMRI 1997; 7:102-110.

30. Giele ELW, de priester JA, Blom JA, wan Engelshoven JMA, Hasman A, Geerlings MJHM. Movement correction of the kidney in dynamic MRI scans usinf FFT phase difference movement detection. Accepted for publication in JMRI.

31. De Priester JA, den Boer JA, Kessels AGH, Christiaans MHL, Giele ELW, Hasman A, van Engelshoven JMA. Automated quantitative evaluation of diseased and non-diseased renal transplants with MR- renography. Submitted to JMRI together with this article.

32. Shuter B, Tofts PS, Wang SC, Pope JM. The relaxivity of Gd-EOB-DTPA and Gd-DTPA in uiver and kidney of the Wistar rat. Mag. Res. Im. 1996;14:243-253.

33. Morkenborg J, Taagehoj JF, Vaever PN, Frokiaer J, Djurhuus JC, Stodkilde-Jorgensen $\mathrm{H}$. In vivo measurement of $\mathrm{T} 1$ and $\mathrm{T} 2$ relaxivity in the kidney cortex of the pig-based on a two compartment steady state model. Mag Res Im 1998; 16:933-942.

34. Pedersen M, Morkenborg J, Jensen FT, Stodkilde-Jorgensen H, Djurhuus JC, Frokioer J. In Vivo measurements of relaxivities in the rat kidney cortex. JMRI $2000 ; 12 ; 289-296$.

35. Legget RW, Williams LR, A proposed blood circulation model for reference man. Health Physics $1995 ; 69: 187-201$.

36. Van der Meulen P, Groen JP, Tints AMC, Bruntink G. Fast Field Echo Imaging: an overview and contrast calculations. Mag, Res. Im. 1988; 6:355-368.

37. Thompson HK, Stamer CF, Whalen RE, McIntos H HD. Indicator transit time considered as a gimma variate. Circ. Res. 1964; 14:502-515. 


\section{CHAPTER 5}

\section{Automated Quantitative Evaluation of Diseased and Non-Diseased Renal Transplants with MR-Renography}

J Magn Reson Imaging 2003; 17:95 - 103

Jacobus A. de Priester

Jacques A. den Boer

Maarten H.L. Christiaans

Alphons G.H. Kessels

Eelco L.W Giele

Arie Hasman

Hans P. van Hooff

Jos M.A. van Engelshoven 


\section{Abstract}

\section{Purpose}

To present a method of automated parametric quantification of dynamic MR enhancement curves of renal transplants and evaluate the disease discriminating properties of the resulting MR renography (MRR) data.

\section{Materials and methods}

27 pattents with non-diseased and 8 patients with diseased renal transplants were included. The examination was repeated in 10 patients and reproducibility of enhancement parameters estimated by analysis of variance. Disease discriminating properties of transplant volumes and enhancement parameters were tested with t-tests and logistic regression analysis.

\section{Results}

The enhancement parameters were reproducible. The mean medullary nephronal washout rate $(\lambda 1)$ and cortical arterial blood volume $(\mu 0)$ were lower in diseased renal transplants. The combination of these parameters was a strong predictor of renal transplant disease (area under ROC curve 0.98 ; $95 \%$ confidence interval $0.96-1.0$ ).

\section{Conclusion}

Automated parametric quantification of cortical and medullary enhancement is feasible and allows accurate detection of non-surgical disease in renal transplants by MRR. 


\section{Introduction}

Renal transplants can be affected by a variety of surgical and medical diseases. Surgical conditions (urinoma, ureteral obstructions, arterial stenoses, etc.) can usually be diagnosed accurately with ultrasound, CT, angiography or MRI (1). Medical conditions like acute and chronic rejection, acute tubular necrosis and drug induced tubulopathy are more difficult to diagnose because clinical symptoms, laboratory tests and imaging findings of these diseases are often overlapping. In many cases renal transplant biopsy is inevitable since a final diagnosis can only be made with histology $(1,2)$. Biopsy, however, has a well-known risk of complications (bleeding, AV-fistula's, etc.) that may be hazardous for the patient and the renal transplant $(1,3)$.

MR-renography (MRR) is an actively researched imaging technique that may improve the diagnosis of medical diseases affecting the renal transplant. This method makes use of a dynamic scan sequence that generates functional information in terms of time dependant changes in signal intensity during passage of a MRI contrast agent through the renal transplant parenchyma (4-6). Examples of images from a dynamic scan sequence are given un figure la.

Functional information is expressed in signal-time curves. The major difference with scintigraphic techniques is that the high spatial resolution of MRI makes it possible to separate the cortical from the medullary structures (2, 4-13). Because various medical diseases affect different parts of the renal transplant, such a separation may make it possible to differentiate these diseases by specific changes in cortical and/or medullary signal curves. Added value of MRR in the diagnosis of diseased renal transplants has been demonstrated in various papers $(2,11,13)$. These studies indicated distinct enhancement characteristics of acute rejection, drug induced tubulopathy and acute tubular necrosis. Notwithstanding these promising results, however, MRR has not gained widespread acceptance as a diagnostic tool. A first barrier for this acceptance is related to post-processing of the dynamic MR data, which, when carried out manually, is difficult and time consuming in many cases. Especially in diseased kidneys, a lack of contrast between cortical and medullary structures, is observed (fig lb). This makes manual placement of regions of interest (ROIs) over cortical and medullary tissue difficult and subjective, even for an experienced operator.

To handle these problems we previously presented a post processing algorithm by which renal transplants are segmented from the image and one by which cortical and medullary signal curves are generated automatically $(14,15)$. These methods proved to be reproducible and accurate and resulted in a dramatic decrease in post-processing time.

An additional barrier is that the shape of the renal enhancement curve is complex and difficult to interpret quantitatively. A part from the early cortical enhancenent peak, which is sharp and easily discemible, a complex pattem of shallow cortical and medullary peaks is observed (16). In combination with the fair amount of noise in MR-renographs this makes it difficult to identify and quantify these peaks in terms of time of occurrence, height and shape. These two barriers probably are the reason why a complete quantitative description of renal enhancement is still missing.

We bypothesize that it is possible to quantify renal enhancement in a way that will make their diagnostic value accessible. 
A
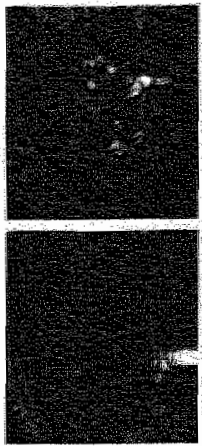

Premeontirast
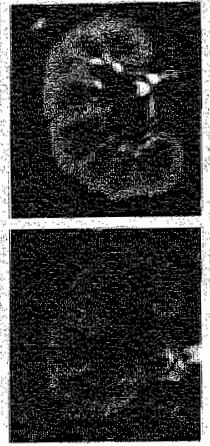

Finrly Einbancenen!
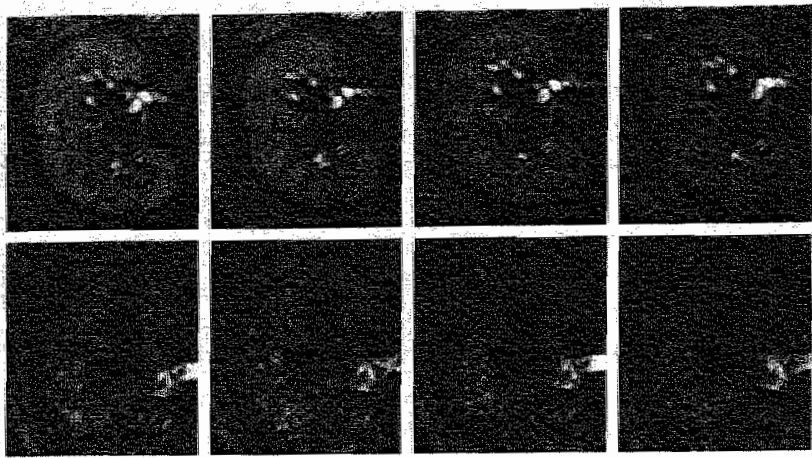

30) stands

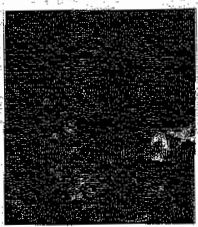

I müute

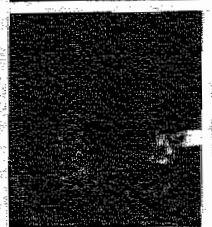

2 minutues

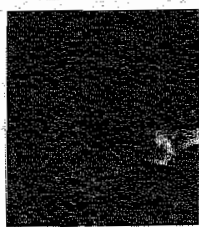

4 minutes

Fignre 1. Inuges of non-discased (a) and diseased renal transplant (b) during warious phases of enhancenent. Clear differentation of cortical and medulary structies in normal renal transplant diring the first minute of passage of the controst agent through the renal paranchyma (a). In diseased trunsplant (b) enhancement is less strong and differentiation of cortex and medulla is unelear.

The present article describes a method to reach quantification by parametric representation of renal enhancement curves of which the main features follow from a physiological model $(5,16)$.

We added this method to our other post-processing algorithms. Its performance was tested in a series of patients with well functioning renal transplants and patients with severely diseased renal transplants. Our objective was to assess the disease detecting capabilities of our technique.

\section{Materials and Methods}

\section{Pationts}

Thirty-five renal transplant recipients were selected for this study. Group 1 consisted of 27 renal transplant recipients who were in good clinical condition and had stable renal function For a period of at least three months prior to the investigation, while group 2 was formed by eight renal transplant recipients with severely disturbed renal transplant function requiring renall dialysis.

Ten patients of group I had a second identical MR examination within a time interval of two weeks. This group (group $\mathbb{F}$ ) was used to test the reproducibility of various aspects of our procedure.

Patients in group I were immunosuppressed by azathioprine (13 patients), cyclosporine (8 patients) or tacrolimus ( 6 patients). Cyclosporine and tacrolimus have vasoconstrictive properties, altering renal perfusion, an effect that is not known from azathioprine (17). Because this could influence renal transplant enhancement, a subdivision of group I was made. In group 1A ( 9 men, 4 women) immunosuppression was azathioprine based, in group IB ( 13 men, 8 women) cyclosporine or tacrolimus were used for immunosuppression. The 
mean and range of the post-transplantation intervals of group $1 \mathrm{~A}$ was 15.3 years and 6.5 . 20.5 years respectively, that of group $1 B$ B 3.0 years and $0.4-10.2$ years.

All patients in group 2 ( 4 men, 4 women) were on tacrolimus-based immunosuppression. Biopsy proven diagnoses for disturbed renal transplant function were delayed graft function in 4 patients, acute rejection in 2 patients and combinations of delayed gralt function and cortical necrosis in 1 patient and cortical necrosis and interstitial nephritis in 1 patient. All renal transplant recipients of group 2 were in their early post-transplantation period (mean 25.0 days, range 6 to 64 days).

None of the patients of group 1 and group 2 had a history of decreased cardiac pump function and none were on diuretics. This study was approved by the medical ethics committee of our hospitall and written informed consent was obtained from all the patients.

\section{Laboratory Data and Patient Preparation}

The MRI examination of each patient was planned in the late afternoon, $8-10$ hours after the last intake of immunosuppressive drugs, to exclude influence of changing drug levels of tacrolimus or cyclosporine on the renal transplant enhancement. From a 24-hour urine sample (collected the day before the examination) the 24-hour urine volume was measured and sodium and creatinine urine concentrations were estimated. Prior to the MRI investigation a venous blood sanple was taken from which serum sodium and creatinine concentrations and the trough levels of cyclosporine and tacrolimus were estimated. From these laboratory data, creatinine clearances and fractional excretion of sodium were calculated.

As pointed by Wolf et al.(16) low hydration influences renal enhancement because it leads to an increase of the fraction of water reabsorbed from the nephrons. The concomitant rise in concentration of Gadolinium-DTPA could cause unwanted T2* effects which decrease signal intensity. Patients with disturbed renal transplant function (group 2) were under clinical surveillance and were held at slight levels of hyperhydration. To match hydration of the nondiseased population with that of the diseased patients and to avoid underhydration, patients with normal transplant function (Group $1 \mathrm{~A}$ and $1 \mathrm{~B}$ ) were administered $500 \mathrm{ml}$ sodiumchloride $0.9 \%$ intravenously one hour prior to the MRI examination.

\section{MRI Procedure}

MRT was performed on a $1.5 \mathrm{~T}$ imager, gradient strength $10 \mathrm{mT} / \mathrm{m}_{\mathrm{n}}$ slew rate $15 \mathrm{~T} / \mathrm{m} / \mathrm{sec}$ (Philips ACS-NT, Philips, Best, The Netherlands). MR studies started with coronal and sagittal planscans (SE;TR/TE=182/10), followed by a multislice axial T2-weighted scan (FSE; TR/TE/TF $=3000 / 150 / 20$ ) and an oblique multislice coronal Tl - weighted scan through the long axis of the renal transplant ( $\mathrm{SE}$; TR/TE $=550 / 14$ ). The long axis images were used to select the optimal scan plane for the dynamic sequence, which consisted of a run of 256 single-slice Tl-enhanced spoiled gradient echo scans (TR/TE/Flip= $/ / \mathrm{ms} / 3.4 \mathrm{~ms} / 60^{\circ}$ ) with a slice thickness of $6 \mathrm{~mm}$, FOV $400 \mathrm{~mm}$, rectangular field of view $90^{\circ}$ and scan matrix $200 \times 256$ (resulting voxel size $6.0 \times 2.0 \times 1.6 \mathrm{~mm}$ ). Scans were performed every 2 seconds. After the tenth dynamic scan, Gadolinium-DTPA (Magnevist, Schering, Germany) was injected in a dose of $0.05 \mathrm{mmol} / \mathrm{kg}$. This low dose was used to avoid T2*-effects(18). Gadolinium was injected as a rapid bolus with a flow rate of $5 \mathrm{~m} / \mathrm{sec}$ with a MR-injector pump (Medrad Spectris, Medrad, Mastricht, The Netherlands), mmediately followed by a saline flush $(0.9 \%$, dose $20 \mathrm{ml}$, flow rate $5 \mathrm{ml} / \mathrm{sec})$. Because renal transplants are situated in the lower abdomen, respiratory motion is not an issue and scans were performed without breathholding. 


\section{Post-proxessing and Curve Generation}

Data analysis was performed on a Sun Spare Ultra 30 work station(Sun microsystems Netherlands, Amersfoort, The Netherlands) with EasyScil software (Philips, Best, The Netherands).

On each of the axial $\mathrm{T} 2$-weighted mages the renal transplant parenchyma was circumscribed with a hand drawn line. Renal yolumes were then calculated by adding up the measured areas and multiplyng these with the slice thickness.

Objective cortical and nedullary signal-time curves were generated from two band shaped. $\mathbb{R O}$ (figure 2) with the autonated image analysis algorithm that was described in a previous paper $(15)$
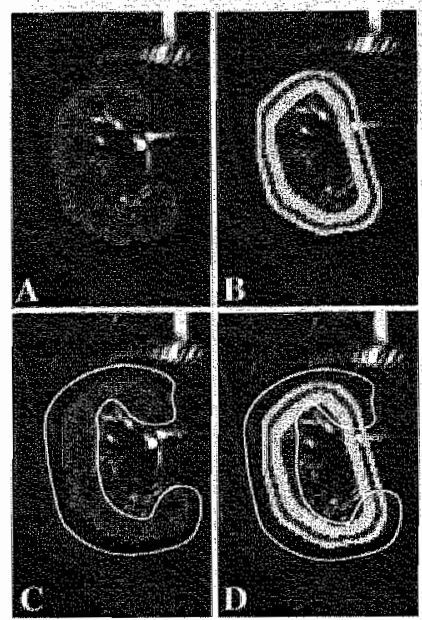

Figure 2. Post processing: $R O$ OI placement. On MR image of renal transplant during early enhancement (a) two antomatically generated concentric ROL's are shown as gray objects (b). Outer ROI is cortical inner ROI crosses medullary pyraninds as well as cortical colnmms. Callices and wascular structures are circumsclibed by hand drawn line (c). Parts of ROIs within lime are used to generate contical and medullary enhancement curves.

\section{Quantification of Enthancement}

\section{a. Physiological model}

The description of the corticall and the medullary enhancement data is bases on a physiological model, following the ideas of Choyke (5) and Wolf (16). The model interprets renal enhancement as the result of the vascular as well as the nephronal history of the contrast agent passage. During bolus passage, an arteriovenous peak is expected both in the cortex and the medulla. The medullary peak is relatively small, late and slow because in the medulla the blood pressure drops in the long peritubular capillary system, which in combination with permeability of the capillary walls results in slow bolus passage (19).

Part of the agent is filtered in the glomeruli and is transported through the nephrons. We will call this part the "the filtered bolus'. As opposed to water, Gadolinium is not reabsorbed so that its concentration increases along the path of the nephron. From its cortical origin onwards, the nephron has three branches that are folded as a hairpin. It traverses the medulla 
in the proximal convoluted tube and loop of Henle, reenters the cortex in the distal convoluted tubes and continues in a collecting tube that traverses the nedula again, ending in the renal cally:

Symchronicity of these ewents in the nephrons will canse the filtered bolus to reside in a thin concentric shell in the kidney. The shell moves through the kidney $(5,6,20,21)$, leading to the occurrence of temporal concentration maxima in each of the concentric ROls. The cortical and medullary renograms will show this as enhancement maxima. So, the model predicts three peaks in the cortical as well as in the medullary renogram, as already observed by Wolf (16). This is illustrated schematically in figure 2 of chapter 4. The first peak reflects the passage of the bolus of contrast agent through the vascular compartinent and it will be called the arteriovenous peak. The second and third peaks reflect the excretory path through the nephrons; these will be called the nephronal peaks. After the filtered bolus has left the kidney contrast agent still remains in the soft tissues and circulation of the patient. This goes with further renal excretion and the tail of the renal enhancement curve will follow the slow decay of the contrast agent in the body.

\section{b. Enhancement parameterization}

Enhancement parameters are obtained from a mathematical enhancement curve that is fitted through the raw and noisy enhancement curve. This fitted curve is composed of four functions. Each of these composing functions describes one of the physiological phenomena dictated by the model. So, one composing function defines the arteriovenous peak, two define the nephronal peaks and the fourth is a descriptor of the tail of the signal time curve.

Each composing function is defined mathematically by three parameters; $\mu, \tau$ and $\lambda$.

Parameter $\mu$ defines the peak amplitude, $\tau$ defines the peak time and $\lambda$ defines the shape of the peak. An example of a fitted enhancement curve and its composing functions is given in figure 3. A detailed mathematical description can be found in appendix $C$ of chapter 4 . In total, therefore, four cortical and four medullary composing functions are used to fit renal enhancement curves. This results in its description by 24 parameters ( 12 cortical and 12 medullary). The convergence of the fitting procedure to a unique solution was reached by use of constraints. Some of these represent domain knowledge of the problem because they define aspects of the enhancement curve that are expected from the physiological model (e.g. nonnegative values and defined temporal onder of signal peaks). Other constraints are arbitrary. An overview is given in Table 1.

As a result, a total of 9 cortical and 8 medullary parameters remain adjustable and after fitting these free parameters become the quantitative descriptors of renal enliancement. They are given subscripts that refer to the arteriovenous peak (subscript 0 ), the first and second nephronal peak (subscripts 1 and 2) and the tail of the signal curve (subscript 3 ).

\section{Statistical Analysis}

a. Reproducibility of enhancement parameters. In group $1 \mathrm{~F}$, for each of the obtained parameters we compared the differences within patients (between sessions) and those between patients by analysis of variance (ANOVA). Per parameter the intra-class correlation coefficient (ICC; the correlation between the values of the first and the second examination) was determined. At $\alpha=0.05$, its significance level is 0.52 . 

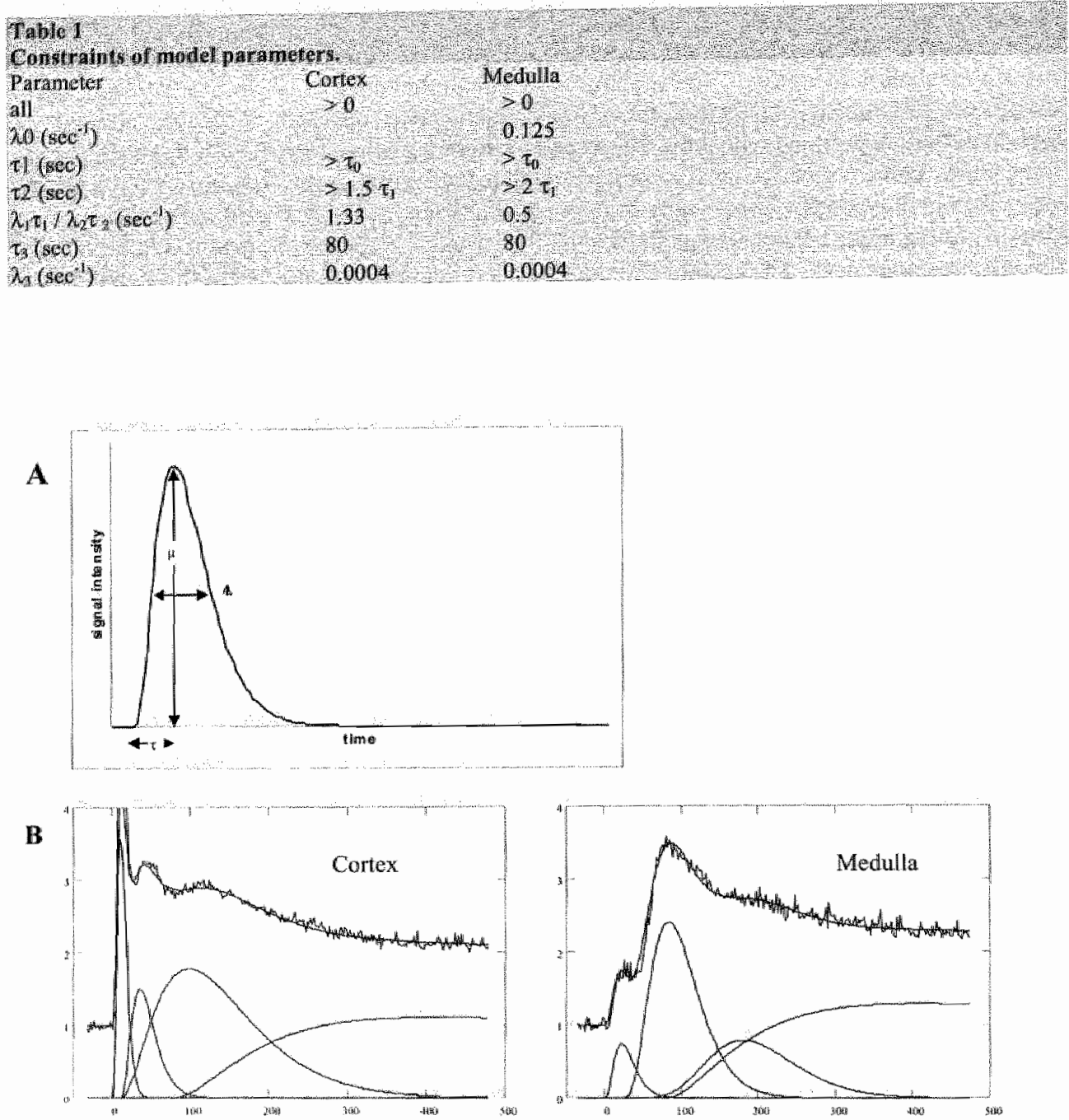

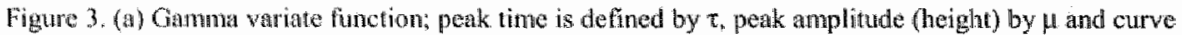
width/shne by $t+1 / 2$. (b) Raw cortical and medullary signal-tirne chrves and corresponding fitted curver with its composing funcions. Contical and medullary emineement are characteribed by three peaks and a tail that are Witco by the separate composing functions. The fitted curves are the sum of the background signal (with wallue 1) and the conposing functiois. 
b. Discase discrimination. For the analysis we used the observed kidney volume and the enhancement parameters per subject, together called "study parameters".

The disease detecting capability of our method was tested in two steps. First, the study parametters from patients of group IA and group IB were joined and compared to those of group 2 with a t-test. Second, a forward stepwise logistic regression analysis was performed with disease as dichotomous dependent variable and the study parameters as independent variables.

To assess the homogeneity of the group of healthy volunteers, in view of possible effects of the various types of immunosuppression used in that group, the differences between the study parameters of group $1 \mathrm{~A}$ and $1 \mathrm{~B}$ were tested with a t-test.

\section{Results}

In table 2 the reproducibility of the MRR procedure is summarized. The table gives statistics of ICC of the obtained parameters. Stated are the median and range of all observed ICC values as well as the list of parameters that had a significant correlation.

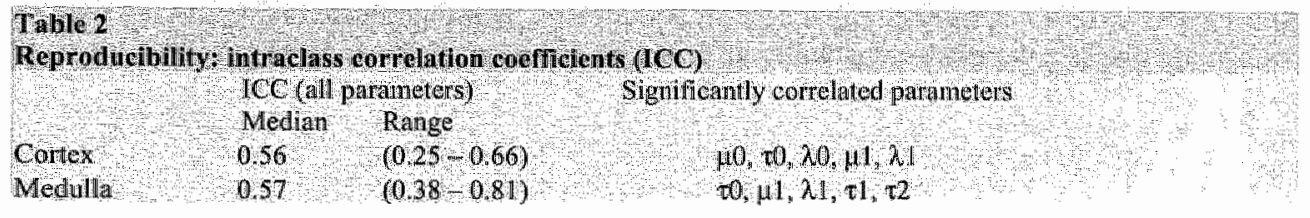

Laboratory findings are listed in table 3. For healthy renal transplant recipients (group $1 \mathrm{~A}$ and 1B) the mean creatinine clearance was higher and the mean fractionate sodium excretion was lower than for patients with diseased renal transplants (group 2). These differences were statistically significant $(P<0.05)$. The high values of the fractionate sodium excretion in group 2 can be attributed to the disturbed function of the renal transplants in this group, causing high fractional loss of sodium in the unine. Despite differences between non-diseased and diseased population, the fractionate sodium excretion was well above $1 \%$ in all groups. Therefore, there was no indication that patients were dehydrated. The trough levels of cyclosporine and tacrolimus were within normal therapeutic ranges for both groups.

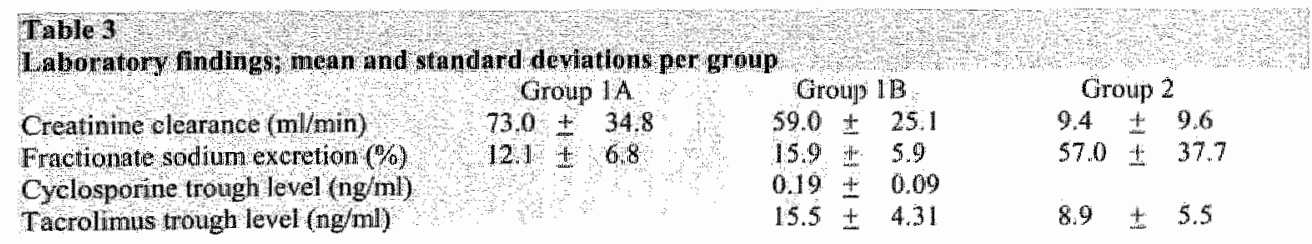




\section{Diseased (group 2) versus non-diseased (group $1 \mathrm{~A}$ and IB) renal transplant recipients}

The study parameters are given in table 4 . In the diseased group, the mean medullary $\lambda_{1}$ was significantly smaller than that in the non diseased group $\left(\mathrm{P}^{<}<0.001\right)$. The logistic regression analysis indicated that he combination of cortical $\mu_{0}$ and nedullary $\lambda_{1}$ was the best predictor of renal transplant disease, Addition of other study parameters did not improve the prediction. A ROC acurve with the weighed combination of cortical $\lambda_{1}$ and medullary $\mu_{0}$ as predictor of renal transplant disease is given in figure 4 . The area under the curve was $0.98195 \%$ confidence interval $0,96-1.0$ ), indicating high sensitivity and specificity. For comparison, a seatter plot of cortical $\mu_{0}$ and medullary $\lambda_{1}$ for diseased and non-diseased patients is shown in figure 5. In terms of MR-renographs these results are demonstrated in figure 6 in which signal-time curves of a diseased and a non-diseased renal transplant are shown. The lower values of cortical $\mu_{0}$ and nedullary $\lambda_{1}$ in the diseased renal transplant (fig.6B) are reflected as a lower amplitude of the vascular cortical peak and flattening of the first nephronal peak of the medulla, as compared to the normal renal transplant (fig.6A).

\section{Non-diseased renal transplant recipients; group $1 \mathrm{~A}$ versus group $1 \mathrm{~B}$}

In renal transplant recipients with cyclosporine or tacrolimus based immunosuppression (group 1B), the peak times of the first $\left(\tau_{1}\right)$ and second $\left(\tau_{2}\right)$ parenchymal nephromal peak of cortical enhancement were significantly shorter than for patients who do not use these agents (group 1A; $P<0.01$ ). The other enhancement parameters, including those that predicted renal transplant disease, were not statistically different between group $1 \mathrm{~A}$ and group $1 \mathrm{~B}$. 


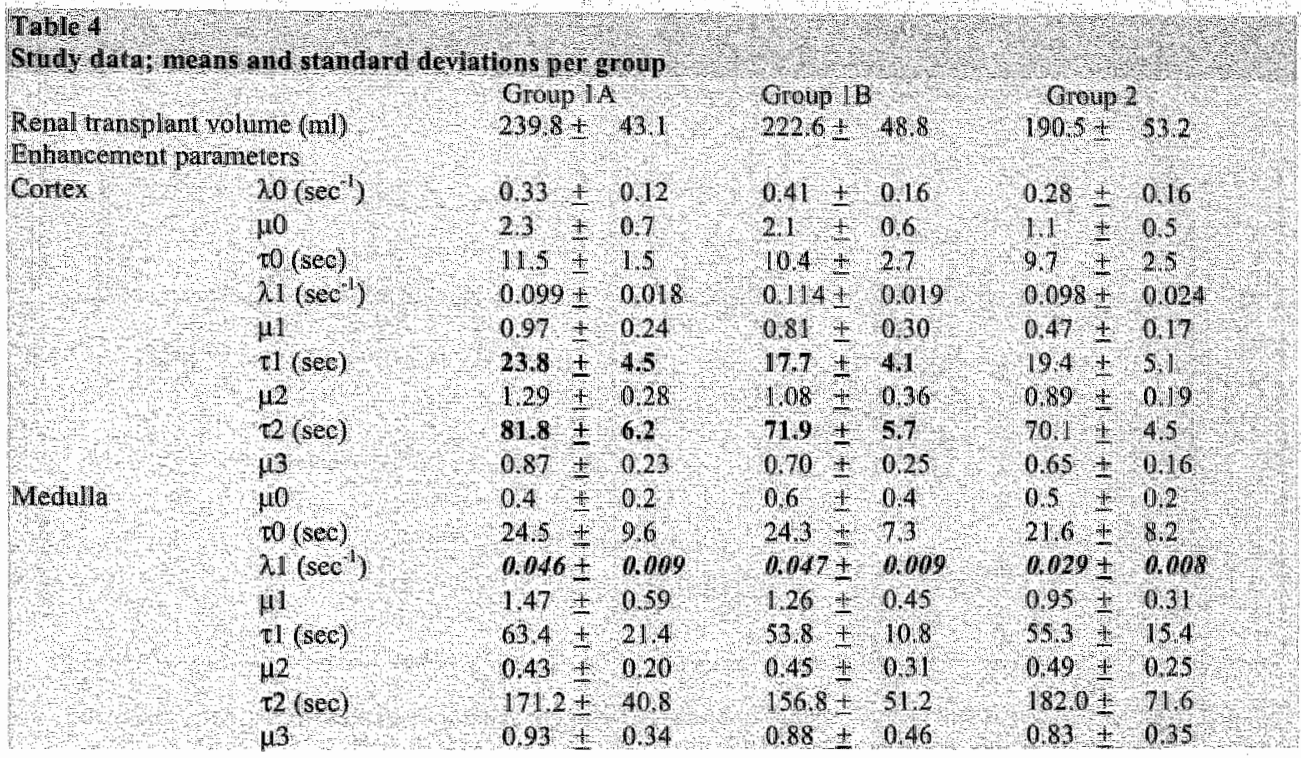

Printed bold: statistically significant difference between group $1 \mathrm{~A}$ and group $1 \mathrm{~B}(\mathrm{P}<0.01)$

Printed italic and bold: statistically significant difference between group $1 A+1 B$ and group $2(P<0.001)$ 


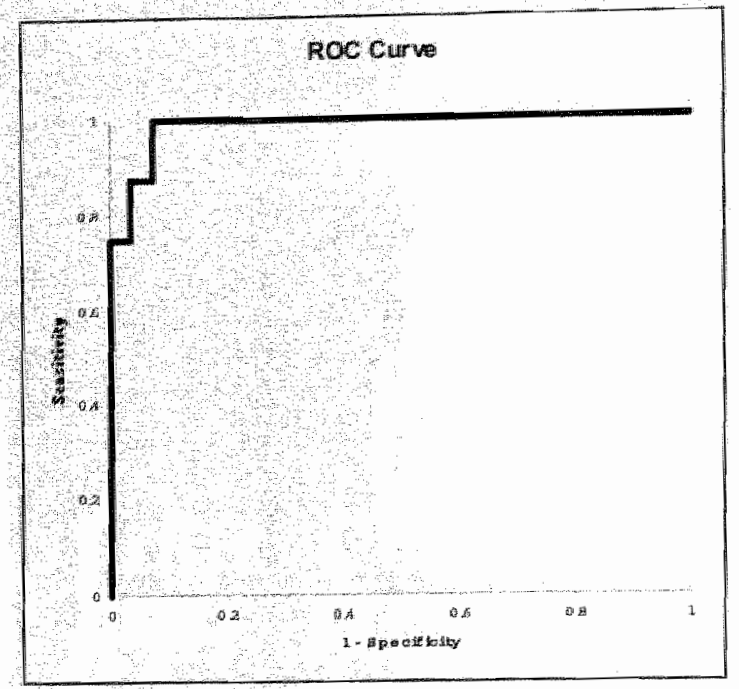

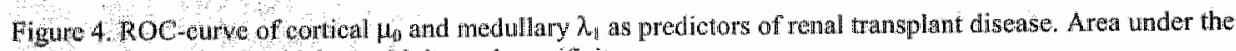
ouve is 0.98 indicatitng high sensituvity and specificity

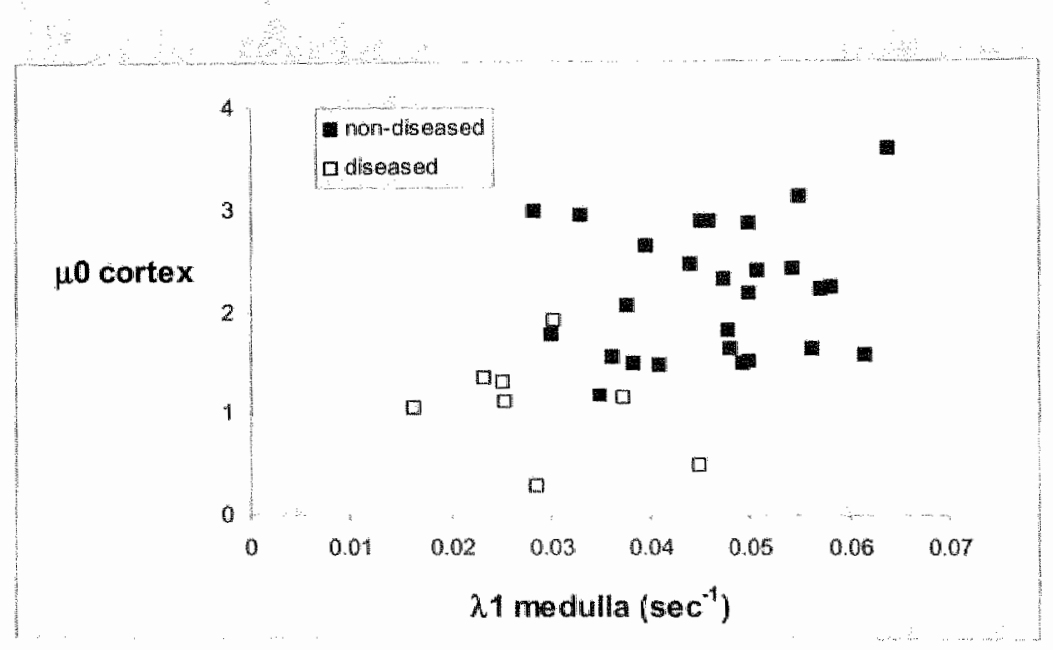

Figute 5. Distribution of cortical Ho and medullary $\lambda_{t}$ in diseased and non wiscased rend transplants. A clear hetdeny of both parameters to be lower in the diseased group is shown. 


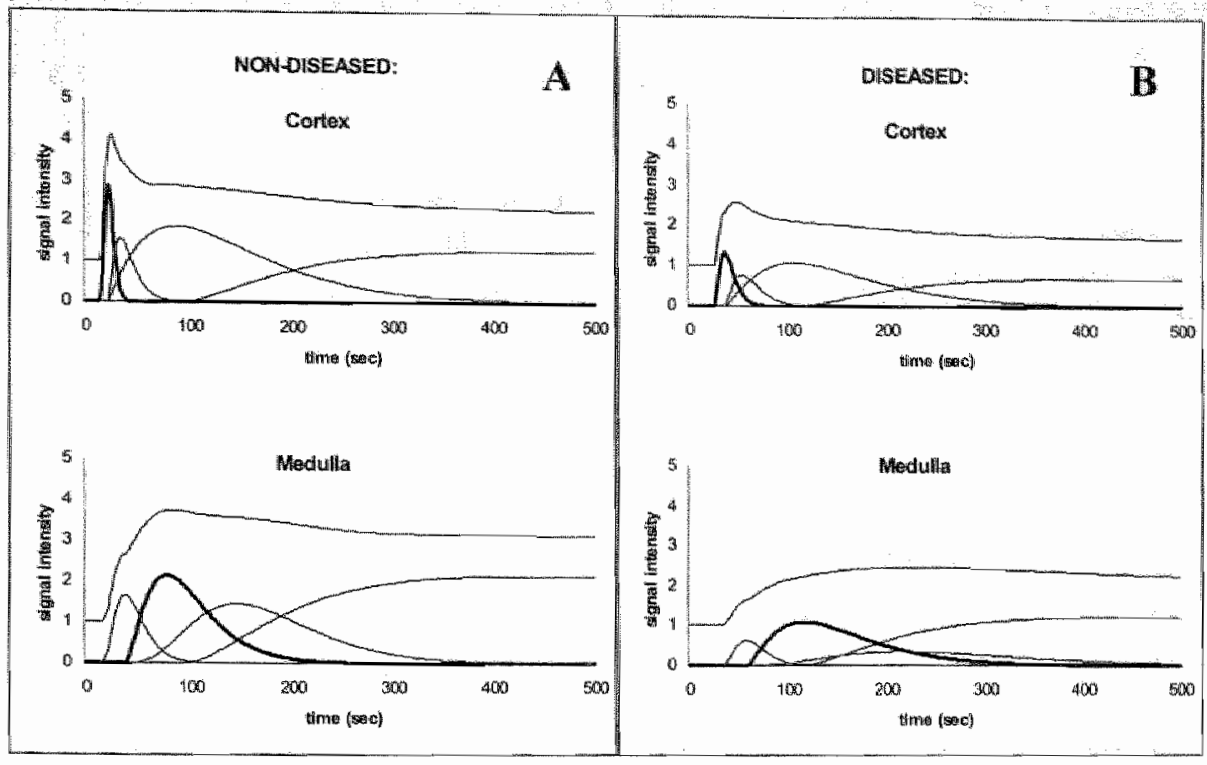

Figure 6. Typical cortical and medullary enhancement curves of a non-diseased (a) and a cliseased renal transplant (b); Lower values of contical $\mu 0$ and medullary $\lambda 1$ in the diseased transplant reftect lower amplitude of vascular cortical peak and flattened first nephronal peak of the medul a, as compared to normal renal transplant (corresponding fit functions printed bold). Also visible differences in curve amplitudes are incidental.

\section{Discussion}

This report shows the first clinical results of a new quantitative analysis method for MR renographic data of renal transplants. Cortical and medullary renographs are quantificd by parameters that describe amplitude, shape and liming of the various characteristics of the enhancement curves.

The furst part of the data inspection regarded the reproducibility of our method of parameterization. Table 2 shows that the reproducibility of the test is alleady sufficient to distinguish between the normal functioning transplbant kidneys of the participating patients. The reproducibility tested in this way includes that of the true kidney behavior between sessions, that of the dynamic MR acquisition procedure as well as that of the parametric analysis. These results are satisfactory and justify further tests.

The parametric presentation of the information aids the clinical interpretation of the enhancement curve by focusing the attention on the main features of the data, in terms of amplitudes, time and shape of the enhancement peaks.

The most important result is the accurate prediction of renal transplant disease, as shown in the ROC curve (fig. 4). Diseased renal transplants are characterized by the combination of lower amplitudes of the cortical arterial perfusion peak $\left(\mu_{0}\right)$ and a flatter shape of the first medullary parenchymal nephronal peak $\left(\lambda_{1}\right)$. The cases used to define this test (by forward logistic regression) were the same as the ones for which the prediction was given. One could 
therefore doubt the trute predictive value for other independent cases. The distribution of both variables, however, is close to normal (fig. 5) which suggests that the performance of the test is not accidental.

The statistically significant difference in medullary $\lambda_{\text {s }}$ is an interesting finding. This has not been described previously in renal transplants and is a strong argument for MRR because no other technique can provide functional information that is strictly medullary in origin.

These result ts are encouraging but could have been influenced by dissimilarity of the diseased and non-diseased population in terms of immunosuppressive drug regimes. All diseased renal transplant recipients used tacrolimus which, like cyclosporine, has vasoconstrictive properties (17), whereas part of the non-diseased population used medication without this property (subgroup IA; azathioprine). To rule out any influence of this dissimilarity, we assessed the differences in study parameters between group $1 \mathrm{~A}$ and group I B. This demonstrated that medullary $\lambda_{1}$ and cortical $\mu_{0}$ were not statistically different between these groups. Therefore, we concludle that the disease-predictive properties of the combination of these parameters is real and does not result from different immunosuppressive drug regimes.

A further interesting result of the study in the non-diseased population is that renal transplant recipients who use cyclosporine or tacrolimus (group $1 \mathrm{~B}$ ) have significantly lower cortical $\tau_{1}$ and $\tau_{2}$ than patients who use azothioprine (group 1A). These enhancement parameters define the peak times of the first and second cortical nephronal peak and are not the same as the partmeters that differentiated between diseased and non diseased renal transplant recipients. This demonstrates that our description of enhancement is capable of resolving different aspects of kidney functionality.

The parametric curve to which our dynamic $M \mathbb{R}$ data are fitted is based on a physiologic modell. This implies that it should be possible to interpret our results from a physiologic perspective. The following is an attempt:

The smaller amplitude of the cortical vascular peak $\left(\mu_{0}\right)$ in diseased renal transplants means a decrease in cortical blood volume. The also visible flatter shape of the first parenchymal nephronal peak of the medulla $\left(\lambda_{1}\right)$ denotes a slower washout from the medulla or a lack of isochronism of the early medullary transport in the nephrons. Considering the different types of diseases in our population it is remarkable that this trend appears to hold for all disease types (fig.5). It suggests that different mechanisms cause similar changes in renal dynamic behavior. Pathophysiologic interpretation is speculative but the decreased cortical blood volume in diseased renall transplants could for instance be caused by loss of vascular stmuctures (necrosis), vasoconstriction or interstitial disease with secondary vascular compromise. The changes in the medulla can be secondary to the events taking place in the cortex or be caused by medullary degeneration.

In read transplant recipients who use agents with vasoconstrictive properties (group $1 \mathrm{~B}$; cyclosporine or tacrolimus), the peak times of the first and second cortical nephronal peak ( $\tau_{1}$ and $\tau_{2}$ ) are significantly shorter than for patients who do not use these agents (group 1A). These parameters reflect the accumulation of Gadolinium-DTPA in the proximal and distal rubules. Similar, although not statistically significant, changes are seen in the medullary $\tau_{1}$ and $\tau_{2}$ (table 4 ). In terms of the curve-fitting model, shorter peak times mean that flow through the nephrons is higher or nephron volume smaller. This could be a reaction of the nephron apparatus to the vasoconstrictive effects of cyclosporine and tacrolimus. Rapid flow could be associated with small nephron diameter or with low concentration of the contrast agent caused by a lower reabsorption of water from the nephrons. More straightforward effects of vasoconstriction would be alterations in the arterial phases of enthancement. These are not demonstrated. Although the cortical arterial peak enhancement tends to be lower in individuals who use cyclosporine or tacrolimus (table 4), this difference is not statistically significant. 
Of course, the physiological interpretations given are speculative but they do give a suggestion of what could be inferred from the enhancement curves when sufficient experience in their interpretation is added.

Limitations of our study are that all the diseased patients had severe renal transplant dysfunction and that the types of diseases were very heterogeneous. Although we were capable to accurately demonstrate disease related changes in renal enhancement, nothing can be said about disease specificity which should be the ultimate objective of MRR. Furthermore, the sensitivity of our technique for milder forms of renal transplant disease is not proven. Additional studies with larger groups of patients and variable degrees of renal transplant dysfunction are requined. The positive results from our study justify such future research.

In conclusion, our method of MR renography, that includes new methods of image analysis and parametric quantification, is highly accurate in detecting medical renal transplant disease. Because our technique is performed fully computerized it is operator independent and postprocessing time is minimal. These are important steps forward towards the clinical use of functional MRI in renal transplant recipients and justify future research that should be directed towards disease-specific changes in MR-renographs. In this respect, functional information obtained from medullary enhancement may play a vital role. 


\section{References}

1. Granger RG and Allison DJ. Diagnostic Radiology. Edinburgh: Churchill Livingstone; 1992 ; $1372-1377$.

2. Szolar DH, Preidler $\mathrm{K}$, Ebner $\mathrm{F}$, et al. Functional magnetic resonance imaging of human renal allografts during the post-transplant period: preliminary observations. Magn Reson Imaging 1997: 15:727-735.

3. Wallace $\$$, Schwarten DE, Smith TP, ai. Intrarenal arteriovenous fistula; transcatheter stem occlusion: J Urol 1978; 1202282-286.

4. Kikinis R. Von Schultess GK, Jager P, et al Normal and hydronephrotic kidney: Evaluation of renal function with contrast-enhanced $M R$ imaging. Radiology $1987 ; 165: 837-842$.

5. Choyke PL. Frank JA, Girton ME, et al. Dynamic Gd-DTPA-enhanced MR imaging of the kidney: Experimental results. Radiology 1989; 170:713-720.

6. Carvlin MJ, Arger PH, Kundell HL et al. Use of Gd-DTPA and fast gradient-echo and spin-echo MR imaging to demonstrate renal function in the rabbit. Radiology 1989; 170:705-711.

7. Semelka RC, Hricak $H_{*}$ Tomei E, Floth $A$, Stoller M. Obstructive nephropathy: Evaluation with dynamic Gd-DTPA-enhanced MR imaging. Radiology 1990; 175:797-803.

8. Von Schultess GK, Kuoni W, Gerig G, Wuthrich R, Duewell S, Krestin G. Semiatutomated ROI analysis in dynamic MR studies. Part I: Application to renal function examination. $J$ Comput Assist Tomogr 1991: 15:733-741.

9. Ros PR, Gauger $J$, Stoupis $C$, et al, Diagnosis of renal artery stenosis: Feasibility of combining MR angiography, MR renograply, and Gadopentetate-based measurements of glomerular filtration rate. AlR 1995; 165:1447-1451.

10. Munechika H, Sullivan DC, Hedlund LW, ef al. Evaluation of acute renal failure with magnetic resonance imaging using gradient=echo and Gd-DTPA. Invest Radiol 1991; 26:22-27.

11. Sharma RK, Gupta RK, Poptani H, Pandey CM, Gujral RB, Bhandari M. The magnetic resonance renogram in renal transplant evaluation using dynamic contrast-enhanced $M R$ imaging. Transplantation 1995; 59: 1405-1409.

12. Roberts TPL. Physiologic measurements by contrast enhanced MR imaging: expectations and limitations. J Magn Reson Imaging 1997; 7:82-90.

13. Nakashima $\mathbb{R}$, Yamashita Y, Tomiguchi S, Tsuji A, Takahashi M. Functional evaluation of transplanted kidneys by Gd-DTPA enhanced Turbo-FLASH MR imaging. Radiat Med 1996; $14: 251-256$.

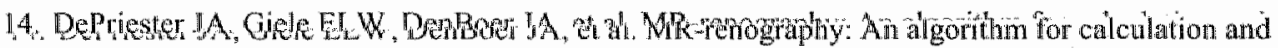
correction of cortical volume averaging in medullary renographs. I Magn Reson Imaging 2000; 12:453-459.

15. De Priester JA, den Boer JA, Kessels AGH, et al. MR - renography by semiautomated image analysis: performance in renal transplant recipients. J Magn Reson Imaging 2001; 14:134 141.

16. Wolf GL, Hoop B, Cannillo JA, Rogowska JA, Halpern EF. Measurement of renal transit of Gadopentetate Dineglumine with echo-planar MR imaging. I Magn Reson Imaging 1994; 4:365372.

17. Marsen TA, Weber F, Egink G, Suckau G, Baldamus CA. Differential transcriptional regulation of endothelin- 1 by immunosuppressants FK 506 and cyclosporine A. Fundam Clin Pharmacol 2000; $14: 401-408$.

18. Takeda M, Katayama Y. Tsutsui T, Komeyama T, Mizusawa T. Does gadolinum-diethylene triamine pentaacetic acid enhanced MRI of the kidney represent tissue concentration of contrast medis in the kidney? In vivo and in vitro study, Magn Res Imag 1994; 12:421 -427.

19. Moran GR, Prato FS. Modeling tissue contrast agent concentration: a solution to the tissne homogeneity model using a simulated arterial input function. Mag Res Med 2001; 45:42-45.

20. Grenier N, Trillaud H, Combe C, Degreze P, Jeandol R, Gosse P, Douws C, Pallussiere I. Diagnosis of renovascular fypertension: feasibility of captopril-sensitized dynamic MRI and comparison with captopril scintigraphy. AJR 1996;166:835-843. 
21. Dupas B, Bach-Gansmo T, Blancho G, Franconi IM, Havet T, Leaute f. Gadolinumenhanced MR imaging of nomal renal transplants. An evaluation of a Tl-weighted dymamic echo-planar sequence. Acta Radiol. 1999; 40:250-4.

22. Press W.H. Numerical Recipes in C, $2^{\text {nd }}$ ed., Cambridge UP, 1996 , chapter 15 . 


\section{CHAPTER 6}

\section{Automated post-processing and enhancement parameterization in Magnetic Resonance Renography. \\ Patterns in hypertensive patients with and without renal artery stenosis.}

Submitted

Jacobus A. de Priester

Abraham Kroon

Eelco L. Giele

Jacques A. den Boer

Boudewijn C. Vasbinder

Alphons G. Kessels

Peter L. de Leeuw

Arie Hasman

Jos M. van Engelshoven 


\section{Abstract}

\section{Background}

Magnetic Resonance Renography (MRR) has the potential to provide detailed functional information of the kidney, Widespread use of MRR is hampered due to difficulties in dataanalysis. Recently, we developed new algorithms that optimized post-processing techniques of MRR.

\section{Objective}

To present characteristics of native kidneys in MRR and to assess the clinical value of the postoprocessing algorithms.

\section{Desingn}

A comparative study in hypertensive patients with and without renal artery stenosis.

\section{Methods}

Our technique was tested in 10 hypertensive patients with normal renal arteries and 12 patients with renovascular hypentension (7 atherosclerotic renal artery stenoses (RAS) and 5 fibromuscular dysplasia (FMD)).

\section{Resullts}

Cortical and medullary MR renograms could be obtained in all patients within 15 minutes.

Compared to normal renal arteries, FMD and RAS were characterized by lower amplitudes of the peaks ( $P<0.02$ ) and tail of the medullary renogram $(P<0.01)$. Patients with RAS demonstrated lower peak times $(P<0.05)$ and peak amplitudes $(P<0.02)$ of the first medullary nephronal peak than patients with FMD. Cortical renograms were not significantly different. The changes observed can be explained by decreased renal blood flow and activation of the renin-angiotensin-aldosterone system.

\section{Conclusion}

This study shows the feasibility of obtaining robust and objective cortical and medullary MR renograms. It shows that MRR can be useful in clinical practise as a non-invasive diagnostic tool to discriminate renovascular hypertension from primary hypertension. However, additional prospective studies are necessary. 


\section{Introduction}

Magnetic resonance renography (MRR) is a dynamic MRl examimation of the k idney that provides functional information in tems of changes in signal intensity of the renal parenchyma during passage of an intravenously administered bolus of gadolimin DTPA (Figure 1). Based on the high spatial resolution of the MR navge, the man objective of MRR is to functionally differentiate cortical and medullary structures, a feature that is not possible with scintigraphic techiques (1-1). Various teports have denonstrated that lhe inaproved insight into renal (patho)physiology that is provided by separate analysis of cortical and medullary enhancement data may be valuable in the differentiation of disease processes that affect the native kidney and renal transplant $(1,8,9,11,12)$.

Notwithstanding these early promising results, however, MRR has not gatued widespread acceptance as a diagnostic tool We believe that this ts because image post-processing and data analysis up to now have been difficult, time consuning, and otten subjective.

Usually, cortical and medullary signal curves are derived from hand-placed regions of interest (ROI) that are positioned over the peripheral contex and the medullary pyramids (Iigure 2 ).

To obtain meaningful signal curves this has to be done with sufficient accuracy $A$ s demonstrated in figure 2B, however, ROI placement becomes problematic 1 contrast between cortex and medulla is small or absent, as is the case in mamy pettents with diseased kidneys.

An additional problem is that quantification of renal enliancement is complicated becanse the peaks of cortical and medullary enhancement curves tend to be shallow $(13,14)$ In combination with the fair amount of noise in MR-renographs, this makes it difficult to objectively identify and quantify these peaks in tems of time of occurrence, height and shape (Figure 3 ).

To handle these problems we previously developed and described a thee step computer algorithm of post-processing, inage analysis and enhancenent panameterization Of MRR data in renal transplants $(14-16)$. An overview is given in figure 4 . In the fist step, the kidney is segmented from the image. In step two, cortical and medullary signal curves are generated from automatically placed ROIs and in the third step these curves are guantified with a curve fitting technique that provides functional infomation in terms of a set of contical and medullary enhancement parameters. Because operator superwision in this process is minimal, operator bias is no longer an issue. In renal transplants this method proved to be robust and resulted in reproducible parametric deseriptions of the MR-renographs that allowed a highly accurate detection of parenchymal renal transplant disease (14). 

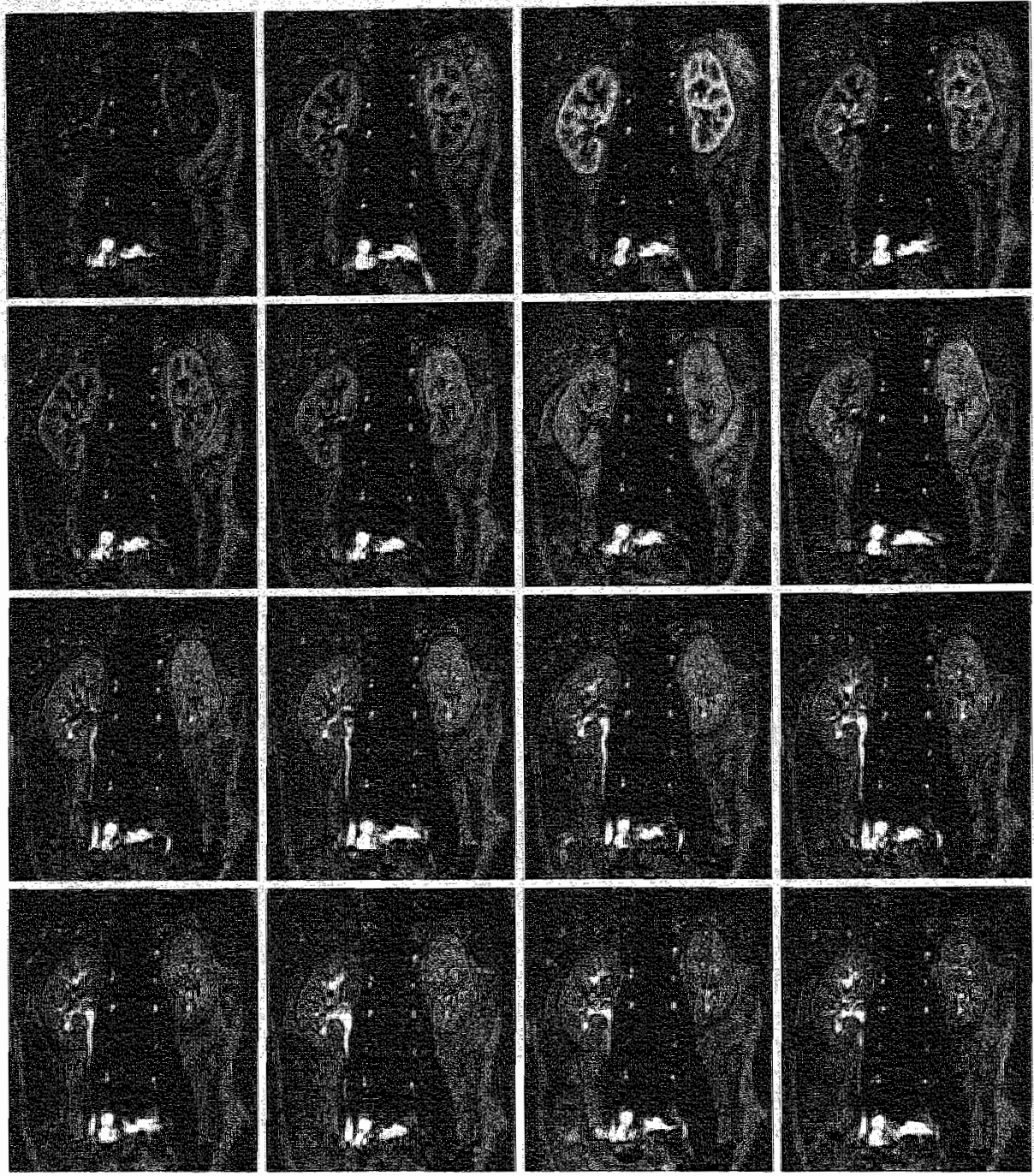

Figure 1. Images from the dynamic scan sequence. Clear differentiation of cortical and medullary structures, especially during early phases of cnhancement 

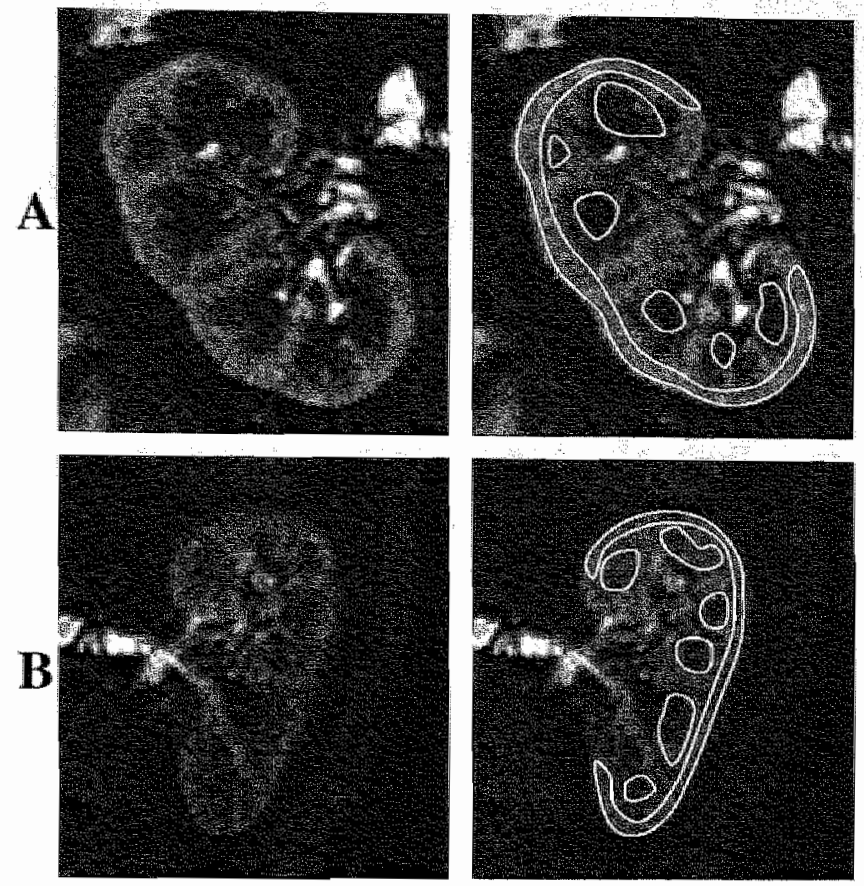

Figgre 2. Illustration of the difficulty of manual ROI placement. MR renographs are derived from ROIs which are positioned over the peripheral cortex and the medullary pyramids. The figure shows images during early enhancement, at which time cortico-medullary contrast usually is large. In an normal kidney (A), the medullary ROIs can be placed relatively easily. In a patient with parenchymal kidney disease (B) contrast befween cortex and medulla is poor. This makes ROL placement difficult and predisposes to errors.

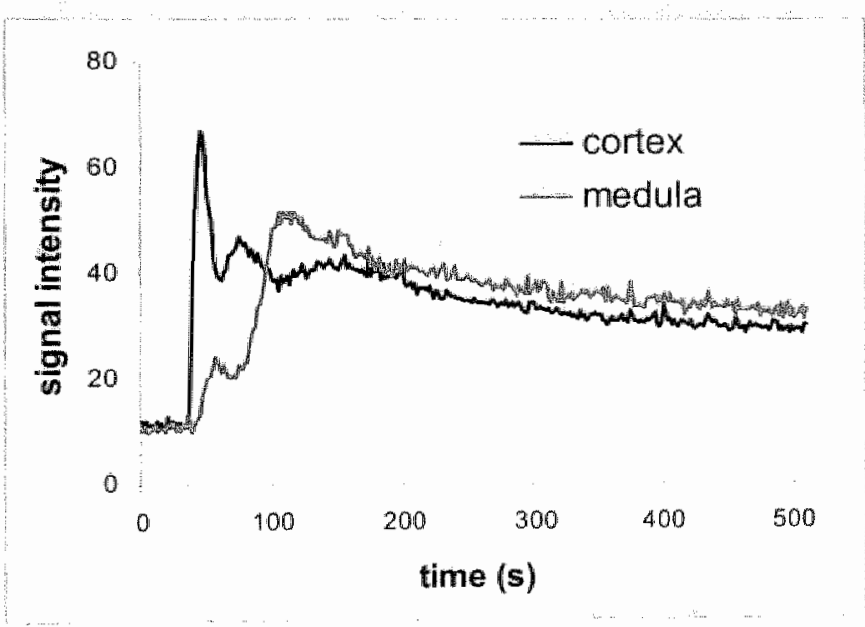

Figure 3. MR renographs as obtained with our tochnique. Cortical and medullary enhancement curves are characterized by three peaks and a tail. Aparl from the first cortical peak, the peaks are sthatlow and noisy, making identification in terms of time of occurrence, height and shape difficult. 


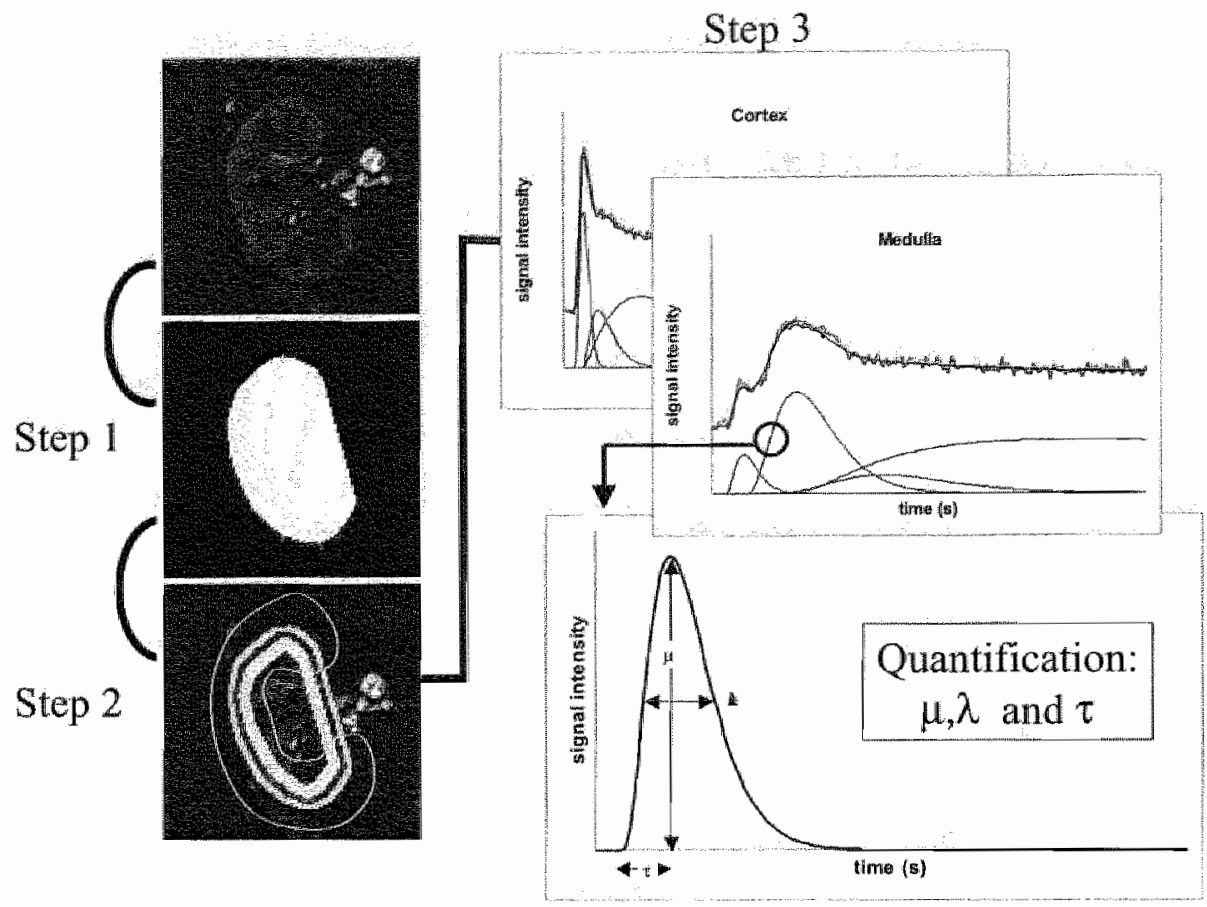

Figure 4. Three step computerized post processing algonthm. The algorithm operates on the dynamic image series, of which the image in the top left of the flow diagram is an example. After segmentation of the kidney from the image (step 1), two automatically generated concentric areas are generated, from which two ROI's are defined by the line that excludes the renal hilus (drawn mamully). The outer ROl is cortical and provides the cortical renograpli: the inner ROI crosses medullary pyramids as well as cortical columns, and the medullary renograph is calculated from both RoI signals (step 2, (15)). The observed renograpls are quantified with a curve fitting algorithm (step 3). The fitred curve is composed of four functions; three defining the peaks, one defining the tail, Parameters that define the composing functions in terms of peak time ( $)$, peak anplitude $(\mu)$ and width/shape ( $t+1 / \lambda$ ) are recorded as the enhancement parameters.

Transtation of these techniques to native kidneys is not straightforward because an additional problem in native kidneys is respiration-induced motion for which our three step algorithm did not account.

We therefore extended our algorithm with a fourth step by inchusion of a tool that registers and corrects the change in position of the kidneys during respiration. Technical details of this method have been described previously (17).

To assess the clinical value of our extended algorithm in native kidneys, we tested it on a group of patients with hypertension. The first objective was to assess the feasibility of determining quantitative enhancement characteristics in native kidneys in a way that parallels our earlier studies in renal transplants. Our second objective was to get an impression of the capabilities of our technique to detect the effects of altered renal perfusion in MR-renogtams, i.e. to get an impression of the diagnostic potential of our technique. For that purpose, we included in the study patients with atherosclerotic renal artery stenosis (RAS) and fibromuscular dysplasia (FMD). 


\section{Methods}

\section{Patients}

Twenty-two patients with treatment-resistant hypertension, who had a clinical indication to perform renal angiography (intra-arterial digital subtraction angiography: ia-DSA), were included in this study. All patients were in good clinical condition and none had a history of decreased cardiac pump function. Antihypertensive medication was witheld three weeks before angiography up to and inchuding the MRI investigation.

On the basis of findings with renal ita-DSA, patients were classified as follows: 10 patients (5 men, 5 women, aged 33 to 72 years, median 56.5 years) had normal renal arteries, 7 patients ( 4 men, 3 women, aged 54 to 72 years, median 63.0 years) had atherosolerotic renal artery stenosis (RAS) and 5 patients (1 men, 4 women, aged 38 to 65 years, median 47 years) had fibromuscular dysplasia (FMD).

RAS were all $>50 \%$, unilateral in 3 patients and bilateral in 4 patients. FD was unilateral in 3 patients and bilateral in 2 patients.

MRR was performed one week after ia-DSA. Immediately prior to the MR investigation blood pressures were measured and a venous blood sample was taken from which the serum creatinine concentrations were obtained. Creatinine clearance was calculated with the formula of Cockeroft and Gault (19).

Patients with RAS and FMD underwent percutaneous transluminal renal angioplasty (PTRA) shortly after the MRI investigation. Patients had either elevated renin concentrations in the venous blood samples or responded with a decrease in blood pressures and/or a decrease in the amount of drugs needed to control hypertension. Therefore, the hypertension of all patients with RAS and FMD was scored as renovascular.

The medical ethics committee of our hospital approved this study and all patients gave written informed consent.

\section{MRI procedure}

MRI was performed on a $1.5 \mathrm{~T}$ imager (gradient strength $10 \mathrm{mT} / \mathrm{m}$, slew rate $15 \mathrm{~T} / \mathrm{m} / \mathrm{sec}$, Philips ACS-NT, Philips, Best, The Netherlands). MR studies started with coronal and sagittal planscans (SE;TR/TE=182/10), followed by a multislice axial T2-weighted scan

(FSE;TR/TE/TF $=300 / 150 / 20$ ) through the kidneys. Images obtained from this scan sequence were used to select the plane of the dynamic scan sequence that was anatomically oriented as an oblique coronal plane through the long ax is of the kidneys. In this way, care was taken to include as much renal parenchyma as possible and to minimize the kidney movement perpendicular to the image plane. The dynamic scan sequence consisted of a run of $256 \mathrm{~T} 1$ weighted spoiled gradient echo scans (TR/TE/F/ip=1 $1 \mathrm{~ms} / 3.4 \mathrm{~ms} / 60^{\circ}$ ) with a slice thickness of $6 \mathrm{~mm}$, FOV $400 \mathrm{~mm}$, rectangular field of view $90 \%$ and scan matrix $200 \times 256$ (resulting voxel size $6.0 \times 2.0 \times 1.6 \mathrm{~mm}$ ). Breath hold commands were not used. Rather, the patient was asked to breathe as regularly and shallowly as possible during the dynamic scan seguence. Scans were performed every 2 seconds. After the tenth dynamic scan Gadolinium-DTPA (Magnevist, Schering, Germany) was injected in a dose of 0.05 mmol $k \mathrm{gg}$. This low dose agrees with (19), and was used to avoid $T 2 *$-effects. Gadolinium was injected as a rapid bolus with a flow rate of $5 \mathrm{ml} / \mathrm{sec}$ with a MR-injector pump (Medrad Spectris, Medrad, Maastricht, The

Netherlands), immediately followed by a saline flush $(0.9 \%$, dose $20 \mathrm{ml}$, now rate $5 \mathrm{ml} / \mathrm{sec})$. 


\section{Post-processing, curve geneiration and parameterisation}

Inage analysis was performed on a Sun Spare Ultra 30 work station (Sun microsystems Netherlands, Amersfoort. The Netherlands) with EasyScil software (Philips, Best, The Netherlands). Post processing was performed in the four steps of our algorithm. The automatic registration of kidney position, was supervised visually by one observer (JAdP) and, if needed, comeeted manually.

Although detailed descriptions of our method of enhancement quantification can be found in a previous article ( 16 ), a brief summary will be given here to understand the interpretation of the enhancement data.

Quantification is based on a physiologic model in which cortical and medullary enhancement curves are characterized by three peaks and a tail (fig. 3 and 4 ).

The first peak reflects the passage of the contrast agent through the vascular compartment and is called the arteriovenous peak. The second and third peaks reflect the excretory path through the nephrons; these are called the nephronal peaks. After the filtered bolus has left the kidney contrast agent still remains in the soft tissues and circulation of the patient. This leads to further renal excretion and the tail of the renal enhancement curve will follow the slow decay of the contrast agent in the body.

Each of these elements is fitted to the observed data as a separate function that is shaped by three adjustable parameters. These parameters define the elements in terms of peak time $(\tau)$, peak amplitude $(\mu)$ and peak shape $(\lambda)$ and are considered as quantitative descriptors of renal enhancement (17). The amplitudes are scaled to the enhanced signal $S$ and the averaged signal of the unenhanced frames of the scan sequence, $S_{0,}$ as:

$\mu=S / S_{0}-1$

Figure 4 gives an example of a raw and noisy signal-time curve and the corresponding fitted enhancement curve with its composing elements.

In total, 4 cortical and 4 medullary elements are required to fit renal enhancement. Because several parameters can be given fixed values, however, only 9 cortical and 8 medullary parameters remain adjustable.

The various enhancement parameters are given subscripts, referring to the arteriovenous peak (subscript 0), the first and second nephronal peak (subscripts 1 and 2) and the tail of the enhancement curve (subscript 3 ).

In the case of linear signal behaviour, the area $A_{0_{0}}$ of the cortical arteriovenous peak is proportional to the amount of Gadolinium that flows into the kidney and can be calculated with the parameter product:

$A_{0,0^{:}}=\mu_{0}\left(\tau_{0}+1 / \lambda_{0}\right)$

To get an impression of the enhancement characteristics relative to renal perfusion, the amplitudes $(\mu)$ of the cortical and medullary nephronal peaks were divided by the $A_{0,0}$. These are clenoted as $\mu^{*}$.

\section{Statistical analysis}

Three analyses were performed. All analyses were kidney based.

\section{Normal enhancement characteristics.}

To test for the presence of systematic left to right differences the enhancement parameters of 
left and right kidneys were compared in patients with angiographically normal renal artenies. This was done with a t-test.

The consistency of our technique was assessed with a one-way ANOVA by which the left to right differences within patients were compared to the differences between patients.

2. Disease detection.

In this analysis the enhancement data of angiographically normal kidneys were compared to those of kidneys affected by either RAS or FMD. In patients with double sided disease (2 patients with FMD, 4 patients with RAS) both kidneys were included.

\section{Disease differentiation.}

The enhancement data of kidneys with FMD were compared to those of kidneys with RAS. Per group of kidneys and per parameter, the distribution of the enhancement parameters was normal. Therefore, the analyses to assess disease detection and disease differentiation were done with t-tests.

A study of left to right differences in patients with unilateral RAS or FMD was not considered warranted because the number of patients available was too small ( 3 patients with RAS and 3 patients with FMD).

Data are presented as mean \pm standard deviation (SD), unless indicated otherwise. A P-value $<0.05$ was considered statistically significant.

\section{Results}

The mean systolic and diastolic blood pressures, as well as the mean serum creatinine levels, are listed in Table 1. For the blood pressures, no statistically significant differences were found. Patients with RAS had significantly lower mean creatinine clearances than patients with FMD ( $\mathrm{P}<0.001)$.

The number of scans in which the repositioning algorithm had to be corrected manually ranged between 10 to $30 \%$ of the scans of the dynamic sequence. The time needed to inspect and correct the reregistered dynanic data set varied between 2 and 15 minutes, with an average of 10 minutes.

\section{Normal enhancement characteristics}

In patients with normal renal arteries, the mean parameter values obtained from the right and left kidneys were not significantly different. The ANOVA test demonstrated that the vartance between patients was always larger than that between the left and right kidneys per patient.

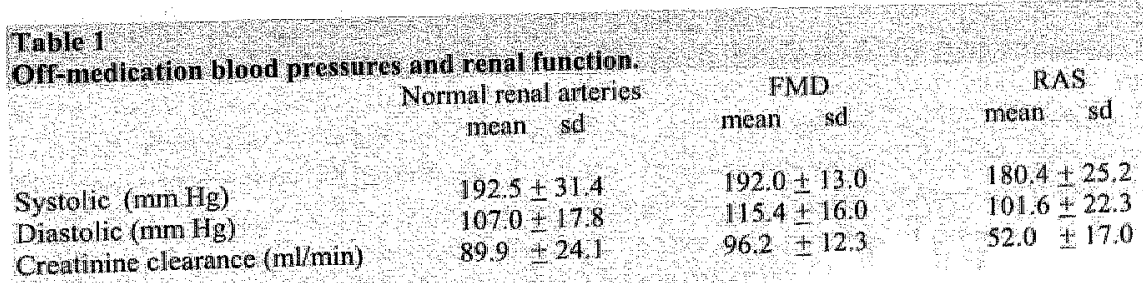

Note: FMD indicates fibromuscular dysplasia: RAS indicates atherosclierotic ment artery stenowis. 


\section{Disease detection}

Enhancement data of kidneys with normal renal arteries, and kidneys with renal artery disease (either FMD or RAS) are given in Table 2.

Between these groups, cortical enhancement parameters were not significantly different. Kidineys with renal artery disease had significantly lower amplitudes of the medullary peaks $\left(\mu_{0}, H_{1}, \mu_{2} . P<0.02\right)$ and the medullary tall $\left(\mu_{3}, \mathrm{P}<0.01\right)$. When the means of the parameters of table 3 were used to define enhancement curves a graphical impression of their difference was obtained, as shown in Figure 5.
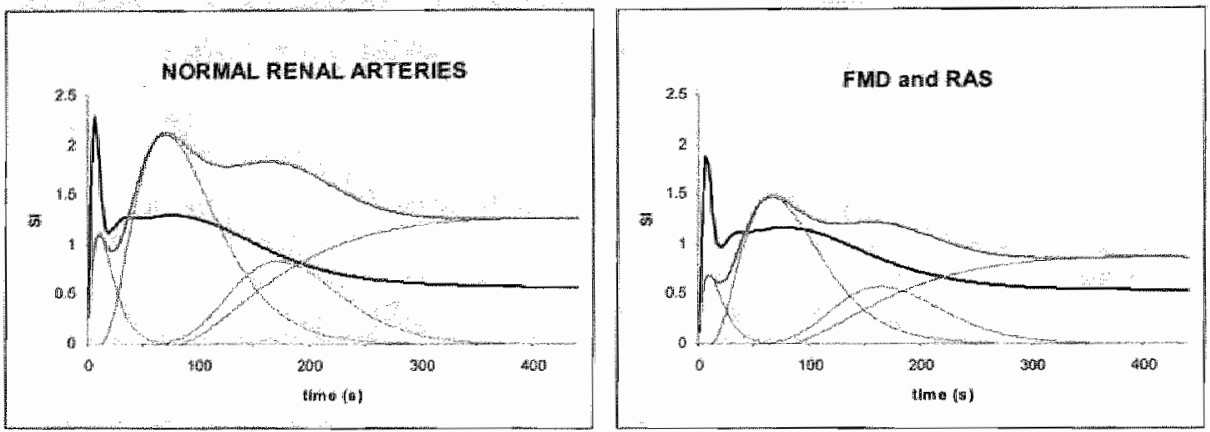

Figure 5. Cortical (black lines) and medullary composed enhancement ourves (thick gray lines). The composing functions are defined by the mean parameters of kidneys with normal artaries (left) and kidneys with renowscular disease (FMD and $\mathrm{RAS}$, right). For the medullary entzancement curve, the composing functions are shown (thin grey lines). Lower medullary $\mu 0, \mu 1, \mu 2$ and $\mu 3$ in renovascular disease are rellected visibly as lower amplitudes of the medullary peaks and medullary tail $(\mathbb{P}<0.02)$. The difference in amplitude of the early cortical peak is also visible in the figure but was not statistically significant.

\section{Disease differentiation.}

As demonstrated in Table 2, in the medullary enhancement curve, RAS was characterized by statistically significant lower values for $\mu_{1}^{*}(P<0.02)$ and $\tau_{1}(P<0.05)$. These parameters describe the amplitude and time of the first nephronal peak. Again, the cortical enhancement parameters were not significantly different. These results are illustrated graphically in Figure 6.
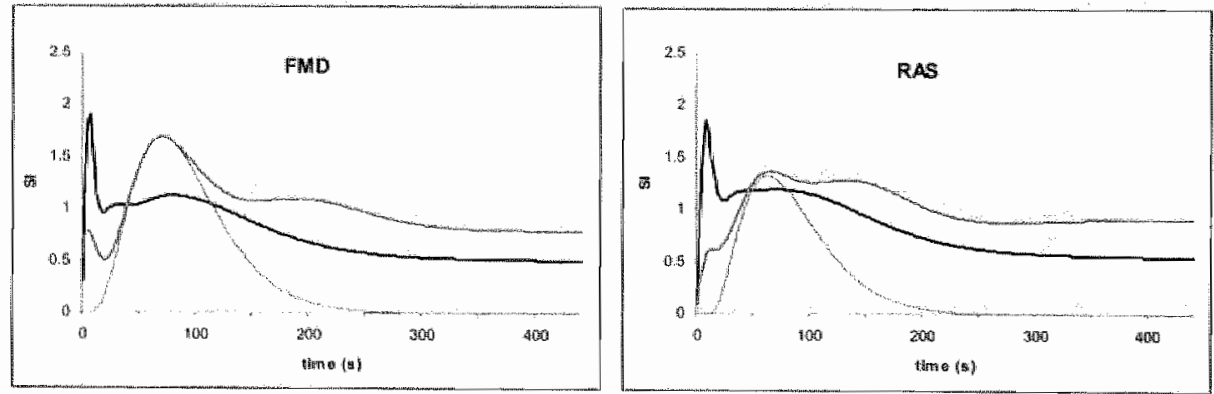

Figure 6. Composed enthancement curves for horomuscular dysplasia (FMD. leti) wersus atherosclerotic renal trtery stenosis (RAS, right), Cortical (black line) and nedullary enhancentent curves (thick gray line) are defined by medt parameter values from Table 2. The composing functions for the finst nedullary apphromal peak (thin grey lines) are shown as well. Shorter medullary $\tau$ and medullary $u$ l of patienis with RAS are reflected as a shorter time 10 peats and lower amplitude of the first medullary neptronal peak. 


\section{Discussion}

This study showed that the presence of renowascular bypertension was characterized by lower amplitudes of the peaks and tails of the medullary MR renographs. Moreower, RAS could be differentiated from FMD by smaller peak times and amplitudes of the first medullary nephronal enhancement curves. No differences were observed in the cortical renographs. These differences establish the proof of concept of our approach and slow the perspective of a diagnostic contribution to the detection and the differentiation of renal artery disease.

A major problem in MRR of the kidneys is the constantly changing position of the kidney caused by respiration. This means that the cortical and medullary ROIs from which signal curves are obtained, have to be repositioned over and over again. Given the large number of scans in a dynamic MRR scan sequence, this makes MRR post-processing very time consuming. The most commonly used alternative approach to handle this problem is breathhold imaging $(7,12)$. With this technique, the patient is asked to keep his breath as long as possible and images are acquired during these breath holding intervals. Image acquisition is stopped during respiration. This approach carries with it several problens. Although variation of kidney position is decreased, it is not banned out completely and manual corrections are still necessary. Even more important is that the intermittent interruption of the scan sequence inevitably results in loss of functional information. Especially during early enhancement, the temporal changes in signal intensity are quick and large, showing various closely packed cortical and medullary peaks. If the patient is breathing during this period, all these phenomena will be missed and valuable information lost.

It was for these reasons that we preferred free breathing during the dynamic scan and that we implemented a position correction algorithm in our post-processing algorithms.

The use of the position corrector resulted in a gain of time. Most of the kidney motion was removed correctly, and the remaining misregistrations were small and occurred in only 10 to $30 \%$ of the scans per dynamic sequence. Although the manual adjustment of these misregistrations is now possible with acceptable speed, taking an average time of 10 minutes, attempts for further relinements of the position corrector are still justified.

It is noteworthy that all the observed differences in enhancement between kidneys with normal renal arteries, RAS and FMD are confined to the medullary MR-renographs. Other studies $(12,13)$ have also emphasized the diagnostic significance of medullary behavior. These findings give a strong argument for MRR which up to now is the only functional imaging technique that can give separate, spatially differentiated, medullary information. In patients with normal renal arteries we did not demonstrate systematic left to right differences. We showed that the variance of the intra-patient left to right differences was smaller than that between patients. This observation supports the assumption that the observed differences are caused by measurement emors.

Assuming that the observed differences could have been caused by measurement errors, we showed that the variance in the left to right difference was smaller than that between the patients. From this we believe that it is safe to conclude that left-right differences in normal kidneys are of minor influence. We used this result as an argument to restrict our attention to the kidney as a unit of analysis. Assessment of left to right differences in patients with unilateral RAS or FMD was not performed because the number of patients with unilateral disease was too small to make such an effort worthwhile.

The curve fitting algorithm that is used to generate the enhancement parameters is based on a physiologic model of renal enhancement (chapter 4). Therefore, our enhancement parameters may have a physiologic meaning. 


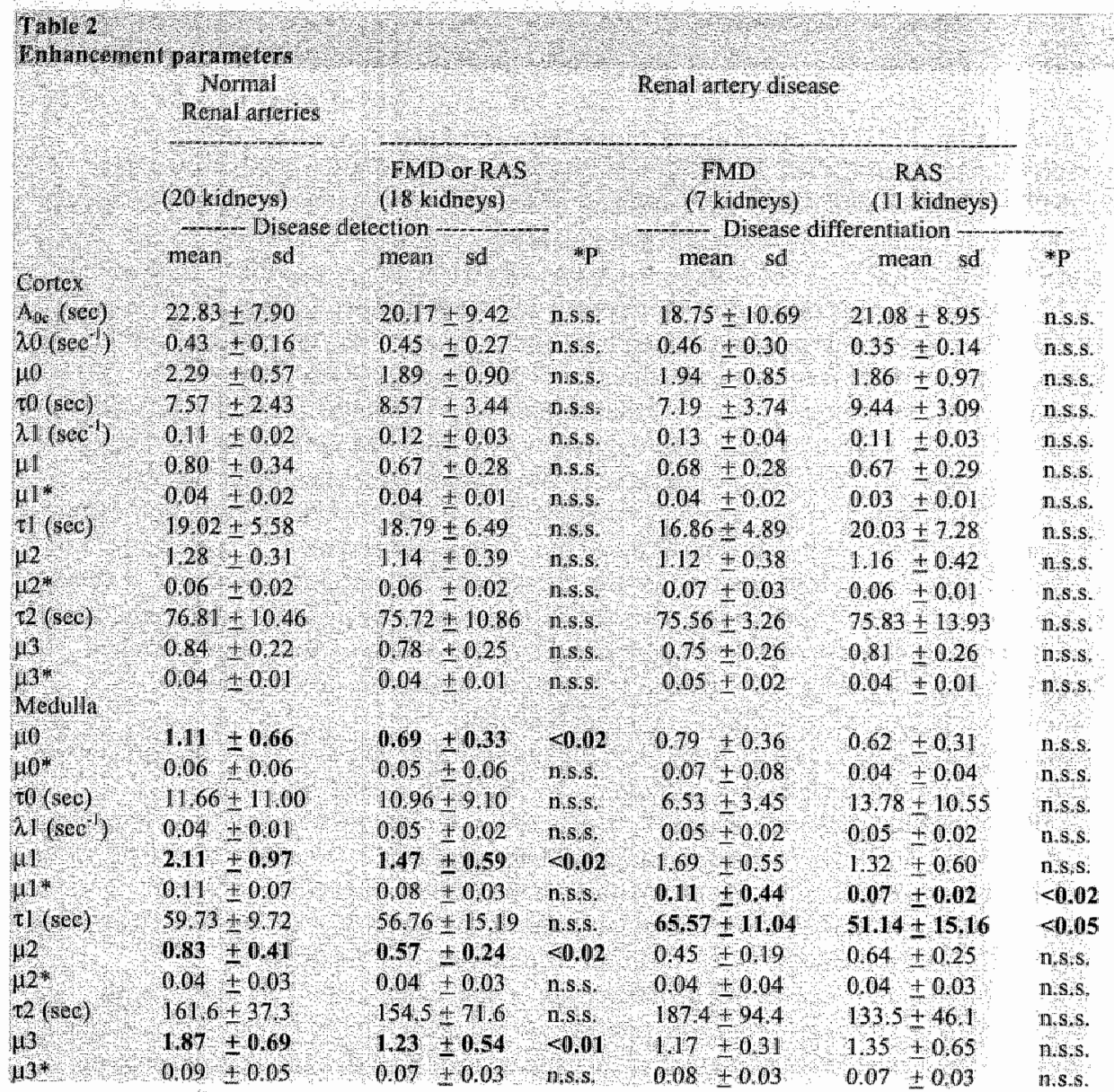

N.s.s.: not statistically significunt $(P>0,05)$

Data with statistically significant differences are printed in bold 
At this point, a pathophysiological interpretation of our study results is speculative because the number of patients in our study is limited. Still, an attempt to do $\$ 0$ is justified because it illustrates the potentially relevant relation between the renovascular status of the patient and the characteristics at MRR.

One of the observed characteristics of renal artery disease (FMD or RAS) was the lower amplitude of the arterio-venous peak $\left(\mu_{n}\right)$. This may indicate a volume loss of the medullary arteries. By definition all our patients with RAS and FMD had renovascular hypertension. In renovascular hypertension, the kidney tries to maintain a nomal intra-glomerular pressure by constriction of the efferent arterioles, mediatted through angiotensine 11. This vasoconstriction may well be associated with a decreased pressure in the medullary arterioles, which are linked serially to the efferent arterioles. The resulting loss of the medullary vascular volume and the correspondingly lower amount of gadolinium in the medullary arteries is a plausible explanation for the observed lowered amplitude of the medullary arterial peak $\left(\mu_{0}\right)$ in renal artery disease. In view of the unaltered width and time of this peak, it is likely to be also an indication of lowered medullary perfusion.

The lower amplitudes of the nephronal medullary peaks $(\mu, \mu 2$ and $\mu$ in patients with RAS or FMD cannot be attributed to smaller amounts of gadolinim in the filtered bolus. Since gadolinium is excreted from the blood by filtration, this would require a decreased glomerular filtration rate. As indicated in Table 1, there were only small differences in creatinine clearance between patients with nomal renal arteries and renovascular disease.

A third explanation for our findings is also related to the activation of the renin-angiotensine system, and may have been caused by relative volume overload of the circulation. This mechanism is known to occur in renovascular hypertension, and corresponds to increased. water retention due to increased reabsorption of water from the nephrons. This will result in a decrease of the nephronal fluid volume in which the gadolinium bolus resides. In terms of MR signal generation the nephron is a compartment that shows slow exchange of water molecules with the surrounding tissue (22). This slow exchange means that the water molecules that experience the paramagnetic effects of gadolinium are primarily located within the nephrons and that a clecrease in the nephronal fuid volume will decrease the number of protons available for the contrast agent to exert its paramagnetic properties. This will decrease the signal intensity and peak amplitude, even when the amount of Gd per voxel remains constant. The differentiation between FMD and RAS in terms of a lower medullary $\mu I^{*}$ in patients with RAS can either be disease related or be caused by differences in renal function, because the mean creatinine clearance in patients with RAS was significantly smaller than in patients with FMD (Table 2).

Medullary $\mu I^{*}$ defines the peak amplitude of the first parenchymal peak, normalized to the renal perfusion $\left(A_{0, c}\right)$. The smaller mean value of this parameter in patients with RAS means that, per volume of blood delivered to the kidney, smaller anounts of gadolinium are filtered into the nephrons. From the literature on nuclear medicine signal analysis (20) and CT (21), it can be inferred that medullary $\mu I^{*}$ is proportional to GFR. Most likely therefore, the observed differences reflect loss of renal function.

Although speculative, these interpretations are intriguing because they relate our findings to the pathophysiologic mechanism of renovascular lypertension and loss of renal function. Unfortunately, we are unable to prove this from our data set because our study population is too small and all our patients with renal artery disease had renovascular hypertension. Larger studies are needed in which FMD and RAS patients with primary hypertension are included and in which MRR studies are repeated after PTA or stenting procedures. Such additional studies will be started soon at our department. 
One could argue that the number of parameters aequired is large enough to introduce an fement of chance into the observed means and their significance. Conservatism would then require a correction of the significance level. However, the differences between kidneys with renal artery disease and kidneys with normal renal arteries are confined to the medullary $\mu$ 's, all of them being smaller, Moreover, with exception of the medullary $\tau 1$, all the observed differences were highly significant $(\mathrm{P}<0.02)$. These observations strongly suggest that the observed differences are real.

We conclude that the post-processing algorithm presented in this paper is an mportant step forward in the development of MRR. Our method optimizes the functional information because breath-hold imaging can be omited and because enhancement is quantified in terms of parameters that are objective and have (patho) physiological significance. Differences were confined to medullary MR renographs and can be explained in terms of reduced renal blood flow and/or actuvation of the renin-angiotensin-aildosterone system. 


\section{References}

1. Szolar DH, Preidler $\mathrm{K}$, Ebner $\mathrm{F}$, Kammerbuber $\mathrm{F}$, Honn $\mathrm{S}$, Ratschek M, et al Functional Imagnetie resonance imaging of human renal allografts during the post-transplant period preliminary observations. Magn Reson Imaging 1997; 15727-735.

2. Kikinis R, Von Schultess GK, Jager P, Durr R, Bino M, Kuoni W, al. Normal and hydronephrotic kidney: Evaluation of renal function with contrast-enluanced MR imaging. Radiology 1987; $165887-842$.

3. Choyke PL, Frank JA, Girton ME, Inscoe SW, Carvlin MJ, Black IL, et al. Dynamic Gd-DTPAenhanced MR imaging of the kidney: Experimental results. Radiology 1989; 170:713-720.

4. Carvlin MJ, Arger PH. Kundel HI, Axel L, Dougherty L, Kassab EA, at al. Use of Gd-DTPA and fast gradient-echo and spin-echo MR imaging to demonstrate renal function in the tabbit. Radiology 1989; 170:705-711.

5. Semelka RC, Hricak H, Tomei E, Floth A, Stoller M. Obstructive Nephropathy: Exaltuation with dynamic Gd-DTPA-enhanced MR imaging. Radiology 1990; 175:797-803.

6. Von Schultess GK, Kuoni W, Gerig G, Wuthrich R, Duewell S, Krestin G. Semiautomated ROI analysis in dynamic MR studies. Part $\mathbb{1}$ : Application to renal function examination. I Comput Assist Tomogr 1991; 15:733-741.

7. Ros PR, Gauger J, Stoupis $\mathrm{C}$, Burton $\mathrm{SS}_{n}$ Mao $J$, Wilcox $\mathrm{C}_{*}$ et al. Diagnosis of renal antery stenosis: Feasibility of combining $M R$ angiography, MR renography, and Gadopentetate-based measurements of glomerular filtration rate. AJR 1995; 165:1447-1451.

8. Munechika H, Sullivan DC, Hedlund LW, Beam CA, Sostman HD, Hertkens RJ, et al. Evaluation of acute renal failure with magnetic resonance imaging using gradientwecho and Gd.DTPA. Invest Radiol 1991; 26:22-27

9. Sharma RK. Gupta RK, Poptani H, Pandey CM, Gujral RB, Bhandari M. The nagnetic resonance renogram in renal transplant evaluation using dymamic contrastenhanced MR imaging Transplantation 1995; 59: 1405-1409.

10. Roberts TPL. Physiologic measurements by contrast enhanced MR imaging: expectations and limitations. J Magn Reson Imaging 1997; 7:82-90.

11. Nakashima R, Yamashita Y, Tomiguchi S, Tsuji A, Takadashi M. Functional evaluation of transplanted kidneys by Gd-DTPA enhanced Turbo-FLASH MR imaging. Radiat Med 1996; $14: 251-256$.

12. Lee VS, Rusinek H, Johnson G, Rofsky NM, Krinsky GA, Weinreb JC. MR renography with lowdose gadopentetate dimeglumine: Feasibility. Radiology 2001; 221:371-379.

13. Wolf GL, Hoop B, Cannillo JA, Rogowska JA, Halpern EF. Measurenient of renal transit of Gadopentetate Dimeglumine with echo-planar MR imaging. IMRI 1994; 4:365-372.

14. De Priester JA, DenBoer JA, Christians MHL, Kessels AGH, Giele ELW, Hasman A, al Automated quantitative evaluation of diseased and non-diseased renal iransplants with $M R$ renography. J Magn Reson Imaging 2003; 17:95-103.

15. DePriester JA, Giele ELW, DenBoor JA, Christians MHL, Kessels AGH, Hasman A, el al. MRrenography: An algorthm for calculation and correchon of cortical volume averaging in medullary renographs. J Magn Reson Imaging 2000; 12:453-459.

16. DePriester JA, DenBoer JA, Kessels AGH, Giele ELW, Christians MHL, Hasman A, VanEngelshoven JMA. MR-renography by semiautomated image analysis: performance in renal transplant recipients. J Magn Reson Imaging 2001; 14:134-14!

17. Giele ELW, DePriester JA, Blon JA, VanEngelshoven IMA, Hasman A, Geerlings MJHM Movement correction of the kidney in dynamic MRI scans using FFT phase difference movement detection. J Magn Reson Imaging 2001; 14:741-749.

18. Takeda M, Katayama Y, Tsutsui T, Komeyama T, Mizusawa T, Does gadolinium-diethylene triamine pentaacetic acid enhanced MRI of the kidney represent tissue concentration of contras media in the kidney? In vivo and in vitro study. Magn Res Imag 1994; 12:421 -427.

19. Cockroft DW, Gault MH. Prediction of creatinine clearance from serum creatinine. Nephron $1976 ; 16: 31-41$ 
20. Pratla $\mathrm{CS}, \mathrm{Blasberg} \mathrm{RG}_{\text {; }}$ Fensternacher JD et al. Graphical evaluation of the blood-to-brain bartier transfer constantit from multiple time-uptake data. J Cereb Blood Flow Metab 1983; 3:1-7.

21. Dawson $\mathrm{P}$, Peters $\mathrm{M}$. Dynamic contrast bolus computed tomography for the assessment of renal function. Inv Radiol 1993; 28:1039-1042.

22. Shuler B, Tofts PS, Warig $\mathrm{SC}$, Pope JM. The relaxivity of Gd-EOB-DTPA and Gd-DTPA in liver and kidney of the Wistar rat. Mag. Res. Im. 1996; 14:243-253. 
CHAPTER 7

GENERAL DISCUSSION AND CONCLUSIONS 
After initial reports in the late $1980^{\circ} \mathrm{s}$, MRR has met with widespread enthusiasm. Various srudick have emphastzed the possibilities of MRR to differentiate renal transplant diseases like rejection, ATN and cyclosporine toxicity. Notwithstanding this, dewelopments appear to have come lo a stand stiil.

As pointed out in the introduction of this thesis, the main reason for this is the complexity of data acquisition and data analysis. The main objective of this thesis has been to create an easy to handle method of data generation and analysis that requires minimal effort from the operator and that results in robust, meaningful functional information of kidneys and renal transplants.

The research described in this thesis is one of two parts in a tandem study. It focuses on the clinical problems encountered during acquisition and analysis of MR renograms. Its counterpart focused on a number of technical problems. Some of the conchusions of that study are reiterated here.

\section{The dynamic scan sequence}

Essential for high quality MRR data is an adequate dynamic scan sequence. In designing such a scan sequence, certain considerations must be made and a number of conditions should be fullfilled:

\section{Weighting and enhancement}

Because gadolinium-DTPA is used as the contrast agent, the dynamic scan sequence should be optimally $\mathrm{T} 1$-weighted in order to optimize enhancement which is based on the $\mathrm{T}$ I shortening effects of this contrast agent. This means that TR and TE should be as short as possible. When we started our investigation in 1995 this meant a TR of 1 II ms and a TE of $3,4 \mathrm{~ms}$. At the present time, shorter TR and TE are possible and will further optimize contrast enhancement.

Comparison between volunteers showed that with a flip angle of 60 degrees an acceptable signal enhancement could be reached. This observation was supported by a test with an aqueous solution of Gadolinium DTPA, in which the same flip angle showed maximum signal at a concentration of $10 \mathrm{mM}$, representative of the highest expected values occurring in the kidncy.

A very important issue is the anount of gadolinium-DTPA to be used in the bolus. At low concentrations, the T1 shortening effects of gadolinium dominate. At high concentrations, however, T2* -effects, caused by susceptibility effects may start to dominate which will then cause a decrease, rather than increase, of the signal intensity. This forms the explanation for the dark rim in the medulla that was observed during bolus passage in earlier literature. In most of the structures of the body, such high concentrations will not be reached. In the kidney, however, water is reabsorbed from the renal tubules and gadolinium-DTPA concentrations in the nephrons can increase dramatically to values that are high enough to induce these $T 2 *$ effects. This can be avoided by prehydration of the patients and by using smaller amounts of Gadolinium as was demonstrated by (1). Prehydration decreases reabsorption of water from the nephrons and limits the concentration increase to about 10 times (2). The use of a small TE, a large flip angle and a small dose of contrast agent (half the normal dose: $0.05 \mathrm{mmol} / \mathrm{kg}$ ) (1) further reduces the risk of unwanted signal loss. 


\section{Temporal resolution}

Gadolinium-DTPA has the same dynamic properties as Tc-DTPA. Therefore, enhancenent characteristics known from renal scintigraphy may serve as an indicator for the temporal resolution required in the dynamic scan sequence. The quickest phenomena occur during early enhancement when peaks may reach their maximum values within 10 seconds, as is known from nuclear studies. To describe such phenomena accuratcly our scan sequence was designed with the objective to obtain a temporal resolution of 2 seconds per frame. This could be achieved by choosing a rectangular field of wiew of $90 \%$ and a scan percentage of $80 \%$ (scan matrix of $256 \times 256$ ).

In retrospect, we believe that this temporal resolution is sufficient. The quickest phenomenon observed in MRR is the first cortical, arteriovenous peak. For this peak, the time needed to reach maximum signal value differs from patient to patient and varies between 8 and 1.4 seconds. This means that even the sharpest peaks are covered by at least 4 frames of the dynamic scan sequence.

In the examination of native kidneys, an additional benefit of the short time per frante is the reduction of movement artifacts.

\section{Spatial resolution}

We use a field of view of $400 \mathrm{~mm}$ which results in a pixel size of $2.0 \times 1.6 \mathrm{~mm}$. This choice of this pixel size was dictated by the observed thickness of the peripheral cortex. Our objective has been to cover the renal cortex by at least three pixels, even in severely diseased kidneys and renal tramsplants.

\section{Future optimization and implications of modern scanner technology on the dynamic scan sequence}

\section{Multi-slice imaging}

The progress in scanner technology since we started our studies makes it possible to improve the imaging protocols. The shorter TR and TE, possible on modern MR imagers, opens up the possibility to perform a multi-slice dynamic scan sequence. When we started our studies this was not possible without giving up the temporal resolution of 2 second which we considered essential for an accurate sampling of the quickly changing signal intensities during early renal enhancement.

A specific problem of single slice imaging is caused by slice selective spin saturation. If the tissue that is imaged moves perpendicular to the image slice (through slice movement), nonsaturated spins will enter the slice and will add to the image intensity, especially if this movement occurs at the time when the center of the $\mathrm{k}$-space is scanned. Through slice movement is an important problem in the dynamic MR sequences of native kidneys, caused by movement of kidneys during respiration of the patient.

We anticipate that the use of a multi-slice imaging sequence will strongly reduce this phenomenon (3). This is because the spins in multiple slices are saturated, and, except for the outer slices, the saturated spins that are moved out of the slices are replaced with other equally saturated spins. This reduces the noise of the MR renographs and will increase the quality of the functional information. 


\section{Silce angulation}

Recent research has demonstrated that the plane of movement of the kidneys is roughly parallel to the surface of the erector muscles of the spine. Therefore, through slice movement can further be reduced if the scan plane is angulated parallel to these muscles (3).

\section{Slice thickness}

The slice thickness should be reconsidered. When we developed our scan sequence we considered a slice thickness of $6 \mathrm{~mm}$ optimal in the trade off between the signal to noise ratio decreases because a thicker slice will cause the cortical volume fraction to rise.

In a model based analysis, pertormed at our department, it became clear that the gain in SNR due to an increased slice thickness outweighs the losses incurred by the increased cortical volume fraction. Given the results from this study, we propose a slice thickness of $12 \mathrm{~mm}$. and risk of volume averaging between neighboring structures.

The signal to noise ratio (SNR) of the image and the renographs improves when the slice thickness is increased. Opposed to this, the SNR of the calculated medullary renograph

\section{The thesis: The optimization of data acquilsition and analysis}

When we tested our scan sequence in a pilot study we were confronted with an early arterial peak in the medullary signal curves that occurred at the same time as the arterial peak in the cortex. This observation is contradictory to what may be expected because renal perfusion is primarily directed towards the cortex and the medullary arteries are derived from the cortical arteries. This serial linking means that the medullary vascular peak should appear later than the cortical vascular peak (4).

The only explanation for the simultaneous peak in the medulla is that it is not a medullary phenomenon but a reflection of the cortical peak, caused by the inclusion of cortical tissue in the medullary ROI. This cortical volume averaging has two sources: In plane misplacement due to inadequate ROI positioning and in depth inclusion of cortical tissue. Although this problem is most likely to happen in diseased kidneys and renall transplants in whom corticomedullary contrast is suboptimal and ROI placement difficult, we also observed this phenomenon in healthy volunteers.

In literature, this problem has not received the attention it deserves. Many articles have been published in which the medullary renographs show early peaks that are a reflection of cortical volume averaging.

When we started our studies we realized that this problem had to be solved before chinical studies could commence. As demonstrated in chapter 2 , the solution was found in the simple, but accurate mathematical algorithm that calculates the cortical volume fractions in the medullary areas and recalculates the generated (conticomedullary) renograph to a signal curve that is truly medullary in nature.

This method has the important positive side effect that medullary MR-renographs are more representative of medullary function because parts of the medullary pyramids that normally would be left out of the analysis (because of the risk of volume averaging) are now included. The lost need for segmentation of the medullary pyramids formed the basis for the semiautomated image analysis method presented in chapter 3 . To our knowledge, this is the first computerized MRR post processing algorithm presented in literature. The technique is robust, reproducible and generates meaningful cortical and medullary signal time curves that can be generated in less than five minutes with minimal operator input. 
The third problem that we were confronted with was that methods for the quantification of MRR enhancement data were llacking. Yet, such quantification would greatly increase the chances of MRR as a clinical tool.

The problem with cortical and medullary signal curves is that the various peaks tend to be shallow and in many cases, barely perceptible. This makes their identification in terms of height, shape and time of occurrence difficult, if not impossible. This problem is exaggerated by the fair amount of noise inherent to the MR-renographs.

We approached this problem with a curve fitting procedure that is based on a physiological model of renal enhancement which is presented in chapter 4 . The nodel states that both cortical and medullary enhancement are characterized by three peaks and a tail. These assumptions are dictated by renal physiology and are confirmed by our own observations and observations by others (5).

Each peak in the cortical and medullary enhancement curves reflects a discrete physiological process in the kidney. The unique feature of our curve fitting algonithm is that each peak is fitted by a separate function. The parameters that define the shape, height and peak time of these functions may therefore be considered as descriptors of these particular physiological processes.

One could criticize that the number of enhancement parameters is too large; nine for the cortex, eight for the medulla. Renal enhancement is complex however, and composed of discrete physiological mechanisms that take place in different structures that are located in different parts of the kidney. Considering this, we believe that the number of parameters is justified. Rather than regarding them as a lot of numbers that describe global renal function, one should handle the parameters as descriptors of different parts of renal physiology. To our knowledge, our method of quantification is the first that provides functional information with a physiological meaning, and the first that has been tested on reproducibility and disease discriminating properties.

\section{The thesis: Clinical orientation}

The successful discrimination of diseased from non diseased renal transplants, demonstrated in chapter 5, forms a convincing proof of concept of the methods presented in the earlier chapters.

The major limitations of this study are that all the diseased patients had severe renal tramsplant dysfunction and that the types of diseases were different. Therefore, no conclusion can be made about the disease specificity of our technique. Furthermore, the sensitivity of our technique for milder forms of renal transplant disease is not proven. Future studies with larger groups of patients and wariable degrees of renal transplant dysfunction are required and. justified by our results.

Translation of these techniques to native kidneys was made possible by mplementation of an additional algorithm that registers and corrects the change in position of the kidreys during respiration (3). In chapter 6, the extended algorithm was tested in patients with hypertension and convincingly different enhancement characteristics could be demonstrated between hypertensive patients with and without renal artery stenosis. As in the study of renal transplant recipients, these results are primarily intended as a proof of concept of our technique.

The findings from this study are intriguing, however, because they suggest that the renogram reflects the pathophysiologic mechanism of renovascular hypertension and the effects of loss of renal function. Unfortunately, we are unable to provide a complete proof of this suggestion because the current data set is too small and because all patients with renal artery stenosis had 
renovascular lypertension. Larger studies are needed in which patients with essential hypentension and with renal artery stenosis are included and in which MRR studies are repeated after PTA or stenting procedures.

Given these results there is a realistic prospect that MRR can become the future one stop shop in the differentiation of renovascular hypertension from essential hypertension. Additional studies are worthwhile and will be started soon at our department.

Both in renal transplant recipients and in hypertensive patients, the distinguishing information is mainly contained in the medullary renographs. This is an important argument for MRR in general and for our efforts in particular. For MRR in general because no other functional imaging technique can provide functional information that is strictly medullary; for our efforts in particular because the value of the medullary MR renograph justifies the efforts made in the first part of this thesis.

We believe that we have fulfilled our objective to create the tools that were necessary to transform MRR into a mature and useful functional imaging technique with clinical potential. Especially if modern scanner technology is used to optimize the dynamic scan sequence, the time has come to commence with clinical studies. These should be focused on diseasespecific changes in native kidneys and renal transplants and on the potential of MRR to differentiate renovascular and essential hypertension. 


\section{Conclusions}

\section{The conclusions of this thesis are:}

1. MRR can provide separate functional information of the kidney coitex and medula. Various pitfalls exist and require careful selection of scan technique as well as post processing.

2. A strongly T1 weighted scan sequence and a low contrast agent dose are needed as precautions to avoid $\mathrm{T} 2$ * reduction of the signal.

3. Cortical volume averaging in mamually placed medullary ROIs is an underestimated problem that requires the use of an algorithm that calonlates and corrects for the cortical volume fraction in medullary area"s.

4. The so calculated medullary enhancement curves are more representative of global medullary function because more medullary tissue can be included.

5. Semi-automated image analysis and post-processing in renal transplants and hative kidneys reduces operator input, decreases post-processing time and generates robust and meaningful cortical and medullary enhancement curves.

6. Enhancement quantification, based on a physiological nodel, produces parameters that have patho-physiological significance.

7. Clinical relevant functional information is especially contained in the medullary MRrenographs.

8. MRR successfully discriminates diseased from non-diseased renal transplants and depicts important effects of renal artery stenosis on renal enhancement in native kidneys. 


\section{References}

1. Takeda M, Katayama $\mathrm{Y}$, Tsutsui T, Konieyama $T$, Mizusawa T. Does gadolinium-diethylene triamine pentaacetic acid enhanced MRI of the kidney represent tissue concentration of contrast media in the Kidney? In vivo and in vitro study. Magn Res Imag 1994:12:421-427.

2. Guyton $A, C$ Textbook of medical physiology Philadelphia, Saunders $1991,403-419$

3. Giele ELW, DenBoer JA, DePriester JA, Van Mameren $H$, Van Engelshoven JMA, Hasman A. Optimal scanner settings for sem autonated renogram detemination. Submitted.

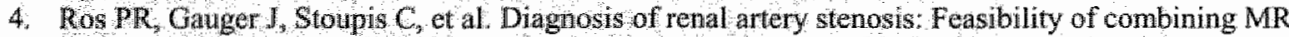
angiography, MR renography, and Gadopentetate-based measurements of glomerular filtration rate. A.R $1995,165,14471451$

5. Wolf GL, Hoop B, Cannillo IA, Rogowska JA, Halpern EF. Measurement of renal transit of Gadopentetate Dimeglumine with echo-planar MR imaging. J Magn Reson Imaging 1994; 4:365-372. 


\title{
CHAPTER 8
}

\author{
Summary
}

Samenvatting

Acknowledgements

Curriculum Vitae 


\section{Summary}

The parenchyma of the kidney is composed of two anatomically and functionally distinct substances: cortex and medulla. The cortex occupies the surface of the organ and has numerous inwards extensions called the renal columins. The medullary tissue consists of contical masses, the pyramids of Malpighi, which are situated more centrally between the renal columns. These structures reflect the anatomy of the functional units of the kidney, the nephrons, in which wine is forned.

Renal function can be affected by a variety of parenchymal disorders. Many of these cause substantial functional disturbances but do not present as macroscopically visible changes in morphology. The existence of such diseases dictates the need for diagnostic tests that should not only cover morphologic alterations but that should also reflect the functional status of the organ.

Vascular disease of the kidney also presents the need for a functional diagnostic test. The two. most common types of renovascular disease that cause renal artery stenosis are atherosclerosis and fibromuscular dysplasia. By decreasing renal perfision pressure and activation of the renin-angiotensine system, these diseases may cause renovascular hypertension (RVH). The differentiation between RVH and essential hypertension on anatomically oriented imaging studies such as angiography is difficult because patients with essential hypertension may develop secondary atherosclerotic stenosis of the renal arteries that looks identical on these studies. Such differentiation is important, however, because, in contrast with RVH, essential hypertension does not benefit from surgical or percutaneous interventions and because of the costs, risks of complications and limited patency of these measures. Unfortunately, an accurate laboratory test or imaging technique that differentiates functional kidney diseases and that is capable to assess the functional relevance of a renal artery stenosis in terms of the existing hypertension is lacking. These limitations dictate the need for a more accurate functional test that provides the desired diagnostic value in both problem areas and this forms the basis for our interests in magnetic resonance renography.

MR-renography (MRR) is a new imaging technique that provides functional information in terms of changes in signal intensity of the kidney parenchyma in serially obtained images during the passage of an intravenously administered bolus of gadolinium-DTPA.

The high spatial resolution of the MR images allows the separate observation of the enhancement curves (renographs) of cortical and medullary structures, a feature that is not possible with other functional imaging techniques. This may be of importance in separating disease processes that affect these different parts of the kidney or renal transplant and the more detailed insight into renal physiology and patho-physiology may be of value in the diagnosis of renovascular hypertension.

Although various reports have suggested added value of MRR in the diagnosis of kidney disease, renal transplant disease and renovascular hypertension, various unsollved problems. prevent MRR to develop from a theoretically promising technique into a mature and clinical usefull tool. The aims of this thesis were to address these problems, to optimize MRR data acquisition and data analys is and to present a first climical orientation.

\section{The optimization of MRR}

Chapter 2 focused on the problem of obtaining valid medullary MR renographs. Generally, medullary MR renographs are obtained by selectively placing regions of interest (ROD) over the medullary pyramids and estimating time dependent changes in signal over these areas. This predisposes to signal contamination from volume averaging with cortical tissue located 
in the renal columns surrounding the medullary pyramids. As a result, signals obtamed from such ROIs are in fact a reflection of cortical as well as medullary function and the major hallmark of MRR, adequate corticomedullary functional differentiation, is lost.

A mathematical algorithm is proposed with which cortical signal contamination in medullary structures can be quantified and eliminated. This algorithm was tested in healthy volunteers and proved highly successful in generating true medullary renographs from corticomedullary ROIs that contained cortical tissue with variable fractional volumes to values as large as $64 \%$.

In chapter 3 a computerized method of ROI placement and curve generation is presented. With this method, the kidney is automatically segmented from the indage and two band shaped ROIs are generated. Cortical renographs are derived from the outer band that is situated over the peripheral cortex. The inner band is located more centrally and overlies the medullary pyramids and the cortical tissue in the renal columns. From this corticomedullary ROI, a medullary MR renograph is obtained with help of the algorithm presented in chapter 2 . The only operator input required is exclusion of the hilar area.

In a group of renal transplant recipients who were examined twice, analysis of variance of the cortical and medullary curves demonstrated significant intraclass correlation. This means that the differences in signal curves between patients were larger than those observed per patient between examinations, indicating good reproducibility.

Because manual selection of ROIs is circumvented, this method results in shortened postprocessing time (taking less than 5 minutes) and minimum operator bias. Moreover, because larger amounts of medullary tissue are included, the obtained medullary signal curves are an optimal representation of medullary enhancement.

In chapter 4 the problem of quantification of cortical and medullary enhancement is addressed. The shape of the renal enhancement curve is complex and difficult to interpret quantitatively. Apart from the early cortical enhancement peak, which is sharp and ensily discernible, enhancement is characterized by a complex pattern of shallow cortical and medullary peaks. In combination with the fair amount of noise in MR-renographs this makes it difficult to identify and quantify these peaks in terms of time of occurrence, height and shape.

We approached this problem with a curve fitting procedure that is based on a physiological model of renal enhancement. The model states that both cortical and medullary enhancement are characterized by three peaks and a tail. These assumptions are dictated by renal physiology and are confirmed by our own observations and observations by others. Each cortical and medullary enhancement peak reflects a discrete part of the physiological process of contrast agent bolus passage in the kidney and is fitted by a separate function. The parameters that define the shape, height and peak time of these functions are considered as descriptors of these particular physiological processes.

The method was tested on the enhancement data of 10 renal transplant recipients. In all patients the quality of fit was high and the enhancement parameters proved to be reproducible when the investigation was repeated.

Careful technical optimization of the algorithms described above and of a method for the correction of respiration induced positional change of native kidneys was reached as part of a parallel doctoral thesis study by Eelco Giele.

\section{Clinical orientation}

In chapter 5 , the methods developed in the previous chapters were combined and applied in non-diseased and diseased renal transplant recipients. In patients with diseased renal 
transplants the mean medullary nephronal washout rate and cortical arterial blood volume were lower than in patients with non-diseased renall transplants. The combination of these parameters was a strong predictor of renal transplant disease (area under ROC curve 0.98 ; $95 \%$ confidence interval $0.96-1.0$ ).

A pathophysiologic interpretation of these results is speculative but the decreased cortical blood wolume in dliseased renal transplants could for instance indicate loss of vascular structures (necrosis), vasoconstriction or interstitial disease with secondary vascular compromise. The changes in the medulla can either be secondary to the events taking place in the cortex or be caused by medullary degeneration. The successful discrimination of diseased from non diseased renal transplants forms a first convincing proof of concept of the methods presented in the eallier chapters.

In chapter 6 , native kidneys were studied. The respiration induced positional change in the innges of these kidneys required correction, and a new algorithmic method for that correction was used. This made it possible to extend the clinical orientation to a group of hypertensive patients with normal renal arteries and a group of patients with renovascular hypertension (RVH). Patients with RVH had either atherosclerotic renal artery stenosis (RAS) or fibromuscular dysplasia (FMD).

In the first analysis the enhancement data of all patients with RVS (either RAS or FMD) were combined and compared to those of the patients with normal renal arteries. Patients with RVS demonstrated lower amplitudes of the peaks and tail of the medullary renogram. The cortical renograms were not significantly different. The most likely explanation of these results is a decreased renal blood flow and activation of the renin-angiotensin-aldosterone system in patients with RVS.

In the second analysis the enhancement data of kidneys with FMD were compared to those of kidneys with RAS.

RAS was characterized by a lower amplitude of the first medullary nephronal peak, normalized to renal perfusion. This means that in patients with RAS, per volume of blood dellivered to the kidney, smaller amounts of gadolinium are filtered into the nephrons. From the literature it can be inferred that the first medullary nephronal peak, normalized to renal perfusion, is propontional to the glomerular filtration rate. Most likely therefore, the observed differences reflect loss of renal function. This hypothesis was confirmed by laboratory data because patients with RAS had a significantly lower creatinine clearance than patients with FMD.

Although speculative, these interpretations are intriguing because they relate our findings to the pathophysiologic mecllanism of renovascular hypertension and loss of renal function.

As stated in the conclusions in chapter 7, significant progress in the acquisition and analysis of MR renographic data is reached in this thesis. The findings of the clinical orientation are encouraging and indicate that MRR may well become a key instrument in the diagnostic workup of patients with functional kidney or renal tratnsplant diease and in the detection of renovasoular hypertension. 


\section{Samenvatting}

Het nierparenchym is opgebouwd ait twee anatomisch en functioneel verschillende types weefsel: cortex en medulla. De cortex vormt het meest naar baiten gelegen deel van het orgaan en heeft een aantal naar binnen gerichte uitlopers, de columnge renales. Het medullaire weetsel bestaat uit een aantal kegelvormige structuren, de piramides van Malpighi, die zijn gelegen tussen de columnae renales. Deze structuren weerspiegelen de anatomie van de functionele eenheden van de nier, de nefronen, watrin de urine word gevormd.

De nierfunctie kan worden aangetast door verschillende parenchymateuze ziekten. Een aantal daarvan veroorzaakt functionele stoomissen maar presenteert zich niet als macroscopisch zichtbare veranderingen. Dergelijke aandoeningen doen de behoefte voelen aan diagnostische tests die niet alleen morfologische veranderingen detecteren maar die ook informatie verschaffen over de functionelle status van de nier.

Een tweede reden voor functionele diagnostische tests zijn vasculaire ziekten van de nieren. De twee meest voorkomende renovasculaire aandoeningen die nierarteriestenosen veroorzaken zijn atherosclerose en fibromusculaire dysplasie. Door afname van de renale perfusie en activatie van het renine-angiotensine systeen kunnen deze ziekten renovasculaire hypertensie (RVH) veroorzaken.

Met anatomische afbeeldingen zoals angiografie is het moeilijk onderscheid te maken tussen RVH en essentiële hypertensie aangezien patiënten met essentiële hypertensie secundaire nierarteriestenosen kunnen ontwikkelen die er identiek uitzien als bij patiëtnten met RVH. Toch is een dergelijk onderscheid belangrijk aangezien chirurgische of percutane interventies van de arteriële stenosen bij essentiële hypertensie geen effect hebben op de bloeddruk terwijl dergelijke ingrepen, welke dus alleen zinvol zijn bij RVH, kostbaar zijn, risico"s met zich meebrengen en op lange termijn een beperkt succes hebben.

Helaas bestaat er momenteel geen betrouwbare laboratoriumtest of beeldvormende techniek die in staat is functionele nieraandoeningen van elkaar te differentiëren of de relevantie van een nierarteriestenose voor de hypertensieve patiënt te bepalen. De behoefte aan zo'n test vormde de basis voor onze belangstelling voor magnetische resonantie renografie of, in het engels, Magnetic Resonance Renography, afgekort: MRR.

MRR is een nieuwe beeldvormende techniek die functionele informatie verstrekt in termen van veranderingen in signaalintensiteit van het nierparenchym tijdens de passage van een intraveneus toegediende bolus gadolinium-DTPA.

De hoge spatiele resolutie van het magnetische resonantiebeeld maki het mogelijk afzonderlijke corticale en medullaire aankleuringskrommen (renogrammen) te genereren, iets dat met andere technieken niet mogelijk is. Dit kan van belang zijn om een onderscheid te kunnen maken tussen ziekten die deze delen van de nier (of niertransplantaat) op een verschillende manier aandoen. Bovendien kan er een verbeterd inzicht in de fysiologie en pathofysiologie worden bereikt welke van waarde kan zijn voor de diagnostick van RVH.

Hoewel verschillende artikelen zijn gepubliceerd waanin toegevoegde waarde van MRR in de diagnostiek van nierziekten en RVH werd gesuggereerd, is tot nu toe de ontwikkeling van MRR tot een volwassen en klinisch bruikbare methode verhinderd door een aantal moeilijk oplosbare problemen. De doelstellingen van dit proefschrift waren deze problemen op te lossen door data acquisitie en analyse te optimaliseren en een eerste klinische orientatie van die techniek te tonen. 


\section{De optimalsatie wan MRR}

Hoofdstuk 2 richit zich op het probleem van het genereren van medullaire MR-renogrammen. In het algemeen worden deze werkregen door het selectief plaatsen van $z$ g. regions of interest (RO) over de mergpiramiden en het bepallen van de verandering in signaalintensiteit in deze gebieden als functic vatu de tijd. Dit draagt het ristco met zicli mee van vermenging van het signal met corticale structuren in de columnae renales die de mergpiramiden omgeven en die bimnen het ROI vallen. De signalen werkregen uit dergelijke ROT's zijn een reflectie van zowell corticale als medullaire functic, wat betekent dat eén van de kenmerken van MRR, het onderscheid tussen cortex en medulla, verloren gat.

Om dit probleem op te lossen ontwikelden wij een mathematisch algoritme warmee vermenging van corticale en medullatre struchuren kan worden gekwantificeerd en gec̈limineerd. Dit algoritme werd getest bij een antal gezonde vrijwilligers en bleek zeer succesvol in het genereren van medullaire renogrammen uit corticomedullaire ROLs waarvan de fractie cortical weefsel varieerde en soms opliep tot 64 procent.

In hoofdstuk 3 wordt een gecomputeriseerde methode voor het plaatsen van ROIs en het genereren van renogrammen gepresenteerd. Met deze methodiek wordt de nier automatisch tit het beeld gesegnenteerd en worden twee bandvormige ROI's gegenereerd. Corticale renogrammen worden verkregen uit de buitenste band die is gepositioneerd over de perifere cortex. De binnenste band bevindt zich meer wentral en is gelegen over zowel de mergpiramiden als thet corticale weefsel in de columnae renales. Uit deze corticomedullaire ROI wordt een medullair renogram verkregen met behulp van het algoritme uit hoofdstuk 2 . De enige handmatige activiteit is de exclusie van de hilus van de nier. In een groep niertransplantatiepatiënten die twee keer werden onderzocht toonde variantieanalyse van de twee onderzoeken een significante intraclass correlatie. Dit betekent dat het verschil in de renogrammen tussen verschillende patienten groter was dan het verschil tussen de twee onderzoeken per patiënt. Dit resultaat duidt op een goede reproduceerbaarheid. Doordat met deze methode de handmatige selectie van $\mathbb{R O}$ Ols kan worden voorkomen wordt de tijd die nodig is om de beelden te bewerken fors verkort (minder dan 5 minuten) en is de afhankelijkheid van de ervaring van de bediener minimaal. Bovendien zijn de verkregen medullaire renogrammen een nauwkeuriger representatie van medullaire aankleuring aangezien de nieuwe ROls groter zijn en dus een grotere hoeveelheid medullair weefsel bevatten.

In hoofdstuk 4 wordt andacht besteed aan het probleem wan kwantificatic van corticale en medullaire aankleuring. De vorm van de aankleuringskrommes is complex en moeilijk kwantitatief te interpreteren. Met uitzondering van de eerste corticale piek, die scherp is en goed te onderscheiden, worden de krommes gekenmerkt door een complex patroon van overwegend wakke corticale en medullaire pieken. In combinatie met de forse hoeveelheid ruis van MR-renogrammen maakt dit hun identificatie en kwantificatie in termen van tijd van optreden, hoogte en vorm moeilijk.

Wij benaderden dit probleem met een methode van curve-fitting die is gebaseerd op een fysiologisch model van de ankleuring. Dit model gat er wan wit dat corticale en medullaire aankleuring beide zijn gekarakteriseerd door een drietal pieken. Deze aanname is gebaseerd op de fysiologie van de nier en wordt bevestigd door eigen observaties en door observaties van anderem. ledere corticale en medullaire piek geeft een apart gedeelte van het fysiologische proces tijdens de passage van de contraststof weer en wordt gefit door een aparte wiskundige functic. De parameters die deze functies definieren in termen van vorm, hoogte en piek-tijd worden beschouwd als beschrijvers wan de verschillende fases van dit fysiologische proces. 
Deze methode werd getest op aankleumgsdata wan 10 gezonde transplantatiepatienten. In alle gevallen werd een goede kwaliteit wan de fit gevonden en de ankleuningsparaneters bleken reproduceerbaar wanneer het onderzoek werd herhatd.

Een nauwkeurige optimalisatie van bovengenoende algoritmes en en methode ter contecte wan ademhalings-gernduceerde positieveranderingen van natieve neren womde en gedeelte van een parallel promotie onderzoek doon Eelco Giele.

\section{Klinische oriëntatie}

In hoofdstuk 5 werden de methoden die in de daanan voorafgaande hoofdstukken werden ontwikkeld gecombineerd en toegepast bij een aantal zieke en niet zieke niertransplantatiepatiënten. Bij patienten met een ziek transplantaat waren de gemiddelde nefronale uitwassnelheid en het corticale bloedvolume lager dan bij patiènten met een gezond transplantaat. De combinatie van deze parameters bleek een zeer goede voorspeller van ziekte (oppervlakte onder de ROC curve 0,$98 ; 95 \%$ betrouwbaarheidsinterval $0,96-1.0$ ). Hoewel een pathofysiologische interpretatie van deze bevindingen speculatief is $k$ an het afgenomen corticale bloedvolnme duiden op verlies van vaststructuren (necrose), vasoconstrictie of interstitiële ziekten met secundaire aframe van het vasculaire volume. De veranderingen in de medulla kunnen secundair zijn aan de veranderingen in de cortex of worden veroorzaakt door degeneratie van het medullaire parenchym. Het succesvolle onderscheid tussen zieke en niet zieke niertransplantaten vormt een eerste overtuigend bewijs van de bruikbaarheid van de methoden die werden gepresenteerd in de voorgaande hoofdstukken.

In hoofdstuk 6 werden natieve njeren onderzocht. De door de ademhaling geïndweeerde posititieverandering van natieve nieren tijdens de scan maakte implementatie van een nieuwe algoritmische methode die daarvoor corrigeert noodzakelijk. De invoering ervan maakte het mogelijk de klinische oriëntatie uit te breiden naar een groep hypertensiepatiênten met normale nierarteriën en een groep met renovasculaire lnypertensie (RVTI). De patiënten met RVH hadden ofwel atherosclerotische nierarteriestenosen (RAS) of fibromusculaire dysplasie (FMD).

In de eerste analyse werden de data van alle patiènten met RVH (RAS of FMD) gecombineerd en vergeleken met de data van patiénten met nomale nierarterieèn. Patiënten met RVH lieten een lagere amplitude van de pieken en staart van de medullaire renogrammen zien, de corticale renogrammen waren niet verschillend. De meest waurschijnllike verklaring voor deze bevindingen is een tragere bloeddoorstroming en activatie van liet renine angiotensine systeem bij de patiënten met RVH.

In de tweede analyse werden de data van patienten met FMD vergeleken met die van patiënten met RAS. RAS was gekenmerkt door een kleinere amplitude van de eerste nefronale medullaire piek, wanneer genormaliseerd werd op de renale perfusie. Dit betekent dat bij patiënten met RAS, per eenheid van bloedwolume afgelewerd aan de nier kleinere hoeveelheden gadolinium worden gefiltreerd in de nefronen. Uit de literatuar kan worden afgeleid dat de eerste medullaire piek, genormaliseerd op renale perfusie, proportioneel is an de glomenulaire filtratiesnellheid. Het is dus het meest waarschinnlijk dat de gevonden verschillen verlies van nierfunctie weerspiegelen. Deze hypothese werd bevestigd door laboratoriumonderzoek waaruit bleek dat patienten met RAS cen significant lagere creatinineklaring hadden dan patiënten met FMD.

Hoewel speculatief is deze interpretatie intrigerend doordat ze onze bevindingen weet te relateren aan het pathofysiologische mechanisme van $\mathrm{RVH}$ en verties van nierfunctie. 
Concluderend, zoals weergegeven in hoofdstuk 7 , is in dit proefschrift belangrijke vooruitgang geboekt met de acquisitie en analyse van MRR data. De resultaten van de klinische orientatie zijn bemoedigend en geven aan dat MRR een belangrijk instrument kan worden in thet diagnostische proces bij patienten met functionele aandoeningen van nieren en niertransplantaten en bij de detectie van renovasculaire hypertensie. 


\section{Acknowledgements}

This study was performed at the department of radiology of the Maastricht University Hospital and was made possible thanks to the help and support of co-authors, colleagues and the following people:

Dr. Jacques A. den Boer

Professor Jos M.A, van Engelshoven

Professor Arie Hasman

Eelco Giele

Alphons Kessels

Maarten Christiaans

Bram Kroon

Marc J.H.M. Geerlings

Etienne Lemaire

Henk wan Mameren

Boudewijn Vasbinder

Hein Stroeve

Sierk Roosma

Henk Schoenmakers and colleagues

Hans Smeets

Edith Köhler and colleagues

Geertjan van Zonneveld and colleagues

Joost de Beij

Auke van der Berg 


\section{Curriculum Vitae}

Jacobus Adriaan (Koo) de Ptiester werd geborei op 9 april 1964 te Oosthwizen.

Na hot behalen van het VWO diplona in 1982 aan het Westfries Lyceum in Hoorn studeerde hij geneeskunde aan de Rijksunversiteit Gent (B) en aan de Rijksuniversiteit Leiden waar hij af tudeerde in 1991. Na een assistentschap interne geneeskunde in het Schieland ziekenhuis te Schiedam begon hij in 1993 an zijn opleiding tot radioloog in het Acadenisch Ziekenhuis Maastricht (Opleiders Prof.Dr. B.K. Janevski en Prof.Dr. M. A. van Engelshoven). Na beeindiging van zijn opleiding in 1998 was hij gedurende 1 jaar werkzaam als fellow aan deze afdeling. Sinds 2000 is hij werkzaam als radioloog in Zaans Medisch Centrum De Heel te Zaandam.

Gedurende $z$ in studie en opleiding tot radioloog deed hij onderzoek aan de afdeling radiologie van het Leids Universitair Medisch Centrum (supervisie Prof.Dr. J.L. Bloem), de afdeling Farnacologie van de Rijksuniversiteit Leiden (supervisie Dr. P. Molenaar), de Medical Research Council Dunn Nutricion Unit en het Adenbrookes Hospital te Cambridge (Engeland, supervisie Prof.Dr. N.J. Bishop) en aan de afdeling radiologie van het Academisch Ziekenhuis Maastricht (Promotoren Prof.Dr. J.M.A. van Engelshoven en Prof.Dr. A. Hasman). Voor zijn onderzoek naar MR-renografie ontving hij in 1998 de Dr. Pelerin wetenschapsprijs.

Hij is getrouwd met lris van der Does en heeft twee kinderen: Costijn (1996) en Wouter $(1998)$ 